May 2002 • NREL/SR-560-31931

\title{
Assessment of the Nevada Test Site as a Site for Distributed Resource Testing and Project Plan
}

\section{March 2002}

S. Horgan, J. Iannucci, C. Whitaker, L. Cibulka, and W. Erdman

Distributed Utility Associates

Livermore, California

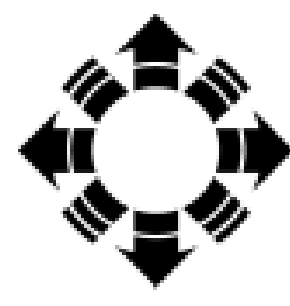

\section{NPEI}

National Renewable Energy Laboratory

1617 Cole Boulevard

Golden, Colorado 80401-3393

NREL is a U.S. Department of Energy Laboratory

Operated by Midwest Research Institute $\bullet$ Battelle $\bullet$ Bechtel

Contract No. DE-AC36-99-G010337 


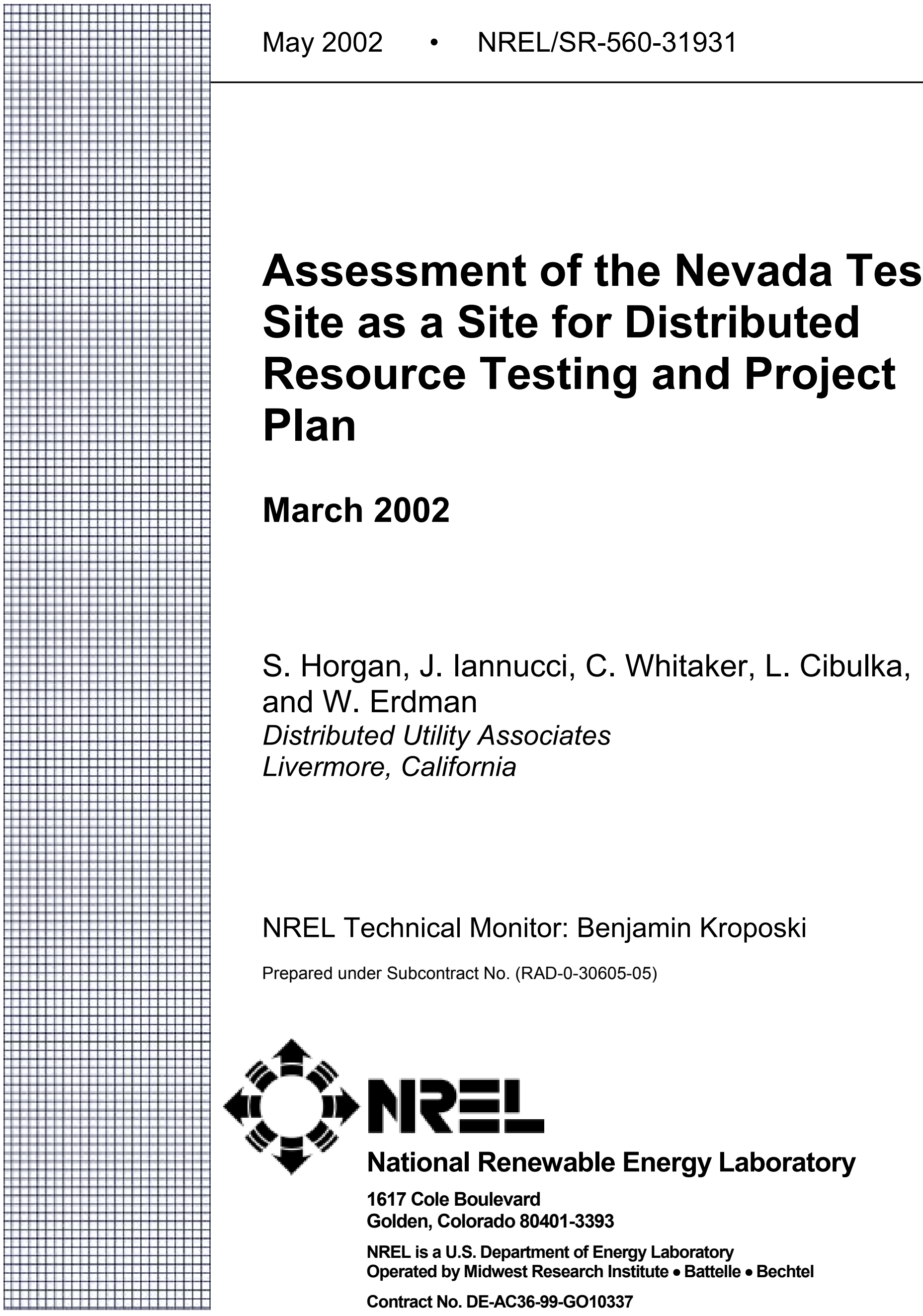




\section{NOTICE}

This report was prepared as an account of work sponsored by an agency of the United States government. Neither the United States government nor any agency thereof, nor any of their employees, makes any warranty, express or implied, or assumes any legal liability or responsibility for the accuracy, completeness, or usefulness of any information, apparatus, product, or process disclosed, or represents that its use would not infringe privately owned rights. Reference herein to any specific commercial product, process, or service by trade name, trademark, manufacturer, or otherwise does not necessarily constitute or imply its endorsement, recommendation, or favoring by the United States government or any agency thereof. The views and opinions of authors expressed herein do not necessarily state or reflect those of the United States government or any agency thereof.

Available electronically at http://www.osti.gov/bridge

Available for a processing fee to U.S. Department of Energy

and its contractors, in paper, from:

U.S. Department of Energy

Office of Scientific and Technical Information

P.O. Box 62

Oak Ridge, TN 37831-0062

phone: 865.576.8401

fax: 865.576.5728

email: reports@adonis.osti.gov

Available for sale to the public, in paper, from:

U.S. Department of Commerce

National Technical Information Service

5285 Port Royal Road

Springfield, VA 22161

phone: 800.553.6847

fax: 703.605.6900

email: orders@ntis.fedworld.gov

online ordering: http://www.ntis.gov/ordering.htm

Printed on paper containing at least $50 \%$ wastepaper, including $20 \%$ postconsumer waste 


\section{TABLE OF CONTENTS}

1. INTRODUCTION................................................................................................................ 1

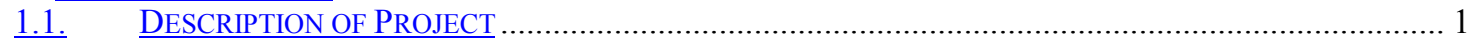

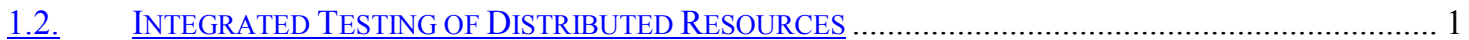

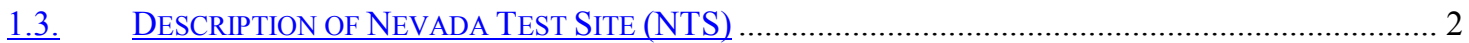

2. ASSESSMENT OF NTS FOR INTEGRATED TESTING OF DISTRIBUTED RESOURCES . 4

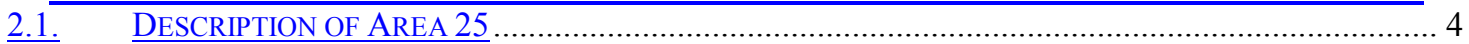

2.1.1. Existing Capabilities and Equipment at Area 25........................................................... 4

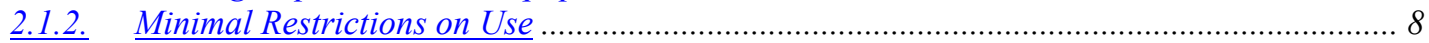

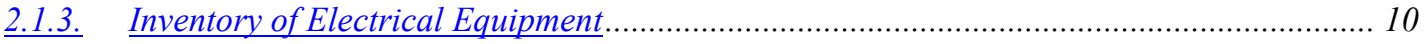

2.2. EVALUATION CRITERIA FOR AN INTEGRATED DR TESTING FACILITY....................................... 10

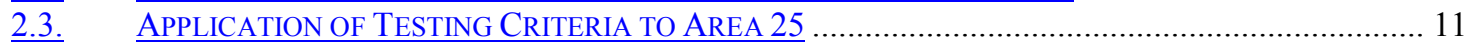

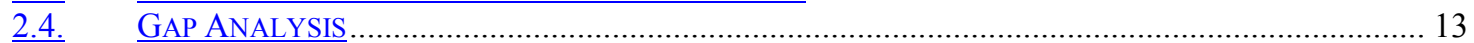

3. PROPOSED UPGRADES TO NTS TO ACCOMMODATE DR TESTING …............................. 15

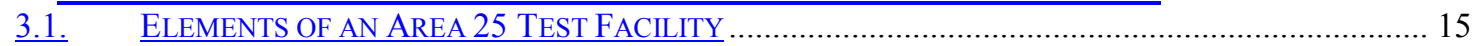

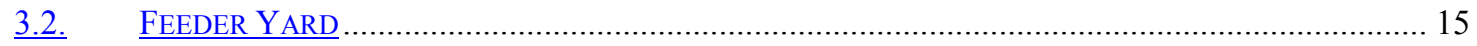

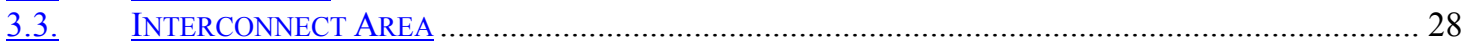

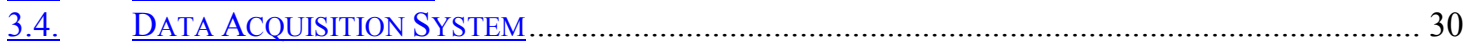

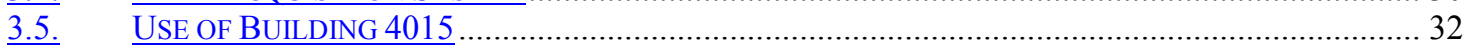

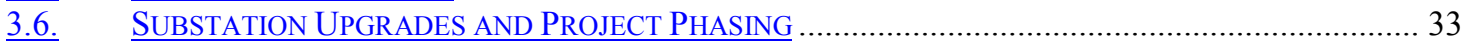

4. INTEGRATED DR TEST PLAN AND SAMPLE TESTS FOR THE NTS ................................. 34

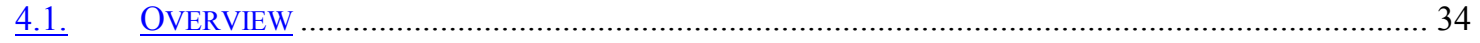

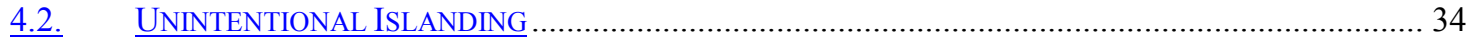

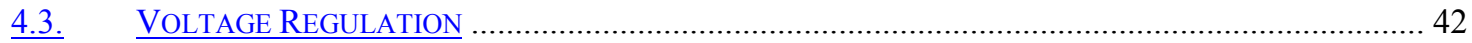

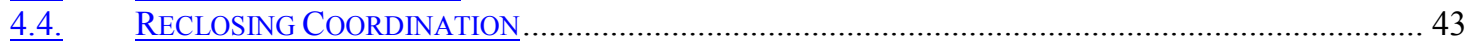

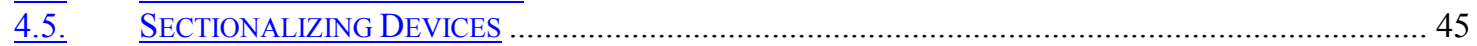

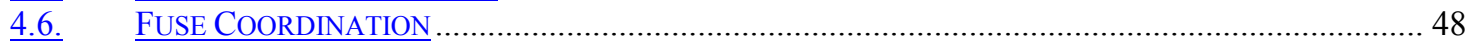

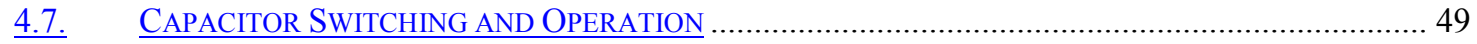

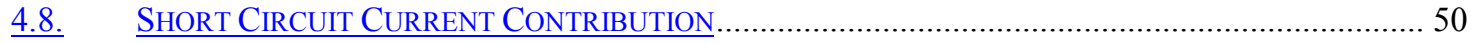

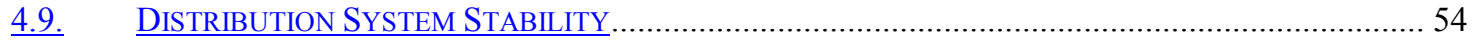

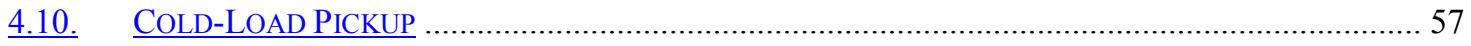

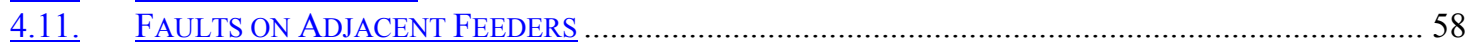

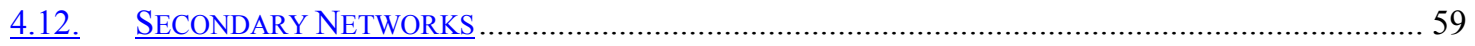

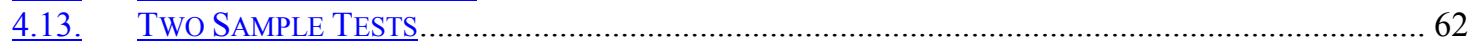

4.13.1. An Islanding Test with Capacitance at the Distribution Level …................................... 62

4.13.2. Voltage Regulation Device Interaction with DR Generation on Long Feeders................. 66

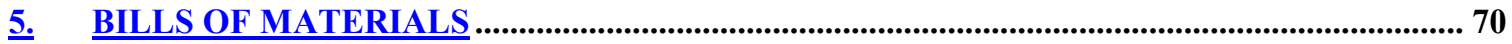

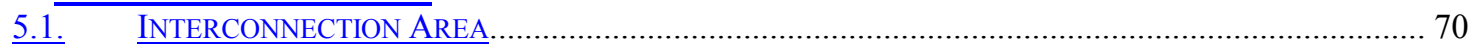

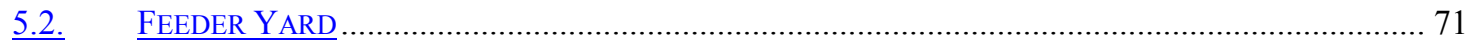

6. CONCLUSIONS AND RECOMMENDATIONS ……........................................................................ 72

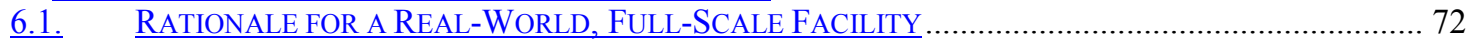

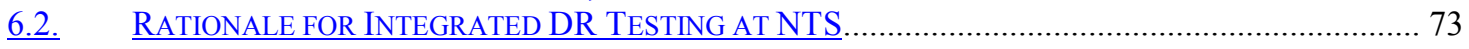




\section{FIGURES}

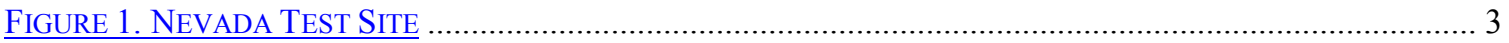

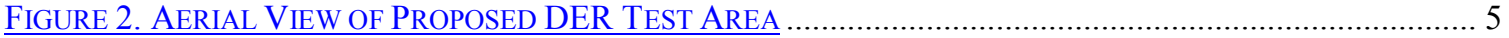

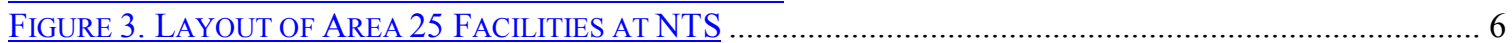

FIGURE 4. SINGLE-LINE DIAGRAM OF SUBSTATION 25-10 AT NTS …................................................... 7

FIGURE 5. POWER FLOW CHART OF BUILDING LOADS AT NTS ............................................................ 9

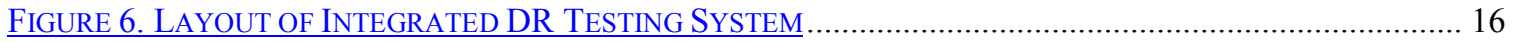

FIGURE 7. LAYOUT OF PROPOSED INTERCONNECTION TESTING AREAS AT NTS ....................................... 17

FIGURE 8. AERIAL VIEW SHOWING LOCATIONS OF PROPOSED TESTING AREAS ..................................... 18

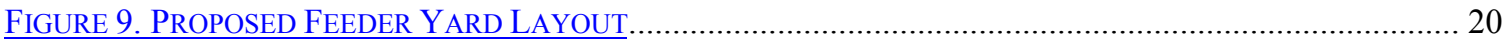

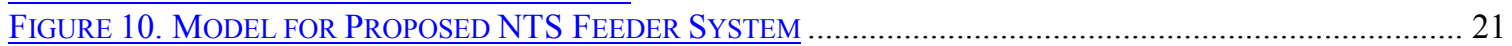

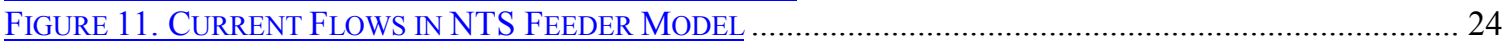

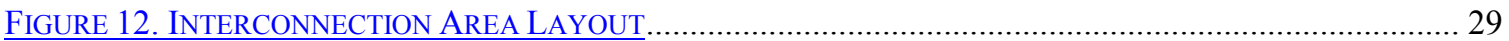

FIGURE 13. THEVENIN EQUIVALENT CIRCUIT FOR A DISTRIBUTION SYSTEM FAULT .................................5 51

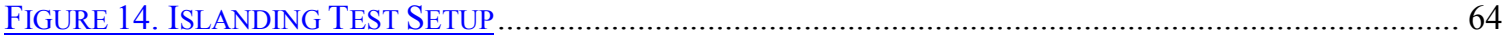

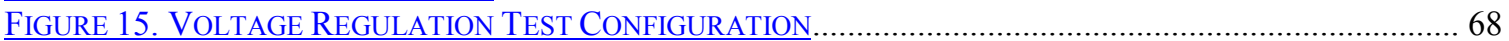

\section{TABLES}

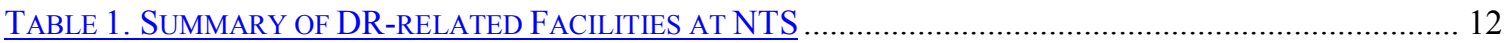

TABLE 2. INDUCTANCE MATRIX (MH/MILE) ………......................................................................... 25

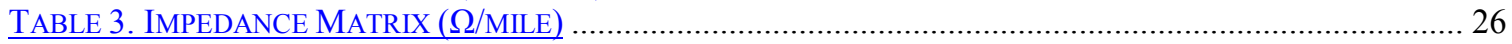

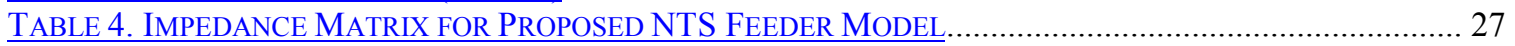

TABLE 5. IMPEDANCE MATRIX FOR MODIFIED NTS FEEDER MODEL …........................................................ 27

TABLE 6. IMPEDANCE MATRIX FOR A SINGLE CIRCUIT DISTRIBUTION FEEDER ……......................................... 28

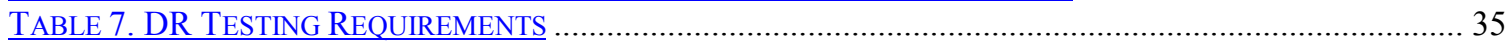

TABLE 8. INTERCONNECTION SYSTEM RESPONSE TO ABNORMAL VOLTAGES ……....................................... 44 


\section{EXECUTIVE SUMMARY}

\section{INTRODUCTION}

The objective of this project was to evaluate the Nevada Test Site (NTS) as a location for performing dedicated, in-depth testing of distributed resources (DR) integrated with the electric distribution system. In this large scale testing, it is desired to operate multiple DRs and loads in an actual operating environment, in a series of controlled tests to concentrate on issues of interest to the DR community. This project plan was developed by the Department of Energy's Distributed Power Program in response to Congressional direction in the Energy and Water Development Appropriations Act of 2001 to complete a distributed power demonstration at the Nevada Test Site and validate interconnection tests in the field. This report was prepared by Distributed Utility Associates under Subcontract No. RAD-0-30605-05 as part of LOI "NREL/DOE Distributed Power Program - Distributed Power Systems Integration Research and Development”.

This report includes an inventory of existing facilities at NTS, an assessment of site attributes in relation to DR testing requirements, and an evaluation of the feasibility of upgrades to the site that would make it a fully qualified DR testing facility.

\section{NTS SITE ASSESSMENT}

Area 25 is the specific location at NTS that has been identified as a possible venue for integrated testing of DR. There are a $2.5 \mathrm{MW}$ substation, a distribution feeder system, assorted buildings, and electrical loads in this locale. One of the important features of Area 25 is the unconstrained use of the substation, because several of the proposed DR tests have the potential for disturbing adjacent customer service on the substation.

The NTS has a significant amount of electric distribution system equipment, load, and rotating generation devices in its inventory. This equipment is stored and maintained on site by an NTS operations group. A good deal of the equipment is readily applicable to the planned DR testing.

The criteria in the following list were developed and used in the previous assessment of potential sites for integrated testing of DR, and were likewise used to evaluate the NTS:

- Available space - number of test cells or bays, their sizes, and limitations

- MW Rating - largest single DR allowable; total allowed DR for facility

- Existing/permanent DRs onsite that would be available for testing

- Existing testing equipment - controls, monitoring and instrumentation, switching load banks, etc.

- Host utility's level of interest, support, and involvement 
- Ability to test in both radial and network circuit configurations

- Grid supply - voltage, MVA, switching arrangements, and limitations

- Fuel supply and storage - natural gas line size, pressure (psia) and flow rate (BTU/hr); diesel, hydrogen, gasoline, LPG availability and/or storage capability

- Flexibility of facility to evolve or adapt to future/unforeseen testing needs

- Limitations - noise, emissions, other

- Ability to test multiple DRs at once, in interactive modes

- Number and expertise of testing staff

- Testing history/experience relevant to DR testing

- Costs for required facility upgrades to accommodate DR testing, as well as for the testing itself

\section{Proposed UPGRAdes to NTS}

The proposed upgrades to the NTS site include the use, but possible later replacement of, the 2.5 MVA substation transformer; and upgrading the distribution system to provide 30 miles of overhead line in a compact area co-located to the south of Area 25. Access to the 30 mile overhead line is available at a proposed interconnect area which is adjacent to building 4015 . The interconnect area is a cleared and surface-prepared area where DR, load banks, and interconnecting cables can all come together for easy and efficient test interconnection.

The co-located interconnect area and overhead line also permits for data measurements over a 30 mile length of feeder using only hundreds of feet of data acquisition system (DAS) interconnecting signal cables. A rather unique, high-speed DAS is proposed to support the extensive testing.

Completed drawings of the proposed site, together with high-level Bills of Material $(\mathrm{BOM})$, are presented in the report.

\section{INTEGRATED DR TESTING REQUIREMENTS}

A section describing the scope of DR testing is presented. The testing is extensive in breadth and depth and represents the input of a large cross section of utility protection engineers. The tests, which were instrumental in the design of the facility, are harmonious with the development of the IEEE P1547 interconnect standard and have been used to help define the requirements of the NTS modified site. The objective of these tests is to perform in-depth investigation of distribution system issues that have been raised regarding impacts of DR at high levels of penetration.

\section{CONCLUSIONS \& RECOMMENDATIONS}

The principal conclusion in evaluating the NTS site is that it is currently not capable of serving extensive DR testing. The site would require significant upgrades to bring it to a 
level where the proposed suite of tests could be completed. However, the site has great potential given its attributes of available space, remote and secure location, inventory of useable electrical equipment, and ability to be upgraded to the degree desired. The test site plan proposed in this report, if adopted, would result in a unique, one-of-a-kind test facility capable of supporting the anticipated integrated DR testing. 


\section{INTRODUCTION}

\subsection{Description of Project}

The objective of this project was to evaluate the Nevada Test Site (NTS) as a location for performing dedicated, in-depth testing of distributed resources (DR) integrated with the electric distribution system. In this large scale testing, it is desired to operate multiple DRs and loads in an actual operating environment, in a series of controlled tests to concentrate on issues of interest to the DR community. This project plan was developed by the Department of Energy's Distributed Power Program in response to Congressional direction in the Energy and Water Development Appropriations Act of 2001 to complete a distributed power demonstration at the Nevada Test Site and validate interconnection tests in the field. This report was prepared by Distributed Utility Associates under Subcontract No. RAD-0-30605-05 as part of LOI "NREL/DOE Distributed Power Program - Distributed Power Systems Integration Research and Development".

This report includes an inventory of existing facilities at NTS, an assessment of its attributes vis-à-vis DR testing requirements, and an evaluation of upgrades to the site that would make it a fully qualified DR testing site.

\subsection{Integrated Testing of Distributed Resources}

Integrated testing of DR is defined as full-scale testing of multiple distributed generation and storage technologies integrated with electric distribution systems under conditions representative of "real-world" operation. The test project is defined by a test plan that confronts a broad range of issues and concerns related to interconnecting DR to the utility distribution system. The test plan is described in section 4 and includes detailed exercising and sophisticated monitoring of the interaction of the various DR with each other and with the electric utility grid.

Integrated DR testing is designed to illuminate specific issues - both problems and benefits - with regard to penetration of DR into the electric distribution system. These issues include interconnection technologies and practices; interactions with distribution system protection equipment; interconnection equipment performance and functional characterization; instrumentation, monitoring and control technologies; and methods of controlling and dispatching distributed generation remotely, whether in a utility/regional hierarchical scheme or in a local/independent mode.

The DR will be interconnected with a variety of distribution system configurations representing the least-understood conditions as well as those of greatest concern. Integrated testing of DR requires multiple distributed generators, storage devices, load banks (resistive, capacitive, and inductive), and other components all of which are 
installed at the test site and operated in a variety of configurations. Measurements of voltage, current, and power quality of DR and load is collected during each of the test configurations. Specific test configurations require specific system level measurements at the DR and load levels as well as system level measurements at the distribution voltage.

\subsection{Description of Nevada Test Site (NTS)}

The Nevada Test Site is a U. S. Department of Energy (DOE) test site located in south central Nevada approximately 60 miles north of Las Vegas (see Figure 1). The land area at NTS is equivalent to that of the state of Rhode Island and the site currently has 1,000 square miles of completely undisturbed land. The site is secured on its borders and it is reasonably isolated from population centers. The site has more than 400 miles of paved road and 300 miles of unpaved road, and there are two airstrips and 10 heliports for access. There is a significant amount of transmission, sub-transmission, and distribution level equipment installed, most of which is operational, but some of which is not currently in use. Personnel numbering approximately 700 individuals are on the site at any one time. 
Figure 1. Nevada Test Site

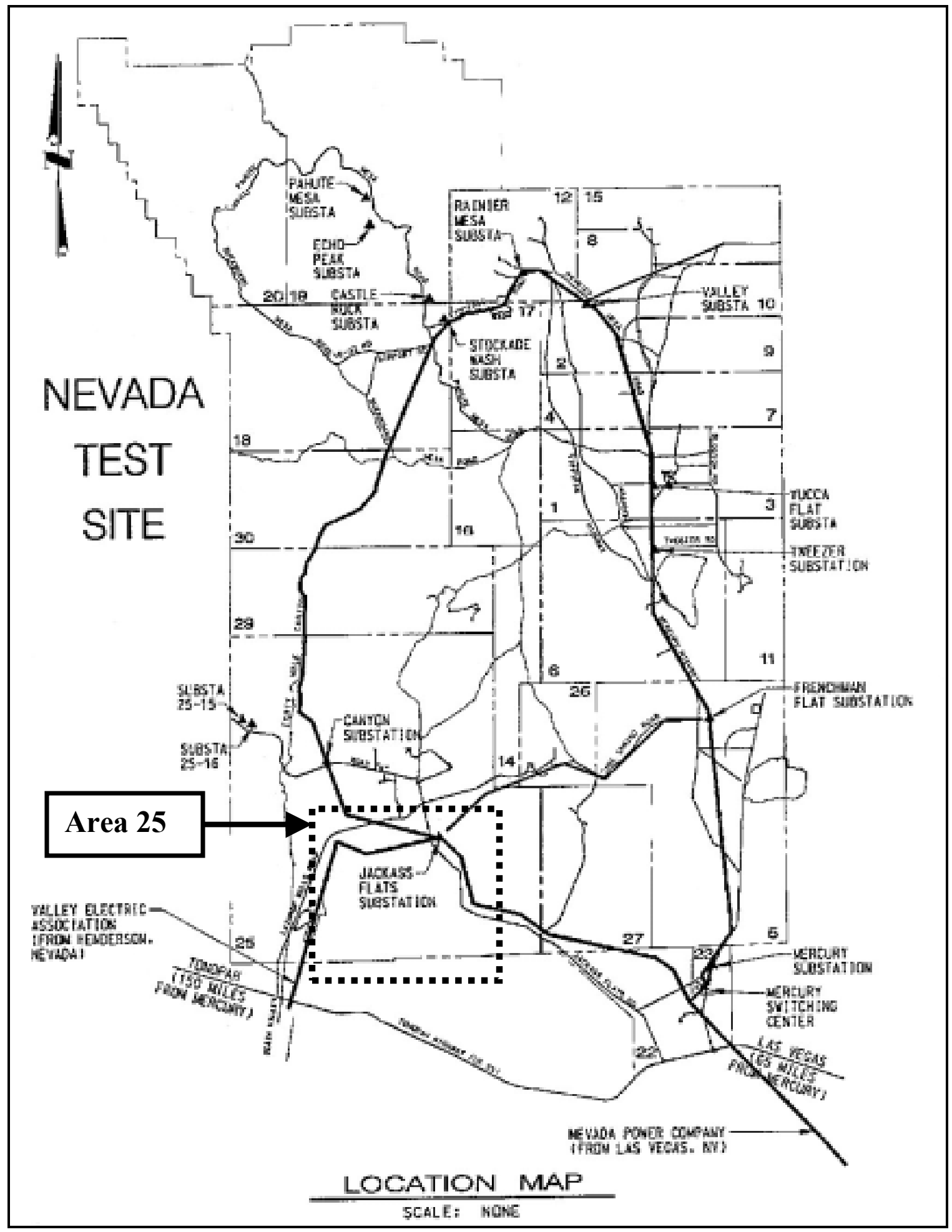




\section{ASSESSMENT OF NTS FOR INTEGRATED TESTING OF DISTRIBUTED RESOURCES}

\subsection{Description of Area 25}

Area 25 is located in the southwest corner of the Nevada Test Site (refer to Figure 1). There are a substation, distribution feeder system, and assorted buildings and electrical loads in the locale (see Figure 2). Area 25 is the specific site that has been identified as a possible venue for integrated testing of DR.

Originally, the Mercury substation area was being considered, however this is a site where a significant amount of activity continues to occur and there are no plans that would cause this activity to diminish. Because of this activity, the site was excluded. An unused site where distribution testing could be performed without concern for power disruption to adjacent customers is considered an important requirement for DR testing.

When the NTS site was first considered, a number of different substations and areas were reviewed. The result of looking at the different areas was to use the site at Area 25. This site has an existing, under-utilized 2.5 MVA substation, a $12 \mathrm{kV}$ distribution system of approximately 1/6 mile in length, relatively large building loads, and access to the electrical apparatus inventory on the NTS site.

\subsubsection{Existing Capabilities and Equipment at Area 25}

\section{Substation 25-10}

Area 25 has an existing substation, which is designated as 25-10 on the site drawings (see Figure 3). This substation was originally installed to service local building loads when the site was active and operational. The substation has $2.5 \mathrm{MVA}$ transformer with $69 \mathrm{kV}$ primary and $12.4 \mathrm{kV}$ secondary. The transformer is a $7.08 \%$ impedance transformer and has multiple taps at $\pm 2.5 \%$ and $\pm 5 \%$ ratings. Other important apparatus at the substation includes transformer circuit breaker and sectionalizing circuit breakers for separate feeders 1202 and 1203. Other, normally supplied protective features are shown in the single-line diagram depicted in Figure 4. The 2.5 MVA substation transformer will support a large percentage of the anticipated testing; however, for some of the tests, it will be necessary to use a larger transformer. Modifications to upgrade the existing 2.5 MVA transformer to 10 MVA are discussed later in the report, but the cost of this upgrade has not been included. 
Figure 2. Aerial View of Proposed DER Test Area

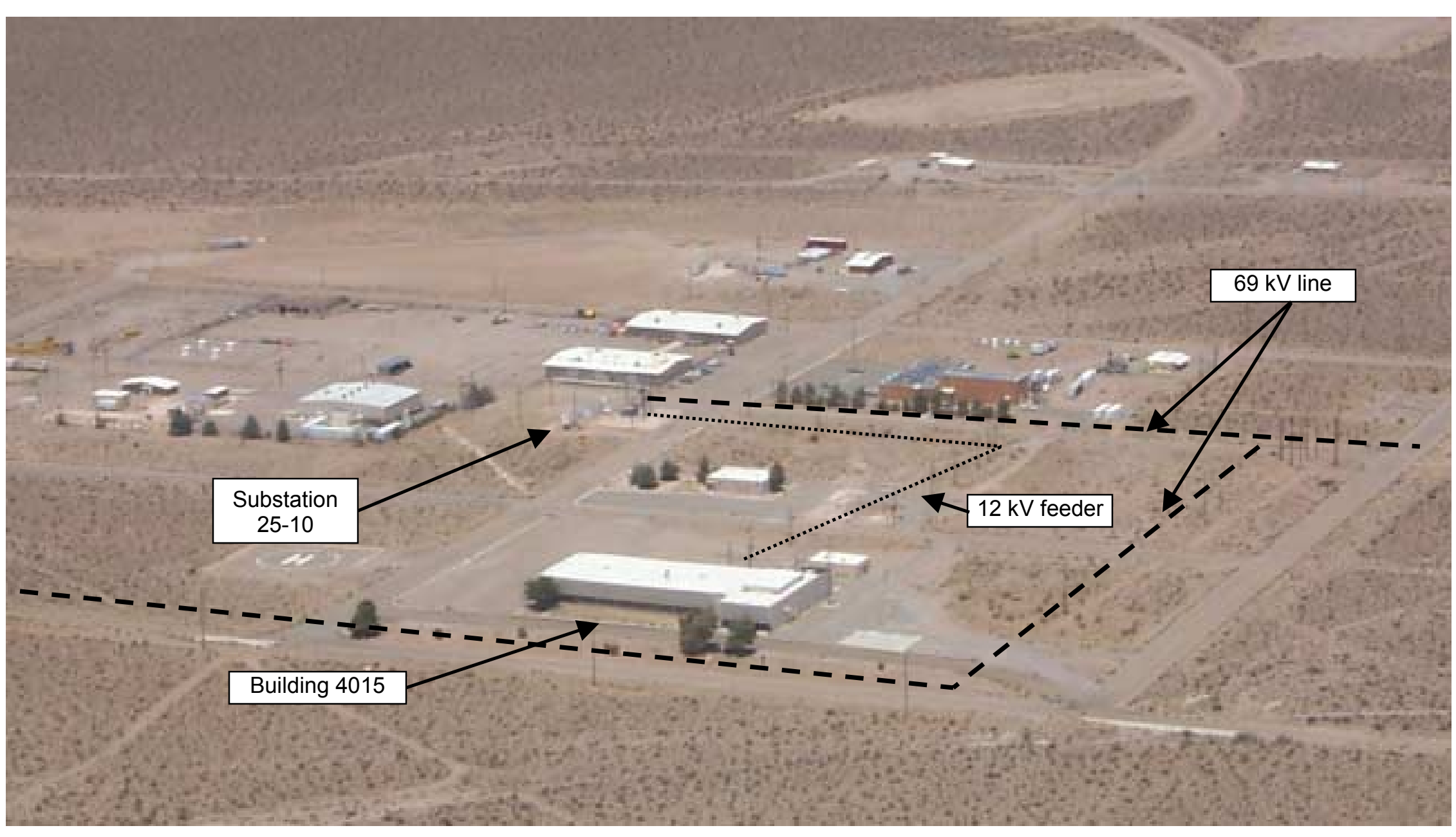


Figure 3. Layout of Area 25 Facilities at NTS

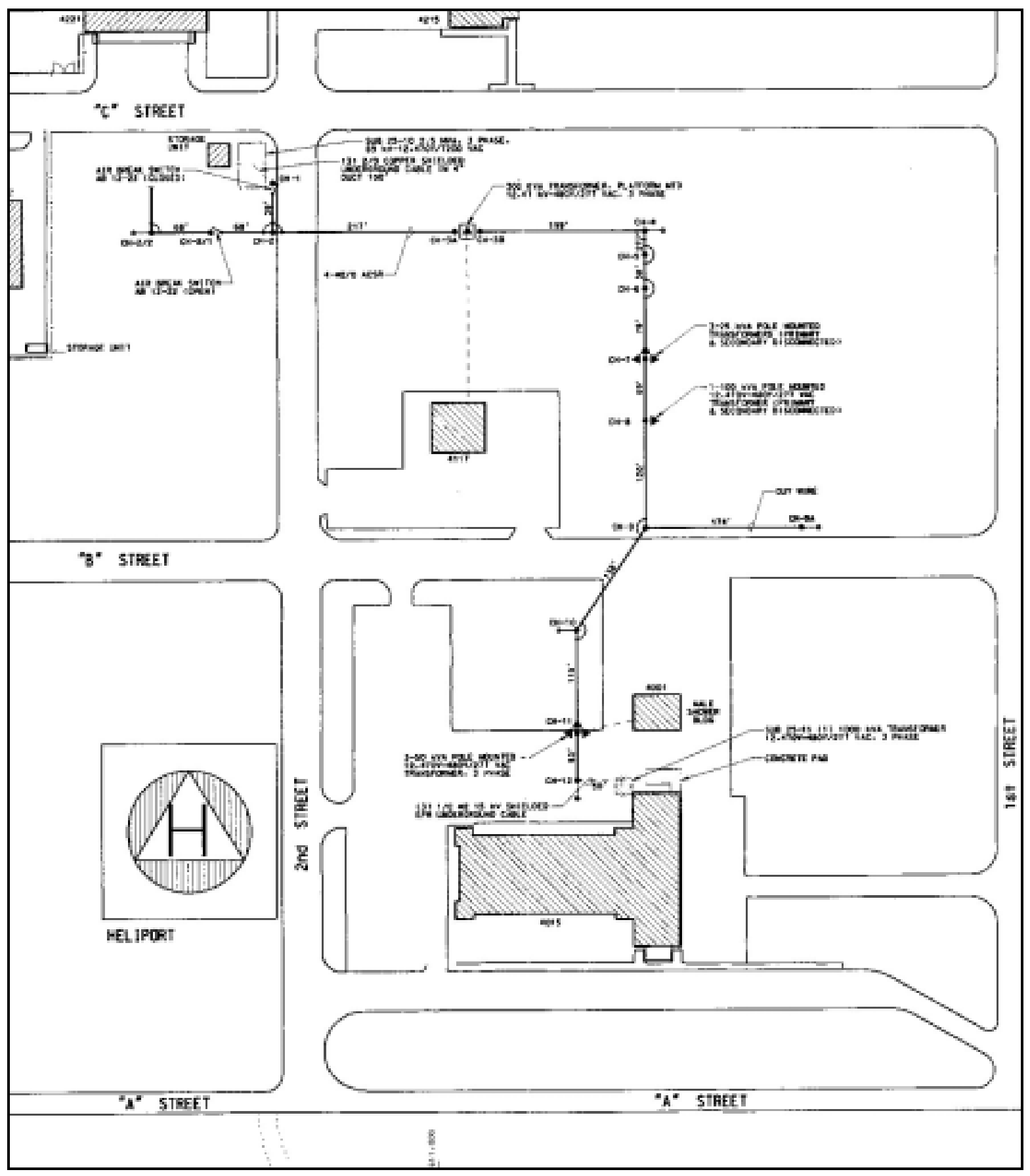


Figure 4. Single-Line Diagram of Substation 25-10 at NTS

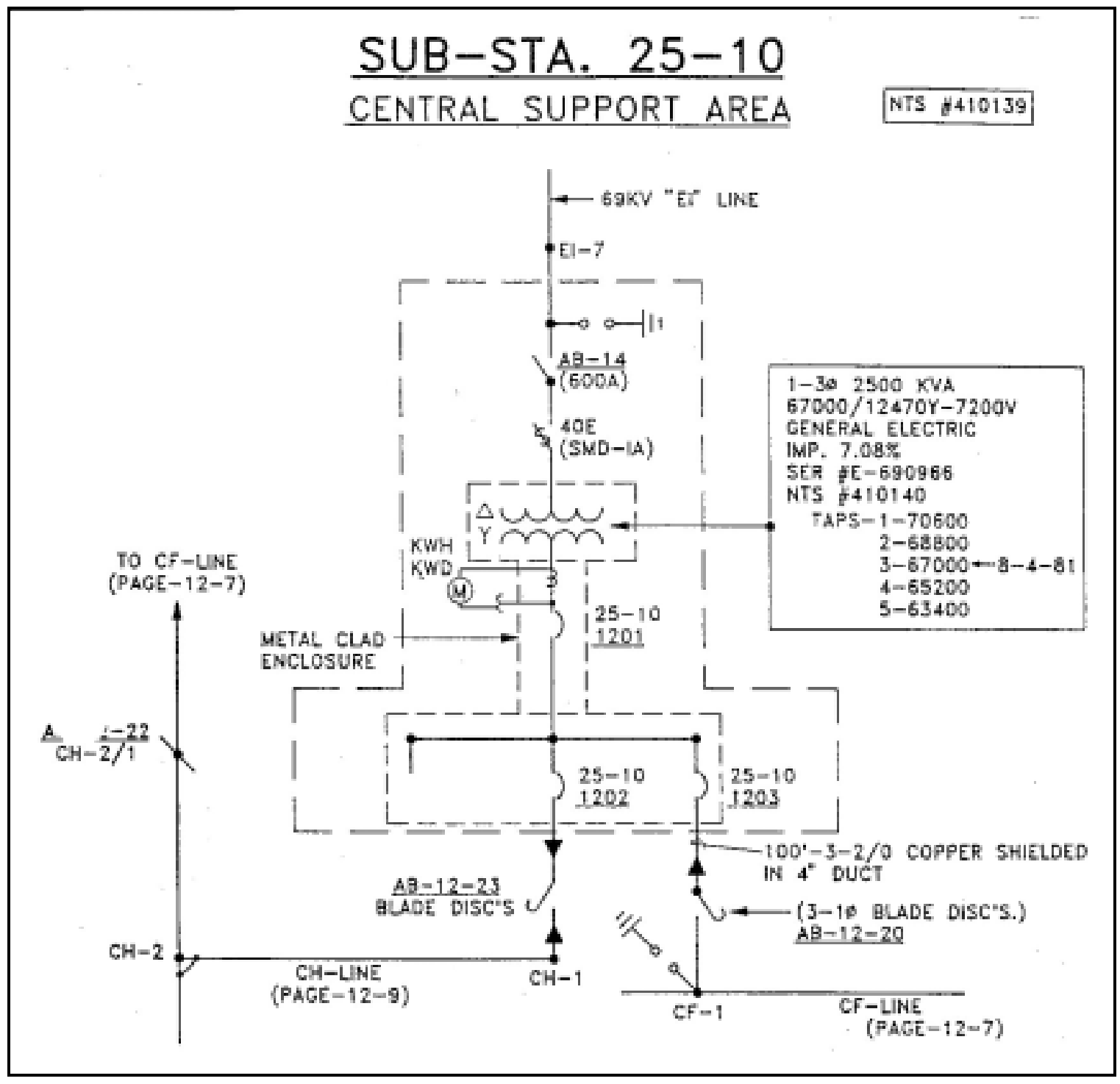




\section{Distribution Feeders}

Substation 25-10 is sectionalized into two feeders designated 1202 and 1203. A drawing of the loads serviced by both feeders is shown below in the Power Flow Chart in Figure 5. Feeder 1202 has been considered for use in integrated DR testing. The feeder extends for approximately $1 / 6$ mile and has supplied various loads including trailers, the men's shower building, a 1 MVA service transformer at building 4015, and others. Building 4015 is important because the testing command center, including controls and data acquisition system (DAS), are proposed to be housed here when the site is fully modified as discussed in this report.

Presently, feeder 1203 continues to serve small communication system loads. It is expected that this load could be served from an alternate supply so as to completely free up the substation for testing purposes. Having a completely load-free site is an important attribute of Area 25.

\section{Building Loads}

As can be seen from the Power Flow Chart in Figure 5, there are a number of buildings that have internal loads which can be switched on for load purposes. These loads are important as they represent relatively large real world loads to be used in the testing of the DR. For example, building 4015 is supplied with a 1 MVA service transformer and has a large $300 \mathrm{~kW}$ compressor, large air handling system, and lighting and communication loads. Applying these loads in the existing configuration would be relatively straightforward. In the proposed modifications to the site, building loads at Building 4015 would continue to be used. However, some of the smaller loads, for example at the men's shower building, would not be used.

\subsubsection{Minimal Restrictions on Use}

One of the important features of Area 25 at the NTS is the potentially unconstrained use of the 25-10 substation. This is very important, as a number of the proposed tests have the potential for disturbing adjacent customer service on the substation. Clearly, if there are no adjacent customers, then this concern or constraint is removed and testing can proceed and be scheduled freely.

A further advantage of this site is that the NTS has been permitted to store and utilize fuels such as compressed gas, diesel fuel, and others. Another potential restriction that provides more flexibility at the NTS is the running of temporary electrical installations. This is a result of the controlled and secure access to the site.

Feeder 1203 currently supplies a small communication load. In the proposed modifications, it is planned that this load will be moved to a different supply which will then free up the 25-10 substation entirely for DR testing. 
Figure 5. Power Flow Chart of Building Loads at NTS

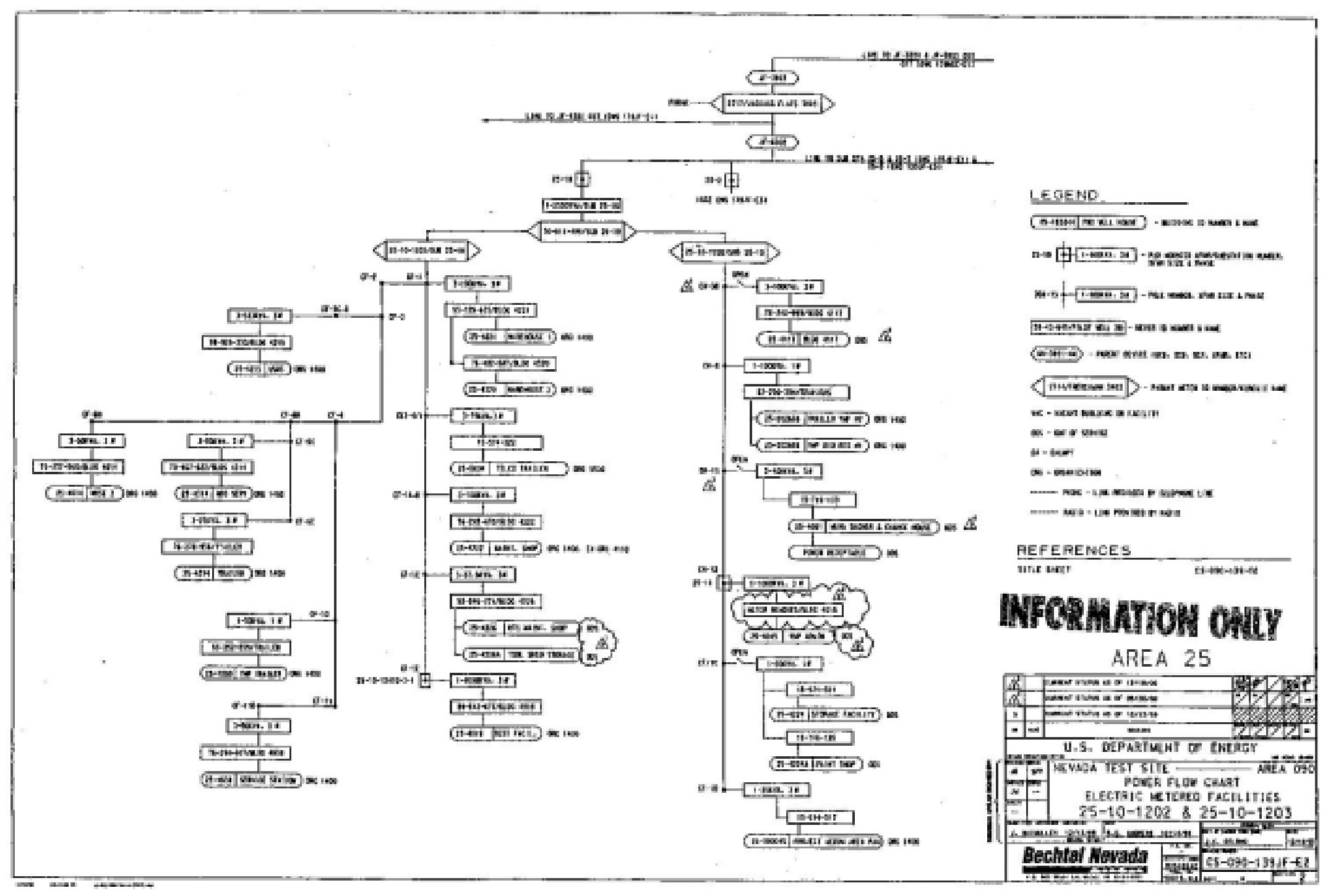




\subsubsection{Inventory of Electrical Equipment}

The NTS has the advantage of carrying a significant amount of electric distribution system equipment in its inventory, including $\mathrm{kW}$ and KVAR load sets and diesel genset ranging from $40-500 \mathrm{~kW}$. The inventory is kept at central repository where it is maintained and distributed on a rental basis. Some of the equipment is readily applicable to the planned DR testing, however there are no advanced DR sources such as microturbines, fuel cells, or advanced batteries in the inventory at this time. Other inventory that might be useful is utility scale pole mount distribution transformers, switchgear, conductors, circuit breakers, poles, and other useful apparatus. The key-major pieces of equipment that would be the most useful for DR testing are:

1) $500 \mathrm{~kW}, 277 / 480$ volt Kohler model 600RQZD71 three-phase diesel generator; trailer-mounted.

2) $350 \mathrm{~kW}, 277 / 480$ volt Stewart \& Stevenson model G424P1.M.002 three-phase diesel generator; trailer-mounted.

3) $330 \mathrm{~kW}, 240 / 480$ volt Caterpillar model SR-4 three-phase diesel generator; trailermounted.

4) $100 \mathrm{~kW}, 480$ volt Stewart \& Stevenson model G-8026 three-phase diesel generator; skid-mounted (transportable by forklift).

5) $60 \mathrm{~kW}, 120 / 208$ or $277 / 480$ volt Caterpillar Olympian diesel generator; trailermounted.

6) $300 \mathrm{kVAR}, 240 / 480$ volt, three-phase Simplex Auxiliary Reactive load bank; forcedair cooled; trailer-mounted.

7) $375 \mathrm{kVAR}, 480$ volt, three-phase Avtron model K841 reactive load bank; forced-air cooled; skid-mounted.

8) $175 \mathrm{~kW}, 240 / 480$ volt, three-phase Simplex model LB125 resistive load bank; forced-air cooled; trailer-mounted.

9) $40.5 \mathrm{~kW}$ Avtron model K587 resistive load bank; forced-air cooled; skid-mounted. Designed for indoor use; rolls on casters and has handles for lifting.

10) $1.7 \mathrm{~kW}$ photovoltaic $(\mathrm{PV})$ generating system.

\subsection{Evaluation Criteria for an Integrated DR Testing Facility}

The criteria in the following list were developed and used to assess potential sites for integrated testing of DR:

- Available space - number of test cells or bays, their sizes, and limitations

- MW Rating - largest single DR allowable; total allowed DR for facility 
- Existing/permanent DRs on site - potential for reducing acquisition costs of new equipment

- Existing testing equipment - controls, monitoring and instrumentation, switching load banks, etc.

- Host utility's level of interest, support, and involvement, both financial and in terms of personnel time and expertise

- Ability to test in both radial and network circuit configurations

- Grid supply - voltage, MVA, switching arrangements, and limitations

- Fuel supply and storage - natural gas line size, pressure (psia) and flow rate (BTU/hr); diesel, hydrogen, gasoline, LPG availability and/or storage capability

- Flexibility of facility to evolve or adapt to future/unforeseen testing needs

- Limitations - noise, emissions, other

- Ability to test multiple DRs at once, in interactive modes

- Number and expertise of testing staff

- Testing history/experience relevant to DR testing

- Costs - for required facility upgrades to accommodate DR testing, as well as for the testing itself. Factors to consider:

- cost of DR technologies (purchase, rental, lease, O\&M, fuel, etc.)

- number of DR installations and removals

- duration of tests

- fuel costs

- analysis and reporting requirements

- requirements of host utility (meetings, trips, etc.)

- special installation equipment required

- control equipment for multiple DRs

\subsection{Application of Testing Criteria to Area 25}

Integrated testing of distributed resources represents the first full-scale integration test of electric distribution systems together with multiple distributed generation and storage technologies. The test project is defined by a test plan that will confront a broad range of issues and concerns related to interconnecting DR to the utility distribution system. The test plan includes detailed exercising and sophisticated monitoring of the interaction of the various DR with each other and with the electric utility grid.

Area 25 at the NTS represents an almost clean slate for DR testing: its abundance of open space could allow a fully integrated DR testing laboratory to be designed around the existing infrastructure, with minimal design and modeling limitations (budget permitting). Its remote location ensures a secure site, and guarantees that testing would not need to be curtailed out of fear of impacting nearby customers. Table 1 summarizes the existing facilities at Area 25 as they apply to accommodation of DR testing. 
Table 1. Summary of DR-related Facilities at NTS

\begin{tabular}{|c|c|}
\hline Parameter & Capabilities \\
\hline Number of test cells or bays & None \\
\hline Natural gas? & No \\
\hline Natural gas pressure (psia) & N/A \\
\hline Natural gas flow rate (BTU/hr) & $\mathrm{N} / \mathrm{A}$ \\
\hline $\begin{array}{l}\text { Other fuels? } \\
\text { (diesel, hydrogen, gasoline, LPG, other) }\end{array}$ & $\begin{array}{l}\text { Diesel available; could possibly bring in } \\
\text { liquefied natural gas }\end{array}$ \\
\hline $\begin{array}{l}\text { Permanent distributed generation units } \\
\text { on site (type, MW) }\end{array}$ & $\begin{array}{l}\text { The following are available for short term and } \\
\text { long term rental. They are not permanent } \\
\text { units. } \\
500 \mathrm{~kW}, 277 / 480 \mathrm{~V} \text { Kohler } 3 \varnothing \text { diesel generator } \\
350 \mathrm{~kW}, 277 / 480 \mathrm{~V} \text { Stewart \& Stevenson } 3 \varnothing \\
\text { diesel generator } \\
330 \mathrm{~kW}, 240 / 480 \mathrm{~V} \text { Caterpillar } 3 \varnothing \text { diesel } \\
\text { generator } \\
100 \mathrm{~kW}, 480 \text { volt Stewart \& Stevenson C diesel } \\
\text { generator } \\
60 \mathrm{~kW}, 277 / 480 \text { volt Caterpillar diesel } 1 \varnothing \\
\text { generator } \\
1.7 \mathrm{~kW} \text { photovoltaic system }\end{array}$ \\
\hline $\begin{array}{l}\text { Load banks? Resistive? } \\
\text { Reactive? Rotating? }\end{array}$ & $\begin{array}{l}\text { The following are available for short term and } \\
\text { long-term rental. These are not permanent } \\
\text { units. } \\
125 \mathrm{~kW}, 240 / 480 \mathrm{~V} \text { Simplex resistive } 3 \varnothing \text { load } \\
\text { bank } \\
40.5 \mathrm{~kW} \text { Avtron resistive } 3 \varnothing \text { load bank } \\
375 \mathrm{kVAR}, 480 \mathrm{~V} \text { Avtron reactive } 3 \varnothing \text { load bank } \\
300 \mathrm{kVAR}, 480 \mathrm{~V} \text { Simplex reactive } 3 \varnothing \text { load } \\
\text { bank }\end{array}$ \\
\hline Live loads? & Various building loads (see Figure 5) \\
\hline Grid connectivity? (Island, connected, either) & Radial connection \\
\hline Max single MW & $2.5 \mathrm{MW}$ \\
\hline Max total MW & $2.5 \mathrm{MW}$ \\
\hline Multiple DGs interacting & Yes \\
\hline Site limitation? Noise & No \\
\hline Site limitation? Footprint & No \\
\hline Site limitation? Height & No \\
\hline Site limitation? Width & No \\
\hline Site limitation? Weight & No \\
\hline Site limitation? Technology type & No \\
\hline Site limitation? Emissions & No \\
\hline Site limitation? Other & None \\
\hline Usual purpose of testing & Various, non-DR related \\
\hline Strengths of facility & $\begin{array}{l}\text { Large amount of outdoor space; secure } \\
\text { location; isolated from customers; ability to test } \\
\text { at distribution voltages }\end{array}$ \\
\hline Weaknesses of facility & $\begin{array}{l}\text { Remote location; no gas service; electric grid } \\
\text { service limit of } 2.5 \mathrm{MW} \text {; no dedicated DR }\end{array}$ \\
\hline Describe major test equipment & See Section 2.1.3 and appendices \\
\hline Number of test staff (full-time, part-time) & None \\
\hline $\begin{array}{l}\text { Total person-years of relevant distributed } \\
\text { generation test experience }\end{array}$ & $\mathrm{N} / \mathrm{A}$ \\
\hline
\end{tabular}


All components of DR testing (generators, loads, interconnection equipment, feeder circuits, DAS, etc.), could be located in close proximity to Building 4015 , facilitating the installation, operation, connection and re-connection, and monitoring of equipment under test.

On the other hand, the remote location of NTS, and the fact that it is a DOE site with tight security access, would increase the logistical issues associated with comprehensive long-term testing. Travel to the site would take about an hour from Las Vegas, unless onsite housing could be arranged. A major drawback of the site is lack of natural gas service, which would necessitate trucking fuel into the site in tankers, and the construction of storage and delivery systems on-site.

There are both $69 \mathrm{kV}$ sub-transmission lines and $12 \mathrm{kV}$ distribution feeder lines traversing various parts of Area 25. It will be necessary to design and locate the installation areas for the DRs, loads, interconnects, and feeder yard so as to avoid interfering with the operation of, and impacts on testing from, these lines.

\subsection{Gap Analysis}

The purpose of the gap analysis is to assess the attributes that are needed for integrated DR testing but lacking at area 25 of the NTS. In so doing, specific material items can be identified along with their associated cost estimates, in order to calculate the costs for upgrading the facility to the needed functionality.

First, it should be acknowledged that area 25 was not designed for DR testing. It consists of an under-utilized substation, a $1 / 6$ mile $12 \mathrm{kV}$ radial feeder, and buildings for performing tests and for functioning as real world loads. Additional assets include an inventory of equipment that can be drawn upon for test materials, and inventoried rotating DR. Perhaps the most valuable asset at area 25, in terms of the proposed site upgrades to follow, is the large amount of free space and the security of the site.

In its existing condition, the site will not support large-scale distributed resource testing covering the tests mentioned in section 4 of this report. In section 3 of this report, details of the proposed modifications to the site are presented. These modifications close the gap between what is existing at area 25 and what is needed to permit the proposed testing. The proposed modified site is unique in that no other test site with its broad capabilities is known to exist inside or outside of the U.S.

One of the most compelling advantages of the existing site which, is taken advantage of both before and after modifications, is that it is minimally utilized. This is important when conducting the integrated DR tests, as many of the test protocols have the potential to interfere with the substation and distribution system customers. Without customers, testing is relieved of a serious scheduling and timing constraint that is prevalent at other sites either inside or outside of NTS. Lastly, the site is secured and controlled and safety concerns and procedures can be readily dealt with. 
At the time the DR test plan was developed, it was not known whether the site could be made available, or what the scope of modifications would be for the site. This report provides the findings of this evaluation of Area 25 and provides details of the state of the existing site and the necessary modifications required to make the site fully capable of performing DR tests in a real world, full-scale sense. While the NTS site has many attractive features to perform such testing, its current state requires extensive modifications to address the entire test plan. The most attractive features about the site are that there is an existing "real world" distribution system that can be expanded upon; the current and planned system operates at real distribution voltages; and the full-scale nature of the facility allows for testing of DR under real world conditions. 


\section{PROpOSED Upgrades to NTS TO ACCOMMODATE DR TESTING}

\subsection{Elements of an Area 25 Test Facility}

A survey of the grounds of Area 25 led the project team to envision how the integrated DR testing laboratory could be laid out, using the existing facilities at NTS as much as possible. Figure 6 illustrates the basic elements of an integrated DR testing system at Area 25, assuming all of the proposed upgrades are made. In Figure 6 the test facility is broken down into its major constituent parts. Substation 25-10 is shown in the upper right hand corner; this substation would provide power to the site for testing purposes, and as mentioned previously the site is not serving other loads.

The 2.5 MVA transformer supply can be brought into the interconnect area as shown and, at that point, pick up transformers for the purposes of running feeder yard at voltages in the range of $2.4 \mathrm{kV}-21 \mathrm{kV}$. Building 4015 is shown in the bottom of the figure and could serve as the staging area for the testing. In addition to this, sensitive indoor equipment such as computers and other DAS hardware can be kept in the building, and access to an office and a phone are available at this location. Building 4015 is also capable of providing building load for test purposes.

The combined interconnect and transformer area is a large, surfaced open area outside of Building 4015 and has ground level cable trays for wiring of various DRs and loads. The interconnect area represents about 10,000 square feet of open, clear space and is located near A Street for easy access to the feeder yard. The last element in Figure 6 is the feeder yard area that is intended to occupy open space south of A Street. The layout of these various elements at Area 25 is shown in Figure 7 and in the aerial view of Figure 8. A detailed discussion of each of the test site elements follows.

\subsection{Feeder Yard}

The feeder yard represents the most innovative aspect of the proposed upgrades to the Area 25 site. The idea of the feeder yard began with a recognition that the existing distribution system, at 1/6 of a mile in length, was too short to adequately deal with many of the important issues of DR on a long feeder system. The need for a longer feeder system was evident and the feeder yard grew out of the need to build a long feeder in a test environment where fast, efficient access to multiple points would enhance testing considerably. The feeder yard, together with the adjacent DR interconnect area, building 4015, and a centralized Data Acquisition System (DAS) constitutes a highly efficient test 
Figure 6. Layout of Integrated DR Testing System

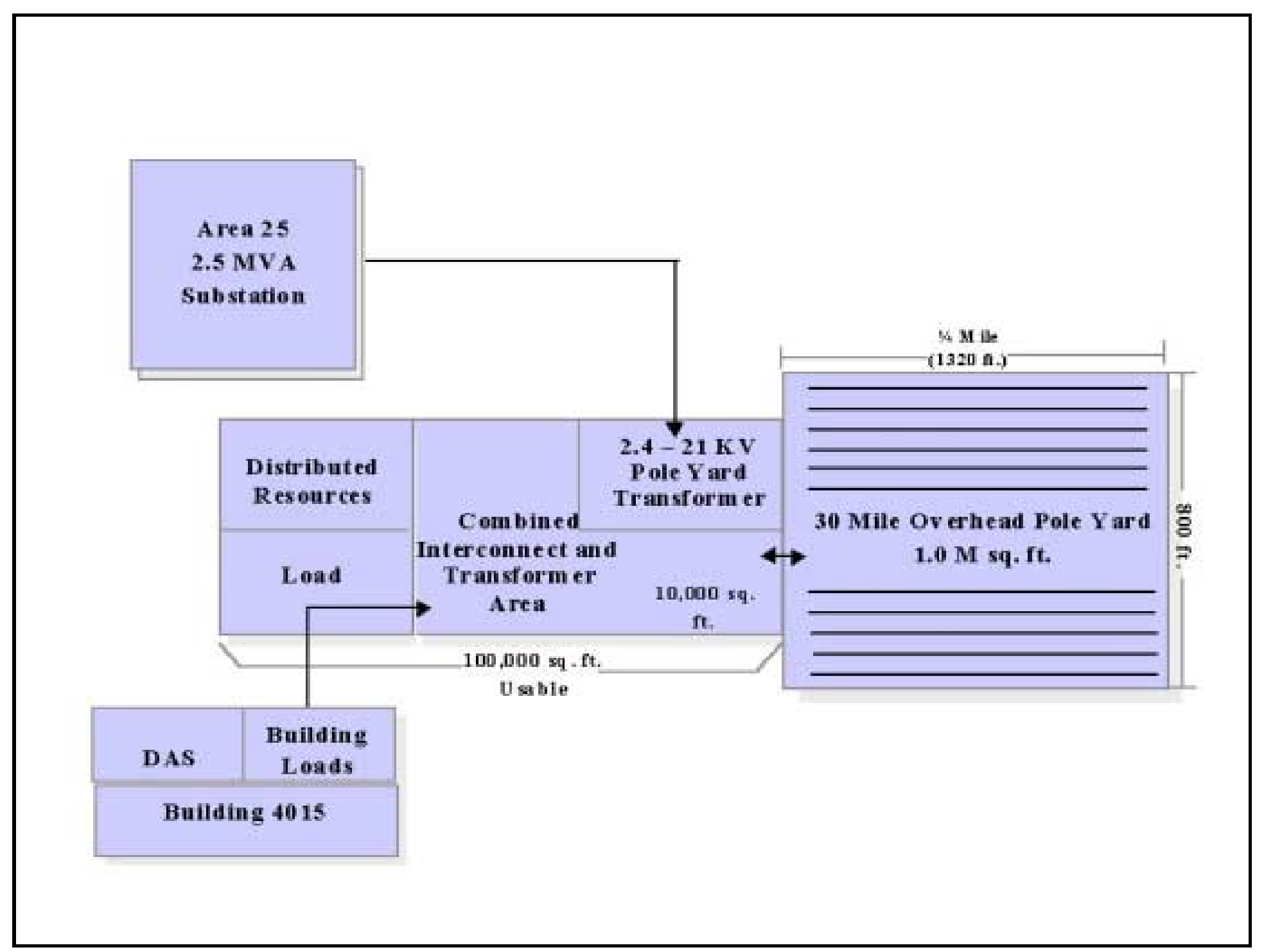


Figure 7. Layout of Proposed Interconnection Testing Areas at NTS

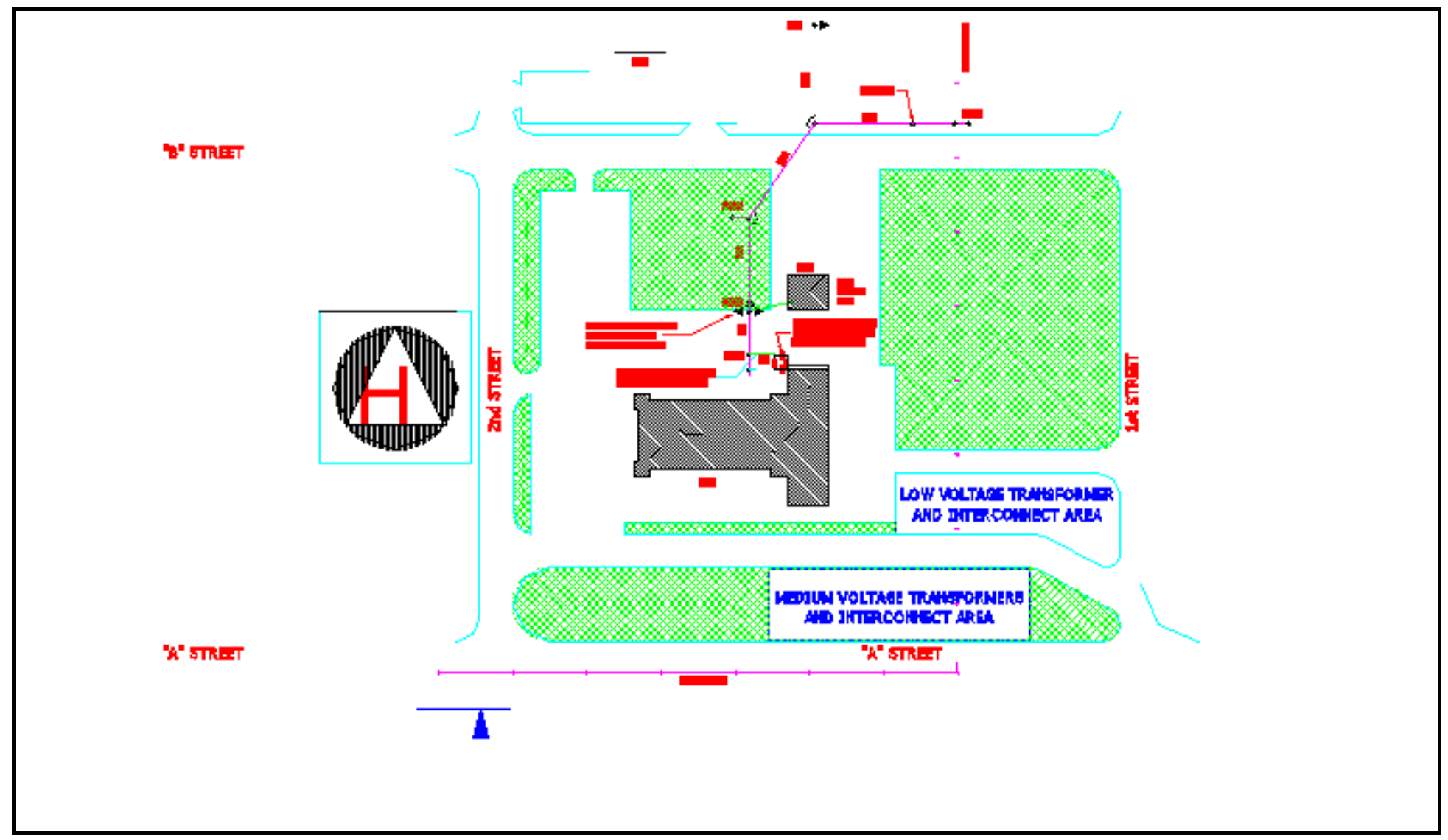


Figure 8. Aerial View Showing Locations of Proposed Testing Areas

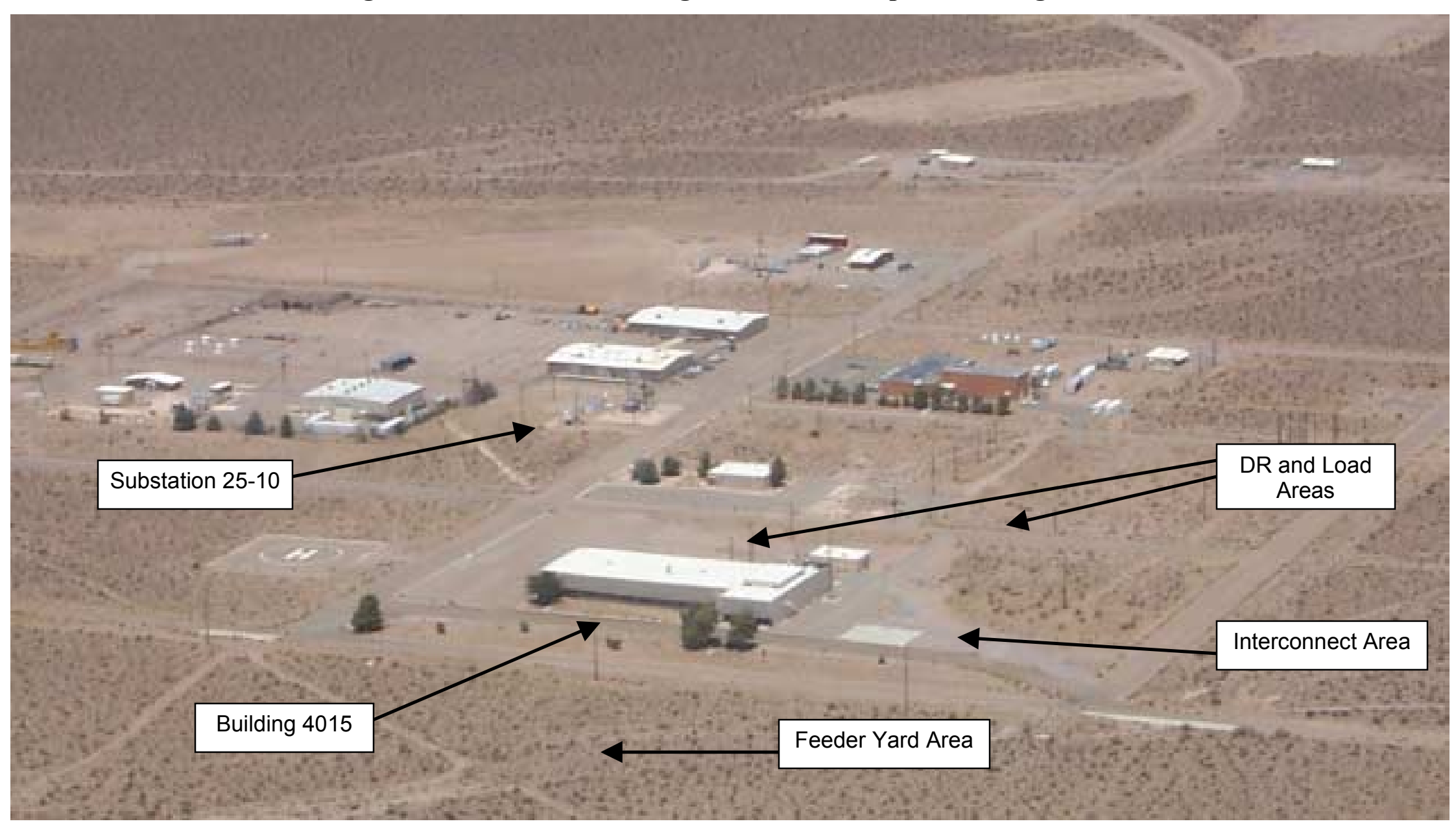


configuration from which testing is staged. The feeder yard has the additional advantage of using real world conductors so that transmission line effects can be captured in the testing. Another important feature of the feeder yard is that it can be configured in a network configuration for testing of DR on networks.

The feeder yard would consist of 30 rows of poles extending $1 / 4$ mile in length. Each pole row has four three-phase sets of conductors mounted on two cross arms as shown in detail in Figure 9. The four circuits are connected in such a way that each $1 / 4$ mile pole row provides one full mile of distribution feeder. Interconnection into the feeder yard is accomplished in the interconnection area (discussed later) and is easily accessed at every one-mile point. It is possible to achieve finer resolution than one mile under unique testing circumstances by creating connections along the one-mile feeder lengths, although these interconnection points require additional work and would not be as efficient as those in the interconnect area. Additional flexibility for the feeder system is provided by tying the substation into the 15 -mile point (or any other intermediate point) and by running adjacent feeders. It would also be straightforward to configure the feeder yard as a radial system.

The feeder yard uses all standard distribution system components and construction techniques. Class 4, 45-foot poles are used throughout the yard. A full bill of materials for the feeder yard is provided in Section 5.2, which lists the materials and quantities to be used. Conductors are sized for a transfer of $10 \mathrm{MW}$ over a 30-mile distance. Figure 9 shows the layout of conductors on the poles and shows the pole row spacing within the yard. The poles are provided at a height that would not require fencing of the feeder yard, although this might be desirable. The $10 \mathrm{ft} . / 20 \mathrm{ft}$. spacing, as detailed in Figure 9, is designed to provide a maintenance corridor for vehicles and other maintenance equipment.

\section{Feeder Yard Impedance Analysis}

The construction of four feeders on two cross arms with circuits running over each other raised an interesting question regarding the symmetry and magnitudes of the self and mutual reactances of the conductors in the feeder yard. It was felt that an analysis of these impedances was necessary to validate that the impedances and transmission line effects in the feeder yard would be representative of "real world" conditions. A study was commissioned with Dr. John Grainger of North Carolina State University to determine the impedances in the feeder yard using the proposed feeder yard geometry.

Because of space and logistical limitations, it is desired to construct the distribution feeder in a "compacted" design. There will be up to 30 rows of distribution poles, each row $1 / 4$ mile long, with poles at about 150 -foot spacing (span length); rows will average about 25 feet apart to allow vehicle access between the rows. As shown in Figure 10 (end view), each row of poles will carry four sets of 3-phase 397 MCM AAC conductors, comprising a total of one mile of feeder "folded" back on itself to fit within the 1/4-mile length. Thus, the start of the line is at points $1 \mathrm{~A}-1 \mathrm{~B}-1 \mathrm{C}$, and the end of the line is at points $4 \mathrm{~A}-4 \mathrm{~B}-4 \mathrm{C}$. The phase conductors are vertically jumpered at the far ends, and laterally jumpered at the near top end to provide the necessary circuit continuity. 
Figure 9. Proposed Feeder Yard Layout

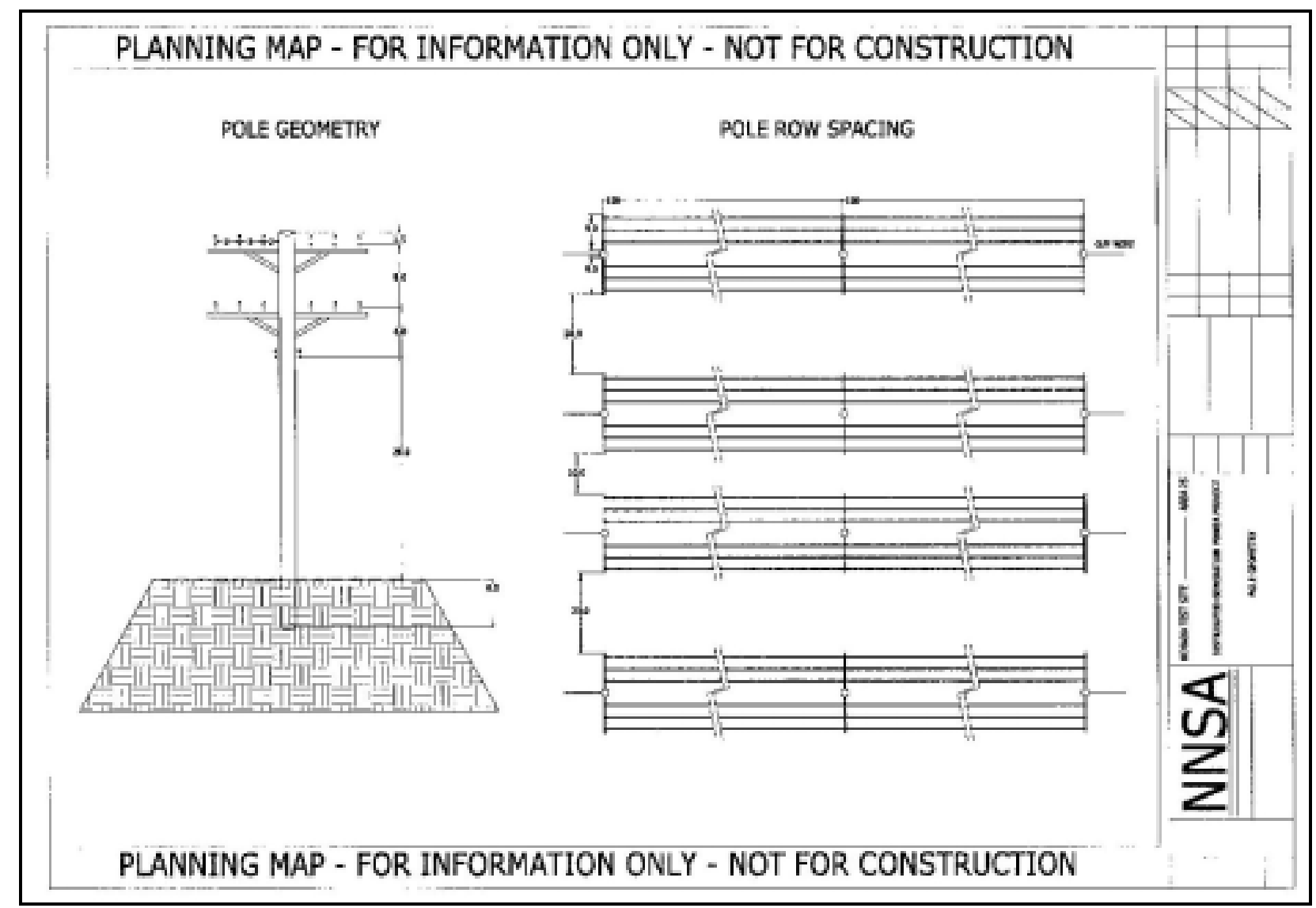


Figure 10. Model for Proposed NTS Feeder System

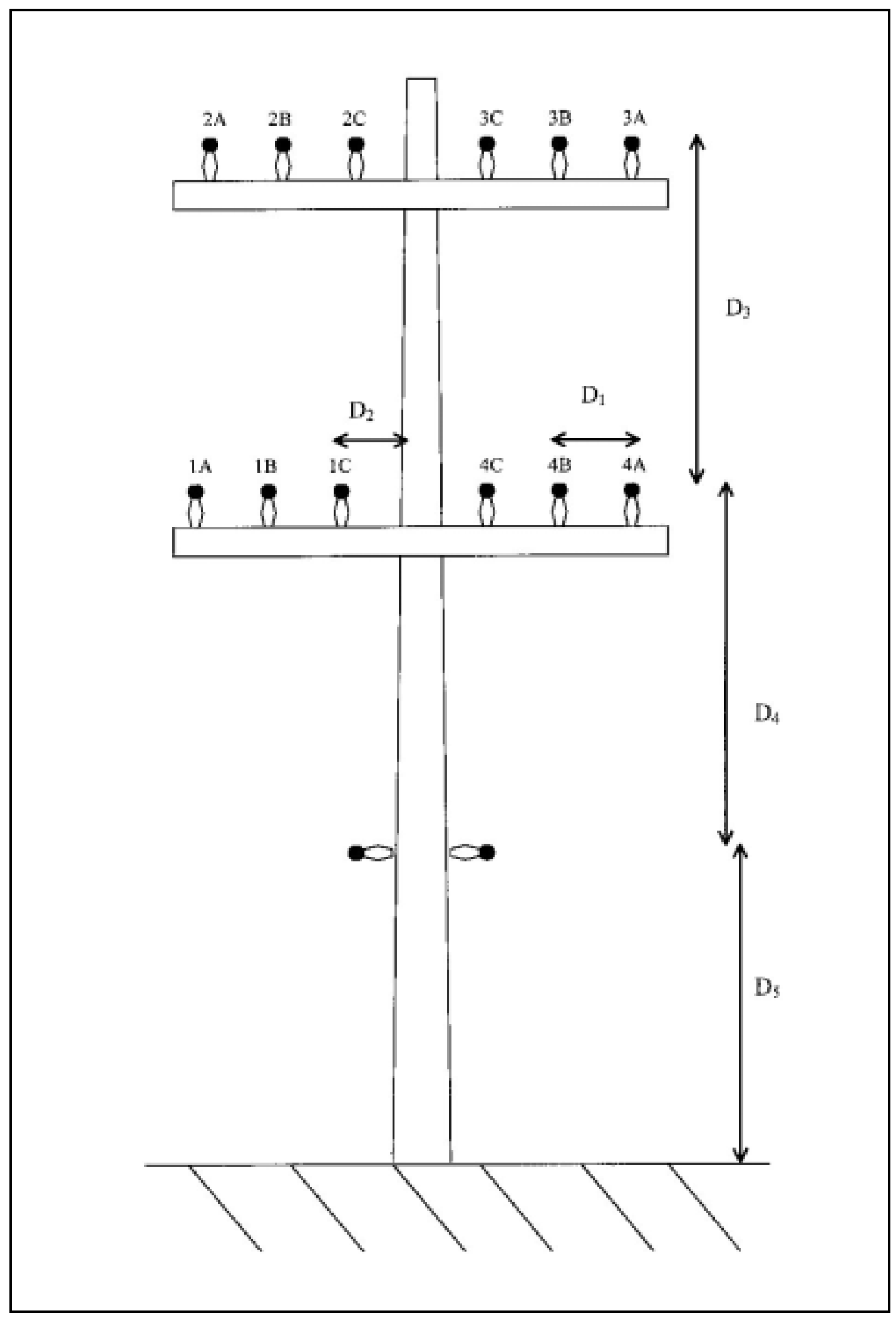


A common neutral configuration is used, consisting of a single run down and back of 1/0 aluminum conductor, with grounding assemblies every third pole. This arrangement allows DRs, loads, and instrumentation to be connected from a common interconnection area, and one-mile line segments to be connected in desired lengths and configurations (radial, loop and network).

It was necessary to know the following:

1. What are the impedance parameters of the line, i.e., resistive, inductive, and capacitive? How would they differ from a "typical" single-circuit distribution line (assume a flat 3-phase spacing about $30 \mathrm{ft}$. off the ground with single ground wire)?

2. How are the impedance parameters dependent upon: a) vertical spacing of the phase conductors, b) horizontal spacing of the conductors, and c) spacing of the pole rows.

3. Will the configuration of the neutral wire allow accurate fault calculations, particularly under unbalanced conditions?

4. Aside from the impedance parameters of the line, are there any other issues with the design that might impact testing results? Our basic objective is to design a "realistic" feeder, one that will represent the average or typical distribution feeder well enough that the testing results are credible. This approach will need to be viewed as credible by a wide variety of distribution planning engineers.

In Figure 10, the proposed dimensions are:

$\mathrm{D} 1=$ phase-to-phase spacing $=3$ feet

D2 $=$ inner phase to pole spacing $=2$ feet

D3 $=$ spacing between top and bottom circuits $=8$ feet

D4 $=$ spacing from bottom layer to neutral wires $=6$ feet

D5 $=$ distance from neutral wires to ground $=24$ feet

The following analytical results pertain to the three-phase feeder model described in the previous section. The series impedance parameters of the feeder are determined in the form of formulas for the self-impedances of each individual phase and mutual impedances between the individual phases and the neutral conductor.

The self and mutual inductive reactances of a distribution feeder are a function of the magnetic fields arising from the currents in the conductors of the feeder. The normally encountered three-phase primary distribution feeder is not balanced owing to its geometric configuration and is never transposed (unlike some overhead transmission lines). Accordingly, no assumptions were made regarding the spatial distances between conductors in establishing the parameters of the model feeder. As a result, the formulas provided below allow calculation of the series impedances of the model feeder for any arbitrary spacing of conductors and thus facilitate sensitivity studies. 


\section{Feeder Model}

In the model feeder there are 32 modules, each with 12 phase conductors and one conductor serving as the common neutral conductor for all modules. The phase conductors in each module form phases $\mathbf{A}, \mathbf{B}$, and $\mathbf{C}$ for each of four series-connected feeder sections, each $1 / 4$ mile in length and mounted on the same poles along a common right-of-way. Thus, all modules are identical, with each module having four A-phase conductors in series for a length of one-mile (likewise for B-phase and C-phase) such that any one module represents one-mile of the 32-mile-long three-phase model feeder. This analysis relates to one module representative of all the individual modules.

The four series-connected sections of each module are labeled 1, 2, 3, and 4 as shown in Figure 11 so that the one-mile long A-phase of the feeder module consists of the series connection of conductors $1 \mathrm{~A}$ to $2 \mathrm{~A}$ to $3 \mathrm{~A}$ to $4 \mathrm{~A}$. Similar statements apply for the series connection of B-phase and C-phase of the feeder module. Thus, if A-phase current $\mathrm{I}_{\mathrm{A}}$ flows into the near (front) end of conductor 1A, then it will return from the remote (back) end via conductor $2 \mathrm{~A}$ thence into the front end of conductor $3 \mathrm{~A}$ and back through conductor 4A to complete the one-mile transit through the module. Similar statements apply to currents $\mathrm{I}_{\mathrm{B}}$ and $\mathrm{I}_{\mathrm{C}}$ flowing through $\mathrm{B}$-phase and C-phase in the order 1B-2B- 3B$4 \mathrm{~B}$ and $1 \mathrm{C}-2 \mathrm{C}-3 \mathrm{C}-4 \mathrm{C}$, respectively.

\section{Interpretation of Results}

At any instant conductors $1 \mathrm{~A}$ and $3 \mathrm{~A}$ will have current $\mathrm{I}_{\mathrm{A}}$ flowing front-to-back while conductors $2 \mathrm{~A}$ and $4 \mathrm{~A}$ will have current $\mathrm{I}_{\mathrm{A}}$ flowing back-to-front (see Figure 11). Likewise, at any instant conductors $\mathrm{BB}$ and $3 \mathrm{~B}$ will have current $\mathrm{I}_{\mathrm{B}}$ flowing front-to-back while conductors $2 \mathrm{~B}$ and $4 \mathrm{~B}$ will have current $\mathrm{I}_{\mathrm{B}}$ flowing back-to-front, and similar statements apply for the C-phase conductors.

Thus, conductors $1 \mathrm{~A}$ and $3 \mathrm{~A}$, sharing the A-phase current equally, may be regarded as forming a two-conductor composite conductor for A-phase with a two-conductor (2A and 4A) return path. Similar remarks can be regarded as applying to B-phase and C-phase.

Based on this interpretation we can now write the self-inductance of A-phase using the formula:

$$
\mathbf{L}_{\text {AA }}=0.7411 \bullet \log _{10}\left(\frac{\mathbf{D}_{12}^{\text {AA }}}{\mathbf{D}_{11}^{\text {AA }}} \frac{\mathbf{D}_{14}^{\text {AA }}}{\mathbf{D}_{13}^{\text {AA }}}\right) \quad \mathrm{mH} / \mathrm{mile}
$$

where: $\mathbf{D}_{12}^{\mathrm{AA}}=$ the distance from conductor $1 \mathrm{~A}$ to conductor $2 \mathrm{~A}$ (for example)

$\mathbf{D}_{11}^{\mathbf{A A}}=$ the geometric mean radius $(\mathbf{G M R})$ of conductor $\mathrm{A}=\mathbf{r}^{\prime}$

$\mathrm{H}=$ Henry, a unit of inductance 
Figure 11. Current Flows in NTS Feeder Model

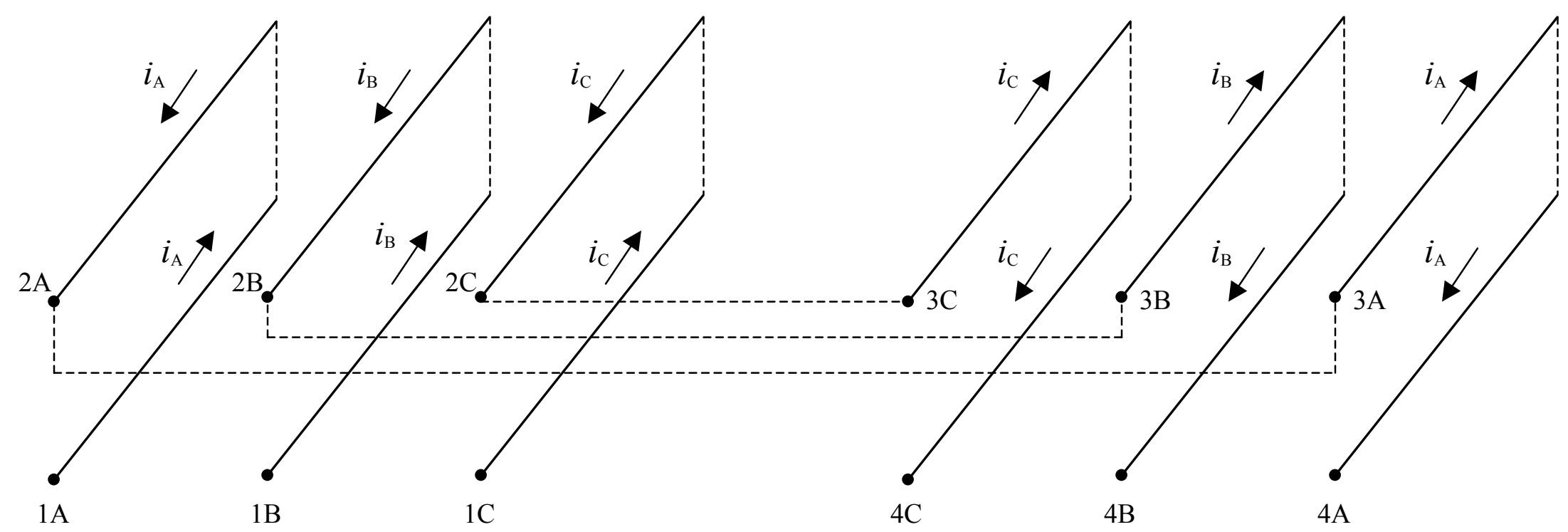


The total inductance is calculated by multiplying by the length of the line, in miles.

Further, because all conductors are assumed to be physically the same:

$$
\mathbf{D}_{11}^{\mathrm{AA}}=\mathbf{D}_{11}^{\mathrm{BB}}=\mathbf{D}_{11}^{\mathrm{CC}}=\mathbf{r}^{\mathbf{\prime}}
$$

The inductance between phase A and phase B ("mutual inductance") is:

$$
\mathbf{L}_{\mathbf{A B}}=0.7411 \bullet \log _{10}\left(\frac{\mathbf{D}_{12}^{\mathrm{AB}}}{\mathbf{D}_{11}^{\mathrm{AB}}} \frac{\mathbf{D}_{14}^{\mathrm{AB}}}{\mathbf{D}_{13}^{\mathrm{AB}}}\right) \quad \mathrm{mH} / \mathrm{mile}
$$

Self- and mutual inductances for other phases are defined similarly. For reference, please see Section 4.8, "Inductance of Composite-Conductor Lines," of the Grainger/Stevenson textbook (Grainger, J. J., and Stevenson, W. D.: Power System Analysis, McGraw-Hill International Editions, 1994).

Similar considerations and interpretations of the Geometric Mean Distance (GMD) concept lead to formulas for the mutual inductances between all three phases of the primary distribution feeder model under consideration for the NTS facility. The matrix of inductances in Table 2 apply to the feeder model.

\begin{tabular}{|c|c|c|}
\hline $\mathbf{L}_{\mathrm{AA}}=0.7411 \bullet \log _{10}\left(\frac{\mathbf{D}_{12}^{\mathrm{AA}}}{\mathbf{r}^{\prime}} \frac{\mathbf{D}_{14}^{\mathrm{AA}}}{\mathbf{D}_{13}^{\mathrm{AA}}}\right)$ & $\mathrm{L}_{\mathrm{AB}}=0.7411 \bullet \log _{10}\left(\frac{\mathbf{D}_{12}^{\mathrm{AB}}}{\mathbf{D}_{11}^{\mathrm{AB}}} \frac{\mathbf{D}_{14}^{\mathrm{AB}}}{\mathbf{D}_{13}^{\mathrm{AB}}}\right)$ & $\mathbf{L}_{\mathrm{AC}}=0.7411 \bullet \log _{10}\left(\frac{\mathbf{D}_{12}^{\mathrm{AC}}}{\mathbf{D}_{11}^{\mathrm{AC}}} \frac{\mathbf{D}_{14}^{\mathrm{AC}}}{\mathbf{D}_{13}^{\mathrm{AC}}}\right)$ \\
\hline $\mathrm{L}_{\mathrm{BA}}=\mathrm{L}_{\mathrm{AB}}$ & $\mathrm{L}_{\mathrm{BB}}=0.7411 \bullet \log _{10}\left(\frac{\mathrm{D}_{12}^{\mathrm{BB}}}{\mathbf{r}^{\prime}} \frac{\mathbf{D}_{14}^{\mathrm{BB}}}{\mathbf{D}_{13}^{\mathrm{BB}}}\right)$ & $\mathrm{L}_{\mathrm{BC}}=0.7411 \bullet \log _{10}\left(\frac{\mathbf{D}_{12}^{\mathrm{BC}}}{\mathbf{D}_{11}^{\mathrm{BC}}} \frac{\mathbf{D}_{14}^{\mathrm{BC}}}{\mathbf{D}_{13}^{\mathrm{BC}}}\right)$ \\
\hline $\mathrm{L}_{\mathrm{CA}}=\mathrm{L}_{\mathrm{AC}}$ & $\mathrm{L}_{\mathrm{CB}}=\mathrm{L}_{\mathrm{BC}}$ & $\mathrm{L}_{\mathrm{cc}}=0.7411 \bullet \log _{10}\left(\frac{\mathrm{D}_{12}^{\mathrm{cc}}}{\mathbf{r}^{\prime}} \frac{\mathbf{D}_{14}^{\mathrm{cc}}}{\mathbf{D}_{13}^{\mathrm{cc}}}\right)$ \\
\hline
\end{tabular}

Table 2. Inductance Matrix (mH/mile)

\section{Calculating Impedances}

The self-impedance of phase $\mathrm{A}$ is given by the equation:

$$
\mathbf{Z}_{\mathrm{AA}}=\mathbf{r}_{\mathrm{A}}+\mathbf{j} \omega \mathbf{L}_{\mathrm{AA}}, \Omega / \mathrm{mi}(\mathrm{ohms} / \mathrm{mile})
$$

where: $\omega=2 \pi 60=377$

$\mathrm{r}_{\mathrm{A}}=$ resistance of phase $\mathrm{A}, \Omega / \mathrm{mi}$ 
The mutual impedance between phase A and phase B is:

$$
\mathbf{Z}_{\mathrm{AB}}=\mathbf{j} \omega \mathbf{L}_{\mathrm{AB}}, \Omega / \mathrm{mi}
$$

The impedance matrix therefore becomes:

Table 3. Impedance Matrix $(\Omega /$ mile)

\begin{tabular}{|c|c|c|}
\hline$Z_{\mathrm{AA}}=r_{\mathrm{A}}+j 0.2794 \cdot \log _{10}\left(\frac{\mathbf{D}_{12}^{\mathrm{AA}}}{r^{\prime}} \frac{\mathbf{D}_{14}^{\mathrm{AA}}}{\mathbf{D}_{13}^{\mathrm{AA}}}\right)$ & $Z_{\mathrm{AB}}=\mathrm{j} 0.2794 \bullet \log _{10}\left(\frac{D_{12}^{\mathrm{AB}} \mathbf{D}_{14}^{\mathrm{AB}}}{\left.\mathbf{D}_{11}^{\mathrm{B}} \frac{\mathbf{D}_{13}^{\mathrm{AB}}}{\mathbf{A}_{13}}\right)}\right.$ & $\mathbf{Z}_{\mathrm{AC}}=\mathrm{j} 0.2794 \cdot \log _{10}\left(\frac{\mathbf{D}_{1 \mathrm{~A}}^{\mathrm{AC}}}{\mathbf{D}_{11}^{\mathrm{AC}}} \frac{\mathbf{D}_{14}^{\mathrm{AC}}}{\mathbf{D}_{13}^{\mathrm{AC}}}\right)$ \\
\hline$Z_{\mathrm{BA}}=Z_{\mathrm{AB}}$ & $Z_{\mathrm{BB}}=r_{\mathrm{A}}+\mathrm{j} 0.2794 \bullet \log _{10}\left(\frac{D_{12}^{\mathrm{BB}}}{r^{\prime}} \frac{D_{14}^{\mathrm{BB}}}{\mathbf{D}_{13}^{\mathrm{BB}}}\right.$ & $\mathbf{Z}_{\mathrm{BC}}=\mathrm{j} 0.2794 \cdot \log _{10}\left(\frac{D_{12}^{\mathrm{BC}}}{\mathbf{D}_{11}^{\mathrm{BC}}} \frac{\mathbf{D}_{1 \mathrm{C}}^{\mathrm{BC}}}{\mathbf{D}_{13}^{\mathrm{BC}}}\right)$ \\
\hline$Z_{C A}=Z_{A C}$ & $Z_{C B}=Z_{B C}$ & $\mathbf{Z}_{\mathrm{cc}}=\mathbf{r}_{\mathrm{A}}+\mathrm{j} 0.2794 \bullet \log _{10}\left(\frac{\mathbf{D}_{12}^{c c}}{\mathbf{r}^{\prime}} \frac{\mathbf{D}_{14}^{c c}}{D_{1}^{c c}}\right.$ \\
\hline
\end{tabular}

\section{$\underline{\text { Remarks and Comments }}$}

The off-diagonal terms in the matrices of results are small in value and may be averaged to yield a single value of mutual inductance between all phases.

By configuring the conductors on the right side of the pole as A-B-C (left-to-right) rather than C-B-A, the impedance matrix becomes symmetrical, further simplifying modeling and calculations. As is shown in the following section, the self-impedances that result from the proposed phasing arrangement result in slightly unequal impedances. If it is not logistically difficult to arrange the jumper connections for A-B-C/A-B-C phasing, it may be desirable in the interest of equalizing the phase impedances.

A unique aspect of the proposed the NTS feeder model is the ease of accounting for the neutral conductor. The $1 / 4$ mile long sections of each feeder module are configured to bend back on each other, so that both conductors $1 \mathrm{~A}$ and $3 \mathrm{~A}$ always carry currents equal but opposite (in their magnetizing fields) to the currents in conductors $2 \mathrm{~A}$ and $4 \mathrm{~A}$. Similar remarks can be made for the currents in the B-phase and C-phase conductors. Consequently, there must be a net current of zero in any neutral conductor carried along the length of the one-mile-long module. This statement is true regardless of the balanced or unbalanced nature of the phase currents.

Therefore, the neutral wire, if included, has no effect upon the impedance calculations of a feeder section. In the real world, neutral wires are necessary in order to carry the neutral for the required distances between substation and loads. In the proposed NTS feeder model, the neutral will always be available at the interconnect yard, so unless singlephase-to-ground faults are to be staged out on the feeder, carrying the neutral wire serves 
no purpose. In any event, a neutral wire can easily be strung for those tests, when and if required.

\section{$\underline{\text { Sample Calculations }}$}

To check the veracity of the feeder model, sample calculations were made to determine how the impedance parameters of the NTS feeder model might compare to a "typical" distribution feeder, i.e., one circuit per pole, and with flat spacing.

For the original NTS feeder design with A-B-C/C-B-A phase arrangements on the crossarm, the impedance matrix is as follows, using the equations in Table 4:

Table 4. Impedance Matrix for Proposed NTS Feeder Model

\begin{tabular}{|c|c|c|}
\hline$Z_{A A}=0.235+j 0.675$ & $Z_{A B}=0.0+j 0.110$ & $Z_{A C}=0.0+j 0.036$ \\
\hline$Z_{B A}=0.0+j 0.110$ & $Z_{B B}=0.235+j 0.661$ & $Z_{B C}=0.0+j 0.085$ \\
\hline$Z_{C A}=0.0+j 0.036$ & $Z_{C B}=0.0+j 0.085$ & $Z_{C C}=0.235+j 0.610$ \\
\hline
\end{tabular}

Note that the self-impedances of the three phases are not the same, and phase $\mathrm{C}$ is in fact significantly lower than phases B and C. (Also, the mutual impedances are not symmetrical, but because they are small compared to the self impedances their effect is not likely to be great). Therefore, if this phasing were to be used, the unequal impedances would need to be dealt with during testing, for example by transposing phases when connecting between pole rows, in order to avoid unbalanced loading that could skew test results.

For the "modified" NTS feeder design, with A-B-C/A-B-C phasing on a crossarm, the impedance matrix becomes:

Table 5. Impedance Matrix for Modified NTS Feeder Model

\begin{tabular}{|c|c|c|}
\hline$Z_{A A}=0.235+j 0.661$ & $Z_{A B}=0.0+j 0.097$ & $Z_{A C}=0.0+j 0.032$ \\
\hline$Z_{B A}=0.0+j 0.097$ & $Z_{B B}=0.235+j 0.661$ & $Z_{B C}=0.0+j 0.097$ \\
\hline$Z_{C A}=0.0+j 0.032$ & $Z_{C B}=0.0+j 0.097$ & $Z_{C C}=0.235+j 0.661$ \\
\hline
\end{tabular}

Note that the self-impedances of all phases are now equal, so that no special connection methods need be followed when connecting feeder sections together. 
A typical distribution line will have one set of three phases on a pole in a "flat" horizontal spacing arrangement, essentially the same as one half of a crossarm as depicted in Figure 10. If the feeder is long, the phases will be transposed, i.e., the phase positions will be changed so that impedance differences will even out, minimizing imbalances in the circuit. Calculating the average phase impedances using the equations in Stevenson and Grainger [reference] results in the following impedances:

Table 6. Impedance Matrix for a Single Circuit Distribution Feeder

\begin{tabular}{|c|c|c|}
\hline$Z_{A A}=0.235+j 0.596$ & $Z_{A B}=0.0+j 0.0$ & $Z_{A C}=0.0+j 0.0$ \\
\hline$Z_{B A}=0.0+j 0.0$ & $Z_{B B}=0.235+j 0.596$ & $Z_{B C}=0.0+j 0.0$ \\
\hline$Z_{C A}=0.0+j 0.0$ & $Z_{C B}=0.0+j 0.0$ & $Z_{C C}=0.235+j 0.596$ \\
\hline
\end{tabular}

This table shows that the impedances of a typical distribution circuit are likely to be about $10 \%$ lower than the NTS feeder, because of the mutual coupling between phases in the "folded" NTS design.

The conclusions are:

1) The NTS feeder model is a good approximation of a "real world" feeder system.

2) The slight difference in feeder impedances is a known quantity and can be taken into account when designing the feeder model and computing impedances during DR testing.

3) Implementing an A-B-C/A-B-C phasing arrangement will avoid having to deal with phase impedance imbalances.

\subsection{Interconnect Area}

The interconnect area is shown in detail in Figure 12 with its location at the Area 25 site shown in Figure 8. This is a large, 10,000 sq. $\mathrm{ft}$. area located at the border of A Street to the south of Building 4015. The requirements of the interconnect area are that it should allow multiple easy connection points into the feeder yard anywhere along the 30 mile feeder length. With the interconnect and feeder yard layouts as shown, this can be accomplished efficiently (without having to drive 15 or 20 miles) by the co-location of the DR, load, and any required transformers. Furthermore, the co-location of these test components allows for easy connection to the DAS, which is also located at building 4015 . 
Figure 12. Interconnection Area Layout

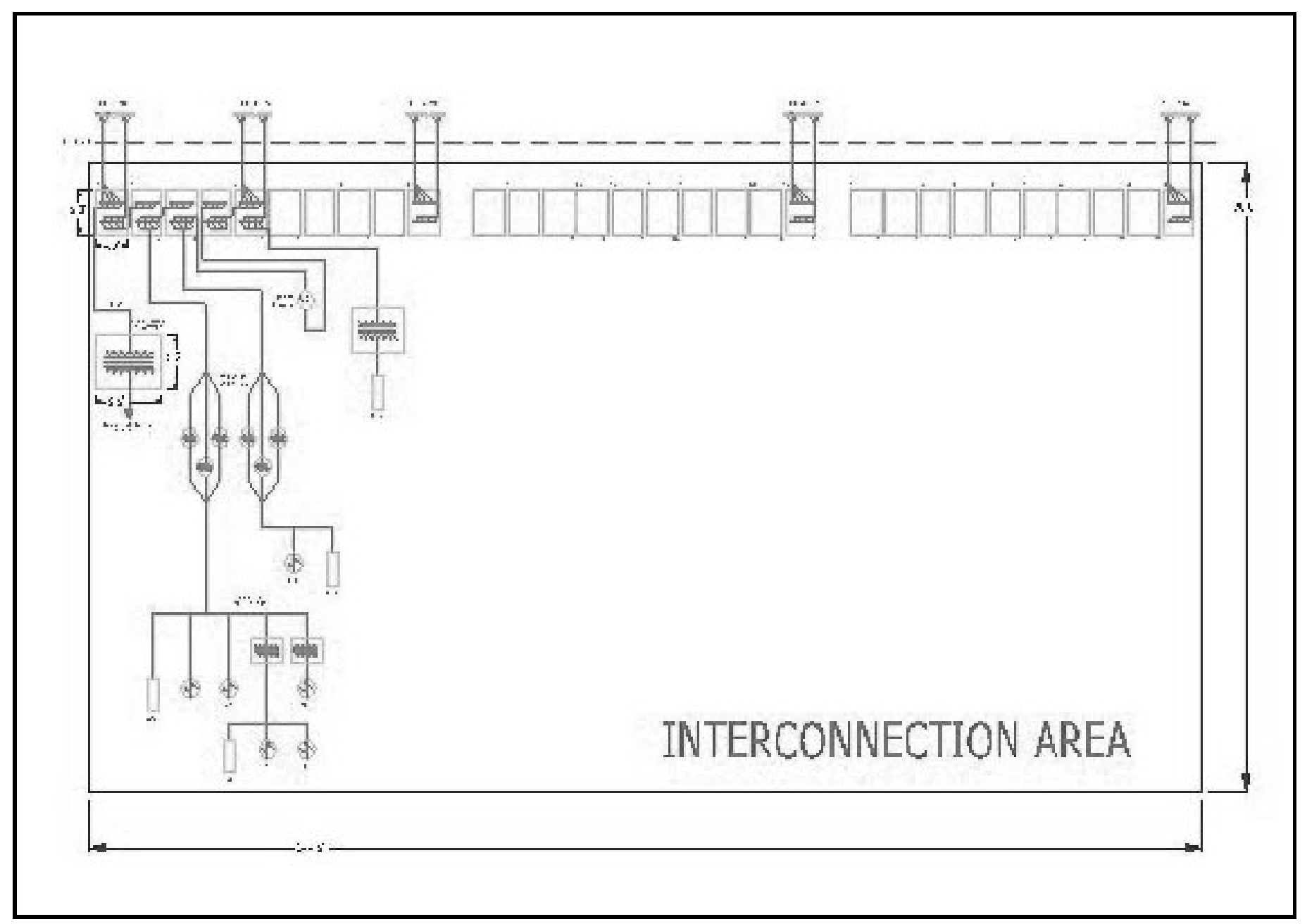


The interconnect area is made up of two sections: a medium voltage section and a low voltage section. There is a quantity of 30 outdoor rated, NEMA 3R, floor mount cabinets. Each cabinet contains termination points for the feeder yard, DR and load. The "Start" and "Finish" connections at each mile of the 30-mile feeder yard are available at these termination points in the medium voltage area. The medium voltage area is then connected to a pole mount or service style transformer, which brings the voltage down to low voltage for direct connection of DR and load. Cables between the medium voltage area and the low voltage area are run above ground where applicable, or in ground-level cable trenches.

While the interconnect area allows measurement and insertion resolution of one-mile increments, it is possible to obtain finer resolution by placing equipment in the feeder yard or by jumpering conductors on poles in the yard. If this latter approach is used, resolution becomes that of the pole spacing - $150 \mathrm{ft}$. This jumpering in the feeder yard reduces the maximum achievable length.

\subsection{Data Acquisition System}

The Data Acquisition System (DAS) for the NTS will have to provide the following functions, capabilities, and specifications. The primary measurement will be true voltage and current (not RMS), one per phase for each DR, load, and Area EPS interconnection point. From these measurements, real and reactive power, true and displacement power factor, harmonics, etc. can be determined.

For NTS, it is assumed that there are 32 three-phase interconnection points on the simulated feeder and that PTs will be permanently installed.

Because the current level will vary depending on the test configuration, CTs will be installed as needed.

A maximum $12 \mathrm{kHz}$ storage rate is specified for all current and voltage measurements to be able to define harmonics and transients up to $6 \mathrm{kHz}$.

\section{Status Signals}

In addition, there will be up to 10 status signals, for example secondary contacts on the utility isolation switch for islanding testing. These channels will need to be sampled at up to $600 \mathrm{~Hz}$, providing 1/10 cycle resolution. In addition, some DR might provide similar contact closures to show status of various aspects such as DR interconnection contactor. 
Potential Transformers (120Vac output):

\begin{tabular}{|c|c|c|c|}
\hline Qty & $\begin{array}{c}\text { Nominal } \\
\text { Voltage }\end{array}$ & Accuracy & $\begin{array}{c}\text { Maximum } \\
\text { Storage Rate }\end{array}$ \\
\hline 96 & $21 \mathrm{kV}$ & $0.5 \%$ & $12 \mathrm{kHz}$ \\
\hline 96 & $480 \mathrm{~V}$ & $0.5 \%$ & $12 \mathrm{kHz}$ \\
\hline & & & \\
\hline
\end{tabular}

Current Transformers (5Aac output):

\begin{tabular}{|c|c|c|c|c|}
\hline Qty & Current Level & $\begin{array}{c}\text { Nominal } \\
\text { Voltage }\end{array}$ & Accuracy & $\begin{array}{c}\text { Maximum } \\
\text { Storage Rate }\end{array}$ \\
\hline 48 & 1000 & $21 \mathrm{kV}$ & $0.5 \%$ & $12 \mathrm{kHz}$ \\
\hline 48 & 100 & $21 \mathrm{kV}$ & $0.5 \%$ & $12 \mathrm{kHz}$ \\
\hline 9 & 3000 & 480 & $0.5 \%$ & $12 \mathrm{kHz}$ \\
\hline 48 & 300 & 480 & $0.5 \%$ & $12 \mathrm{kHz}$ \\
\hline 48 & 75 & 480 & $0.5 \%$ & $12 \mathrm{kHz}$ \\
\hline 96 & 40 & $240 / 120$ & $0.5 \%$ & $12 \mathrm{kHz}$ \\
\hline & & & & \\
\hline
\end{tabular}

\section{Other Measurements}

It is likely that meteorological data will need to be monitored. It is also possible that DR or Area EPS component temperatures will need to be monitored.

\begin{tabular}{|c|c|c|c|c|}
\hline Qty & Parameter & Range & Accuracy & $\begin{array}{c}\text { Maximum } \\
\text { Storage Rate }\end{array}$ \\
\hline 1 & $\begin{array}{c}\text { Ambient Air } \\
\text { Temperature, }{ }^{\circ} \mathrm{C}\end{array}$ & -20 to $+60^{\circ} \mathrm{C}$ & $\pm 1{ }^{\circ} \mathrm{C}$ & 5 minute \\
\hline 1 & Wind Speed, $\mathrm{m} / \mathrm{s}$ & 0 to $45 \mathrm{~m} / \mathrm{s}$ & $\pm 0.5 \mathrm{~m} / \mathrm{s}$ & 5 minute \\
\hline 1 & Relative Humidity, $\%$ & 0 to $100 \%$ & $\pm 1 \%$ & 5 minute \\
\hline 1 & Irradiance, $\mathrm{W} / \mathrm{m}^{2}$ & 0 to $1500 \mathrm{~W} / \mathrm{m}^{2}$ & $\pm 5 \%$ & 5 minute \\
\hline 10 & $\begin{array}{c}\text { Type T or } \mathrm{J} \\
\text { Thermocouple }\end{array}$ & & $\pm 1{ }^{\circ} \mathrm{C}$ & 5 minute \\
\hline & \multicolumn{2}{|r|}{} & 5 minute \\
\hline
\end{tabular}

\section{Control Output}

The DAS will need to provide 10 control signals that will be used to operate contactors, $\mathrm{DR}$, and other equipment. These signals will need to respond within $1 \mathrm{~ms}$. 


\section{Signal Conditioning}

Signal conditioning shall be provided to accommodate the specified signal levels, storage rates, and accuracies.

\section{Dataloggers}

To minimize the impact of EMI, it is anticipated either that the CT/PT outputs will be collected and carried to a central point, or that the signal conditioning and analog to digital conversion will be distributed throughout the field. It is critical that the timing between individual measurements be well defined so that transient response can be correlated. D-A conversion will have a minimum 16-bit resolution and $\pm 0.1 \%$ accuracy.

\section{Real-time Data Processing}

Using Labview or similarly configurable DAS control software, the DAS will need to calculate real and reactive power, power factor, and harmonics for selected channels and be able to provide programmable control response based on those signals.

\section{Data Storage}

The DAS will need to handle sustained data rates up to 2 GB per second for up to several minutes.

\section{Post Processing}

The data acquisition system will be taking real time data at relatively high rates. For this reason, there will be a minor amount of real time calculation occurring and most processing of data will occur after the data collection function. This post processing will be performed on PC level hardware with standard data manipulation software. Exact programs to be used will be identified later.

\subsection{Use of Building 4015}

Building 4015 is located adjacent to and north of A Street. It is planned that this building will serve as the central operations and maintenance facility for all Area 25 testing. The building is equipped with offices, telephone and communication equipment, maintenance and storage space, and is planned as the location for housing all sensitive DAS equipment. It is planned that the open land outside, to the east and south of the building, will be the location for the interconnection area discussed above. There is more than 100,000 square feet available in addition to the interconnect area land requirements. This area could be used for storage of fuel and large equipment that would not fit inside of building 4015 . The building has not been used for some time and some remedial work would have to be performed before the building could be used. 


\subsection{Substation Upgrades and Project Phasing}

The existing substation is rated at 2.5 MVA. This is considered rather small by usual utility standards. With this size substation, it is planned to wheel up to $10 \mathrm{MVA}$ through the feeder yard at $21 \mathrm{kV}$ without any substation upgrade. Certain tests in the test protocols, however, will require a larger substation for meaningful results. An example is the testing for adjacent feeder faults with DRs present on the distribution system. For tests that might require a larger substation, it is planned that a larger substation transformer can be brought in on a rental or lease basis and installed and interconnected at the $69 \mathrm{kV}$ level. It is anticipated that the largest substation transformer the test protocols will require is $10 \mathrm{MVA}$. Connection of this leased transformer to the $69 \mathrm{kV}$ line will likely require permission from the local utility. 


\section{Integrated DR Test Plan AND SAMPle Tests FOR THE NTS}

\subsection{Overview}

A key aspect of the DR test plan project is a thorough test of the feasibility and value of co-location of diverse DR technologies in the electric distribution system, and the integration of those technologies into the distribution system. Ideally, several DR technologies will be installed within electrical interaction proximity of each other to allow their aggregate benefits and compounding operational issues to become evident.

The DR units will be instrumented and monitored to measure the potential electric distribution system advantages and challenges of substantial penetration (significantly greater than $10 \%$ of local peak load) of DR at distribution voltage levels. The data will be gathered and analyzed to characterize the actual value or consequence of DR to the utility and the DR owner.

Table 7 provides an outline of DR-related testing categories and issues to consider when developing test procedures. Not all of these categories and issues will necessarily be addressed as part of the DR test project, but their requirements were taken into account when assessing the site development needs and they will be used to develop detailed test procedures.

Based on this outline, a series of test protocols was developed to describe in a minimum of detail what tests would be performed to address the topics listed under heading 3: Grid Impacts. The following is a discussion of some of the major topics surrounding the interconnection of DR to the Area EPS.

\subsection{Unintentional Islanding}

\section{$\underline{\text { Background }}$}

Unintentional islanding is probably the most contentious - certainly the most discussedinterconnection issue. Area EPS operators have tremendous liability serving the customers in their service areas. The payouts that the Area EPS operator makes to cover customer equipment damaged by momentary sags and surges can be staggering. The problem is bad enough when the utility has control over the generation equipment providing the power. The thought of customer-owned generation operating a portion of the Area EPS without utility control keeps utility protection engineers awake at night. 


\section{Table 7. DR Testing Requirements}

1. Commissioning Tests

2. Performance

2.1 Load following

2.2 Parallel—Stand-alone transition

\section{Grid Impact}

3.1 Power Quality

3.1.1 Harmonics

3.1.2 Power Factor

3.1.3 Flicker

3.1.3.1 Flicker meter

3.1.3.2 In-rush

3.1.4 DC Injection

3.1.5 EMI/EMF

3.2 System Protection

3.2.1 Abnormal Conditions

3.2.1.1 Voltage trip points

3.2.1.2 Frequency trip points

3.2.1.3 Reverse power/Under power trip points

3.2.1.4 Fault detection

3.2.1.5 Loss of Synchronism

3.2.2 Unintentional Islanding

3.2.3 Intentional Islanding

3.2.4 Synchronization

3.3 Distribution System Impact/Interaction

3.3.1 Network system

3.3.2 Fuse protection

3.3.3 Recloser coordination

3.3.4 Short circuit current contribution

3.3.5 Capacitor switching and operation

3.3.6 Stability

3.3.6.1 DR type testing

3.3.6.2 Interaction between DGs

3.3.6.3 Islanding

3.3.7 Cold load pick-up

3.3.8 Sectionalizing devices

3.3.8.1 Automatic circuit reconfiguration

3.3.8.2 Misoperation due to DR voltage

3.3.9 Voltage regulation

3.3.10 Substation backfeed

3.3.10.1 Adjoining feeders

3.3.10.2 Transmission system

3.3.11 Single phase faults

3.3.12 Faults on adjacent feeders

3.4 DR Interaction

\section{Data}

4.1 Measurements

4.1.1 Voltages

4.1.2 Currents

4.1.3 Power
4.1.4 Power factor

4.1.5 Harmonics

4.1.6 Impedance

4.1.7 EMI/EMF

4.2 Sampling rates

4.3 Averaging rates

5. Test Equipment

5.1 Monitoring

5.2 Control

5.3 Loads

5.4 Faults

6. Issues

6.1 Legacy vs. future systems

6.2 Export vs. non-export

6.3 Control aggregation

6.4 Scalability

6.5 Long-term vs. short-term

6.6 Low vs. high penetration

6.7 DR as nuisance vs. DR as utility resource

6.8 Start-up vs. steady-state operation

6.9 Single-phase vs. three-phase

6.10 3-wire vs. 4-wire

6.11 DR type

6.11.1 Inverter-based

6.11.2 Synchronous

6.11.3 Induction

6.12 Prime mover

6.12.1 Fuel cell

6.12.2 Photovoltaics

6.12.3 Microturbine

6.12.4 Combustion turbine

6.12.5 Reciprocating engines

6.13 Storage

6.13.1 Batteries

6.13.2 Flywheels

6.13.3 Capacitors

6.13.4 SMES

6.14 Controls

6.14.1 DR unit control

6.14.2 Area control

7. Benefits

7.1 Asset utilization

7.2 Voltage and stability support

7.3 Ancillary services

7.4 Reliability/PQ

7.5 Demand reduction

7.6 Energy efficiency/CHP

7.7 Emissions trading/offsets

7.8 T\&D congestion

7.9 Risk reduction/sharing

7.10 Emergency/backup power 
Many of the problems that utilities encounter result from small generators connected inappropriately and illegally to a customer's electric service panel without disconnecting from the Area EPS. Intended to power the customer's loads in an outage, these generators are not designed to operate in parallel with other generation nor power significant portions of the utility grid. They have caused damage to other customers' equipment (primarily due to undervoltage), are usually damaged catastrophically when the utility returns, and have on occasion injured and killed unsuspecting utility lineworkers.

Testing and theoretical analyses have shown that under reasonably well balanced load and generation conditions, loss of the utility, such as by opening a sectionalizing switch, will not necessarily lead to immediate system instability. Sandia National Laboratory (SNL) has shown that inverters using only under/over frequency and under/over voltage tripping can maintain a stable island with a load to generation ratio between $80 \%$ and $120 \%$.

If the DR is not tripping off, then the frequency and voltage must be within specifications. The frequency and voltage windows that the DR is allowed to operate in ( 59.3 to $60.5 \mathrm{~Hz}, 106-132 \mathrm{VAC}$ ) are substantially wider than the utility is normally required to maintain (59.97 to $60.02 \mathrm{~Hz}, 114$ to $126 \mathrm{VAC}$ ). The wide windows let the DR ride through disturbances and utility problem situations. Should islanded DR operate loads for an extended period at either extreme of voltage, other customers' equipment could be damaged, and the deep-pocketed Area EPS would most likely be held responsible.

The next question is: How likely are such "ideal" balanced island conditions likely to occur and remain stable for any significant period of time? Begovic, Ropp, et. al. looked at the probability of an island occurring, relying only on voltage and frequency trip points. This paper notes that all techniques of detecting islanding can be fooled and defines the term Non-Detect Zone (NDZ) to describe the conditions, specific to each detection method, that cause it to fail to detect. Having a non-detect zone does not mean the method is inadequate, as the NDZ might be well outside reasonable operating conditions or it might require multiple unique (unlikely) situations to occur simultaneously.

In fact, much of the debate surrounding islanding has to do with the probability of the required conditions occurring. It is generally agreed that the probability need not be zero for a method to be effective, but the debate continues over what is an acceptable level of probability, and what the probability is of any specific situation or set of conditions occurring.

Various techniques have been developed to detect and prevent the formation of an unintentional island. The vast majority of potential islands are unstable and quickly fall outside of standard voltage or frequency limits. Simple detection techniques developed in the 1980 s, such as frequency shift, were able to reduce the islanding window, or non- 
detect zone, significantly. Advanced techniques, now standard on commercially available products, have squeezed the non-detect zone even further such that the NDZ exists only for unrealistic grid conditions.

\section{$\underline{\text { Islanding Detection Methods }}$}

The most effective method for detecting an island condition is for the utility to provide a signal telling the DR it's okay (or, more commonly, it's not okay) to parallel. For $100 \mathrm{~kW}$ and larger DR systems, the use of such a signal - typically called transfer trip — may be an economically justifiable anti-islanding technique. However, depending on the implementation, it is not always flawless, and it is not economical for smaller systems. For this reason, among others, there has been substantial activity in developing active and passive ${ }^{1}$ islanding detection methods for small inverters for photovoltaic systems. Beginning in the early 1980s, PV inverter manufacturers began developing and implementing anti-islanding techniques. At the time, the most effective techniques were those that attempted to destabilize the grid, most commonly trying to push the frequency up or down. With utility generation sources present, the inverter is unable to affect the line frequency; however, when the utility sources go away, the inverters can shove the island frequency out of tolerance and trip off. This approach, commonly used in the U. S. and other places, can potentially be defeated by rotating loads or DRs on the same line or by a balanced number of DRs trying to push in opposite directions. For example, when the utility goes away, a motor load tends to spin down, reducing frequency; while an under-loaded rotating generator will tend to speed up. Either of these could tend to balance out a simple frequency push method. In addition, if the push is uncoordinated, half of the DRs could be pushing up and the other half pushing down, thus again stabilizing the island.

A method currently favored in parts of Europe is based on measuring the impedance of the Area EPS. By injecting a current pulse and measuring the voltage response, the impedance of the Area EPS grid can be measured. Typically, the grid impedance changes when the utility disconnects from the island. Thus, when the impedance drops below a predetermined value or when it changes by more than a certain amount, the unit initiates a disconnect. This technique is very sensitive to loss of utility but has a few drawbacks. The act of injecting a current pulse is a form of distortion. If this pulse is of high enough magnitude and performed frequently enough, it will have an adverse impact on harmonics. The solution to this is to keep the current pulse small and relatively infrequent, e.g., once a second. Infrequent measurements slow the detection.

\footnotetext{
${ }^{1}$ The terms active and passive islanding detection have a variety of interpretations. Often, they are used to differentiate between techniques that try to actively affect a change in one or more Area EPS parameters, such as frequency push, and those that passively measure grid parameters such as under/over frequency. Alternatively, they are used to distinguish between methods that control the inverter output and those that don't. The impedance methods, where the inverter output is changed as a way of measuring - but not affecting - grid impedance would be considered passive under the first definition, and active under the second. Another interpretation might be that passive methods attempt to detect the island condition, while active methods attempt to inhibit the formation of an island.
} 
There is also a potential interference problem at high penetration levels leading to nuisance tripping. If two units are close enough and inject the pulse at about the same time, there will be a reduction in the perceived impedance (twice the current should result in a doubling of the voltage change), which could lead to a trip. Nonetheless, there are several small inverters that have effectively implemented this technique and some empirical data suggests there is little interference between units.

As a result of the1997 Sandia Anti-Islanding working group, discussed below, two detection methods were developed. These methods are similar to techniques developed by Toshiba, and before them, American Power Conversion. Essentially, the Sandia Frequency Shift (SFS) and Sandia Voltage Shift (SVS) attempt to push the frequency or voltage first in one direction, then the other. If the parameter in question appears to be affected, the unit continues to push again in the same direction, successively harder each time. Together, these methods tend to be much more effective at detecting island conditions and do so much more quickly. These methods may also be subject to selfinterference if an aggregate of units is attempting to push in one direction while a nearly equal aggregate of units is pushing in the other. Incorporating a small random offset in the rate at which each unit attempts to push should reduce this possibility. There is also a concern that large DRs on weak Area EPS line segments trying to push the utility frequency or voltage around may actually do so, even with the utility present.

Along with these two detection methods, a more precise procedure for evaluating islanding detection techniques was described based solely on passive resistive/inductive/capacitive elements. Most notably, the pass/fail criterion was defined in terms of circuit resonance, or Q. This test is felt to eliminate the need for rotating loads, which are very difficult to define and implement in a replicable way. Also, the circuit $\mathrm{Q}$ is related to power factor, a parameter of significance to Area EPS engineers. The selected Q of 2.5 is equivalent to a circuit with a power factor of about 0.37 , which is poorer than would be reasonably expected on an operating or islanded Area EPS line segment. This test procedure has been adopted and documented in IEEE 929, UL 1741, and is being considered for IEEE P1547 as well as internationally by the International Electrotechnical Commission (IEC) Technical Committee 82.

The use of a motor load in the test circuit is considered necessary by some. The inertia provided by a motor is a characteristic not found in passive RLC circuits. This inertia may impact methods that attempt to destabilize the island. However, the non-linear current required by the motor is not easy for some inverters to provide, thus their presence may enhance the DR's ability to detect an island.

\section{Notable Activities in DR Islanding}

- $\quad$ Rokko Island (Kobe, Japan) - Initiated in 1987, operated by Kansai Electric Co. The facility consists of 100 residential PV systems (2- and 3-kW each), two 15$\mathrm{kW}$ wind turbines and up to 10 or so $50-\mathrm{kW}$ fuel cells. The DR units are tied to a configurable $6.6 \mathrm{kV}$ distribution system. Each DR also had local resistive and reactive load controlled by the main data acquisition system. The purpose of this 
facility was to evaluate the impact of high penetration of customer-owned DR on the distribution system. Numerous tests have been performed and technical papers presented. Results indicate that there are numerous ways of detecting potential islanding conditions, which have varying degrees of success.

- Sandia Anti-Islanding Workgroup - In 1997, a group of U. S. inverter manufacturers and interested parties met at Sandia National Laboratories to discuss methods of islanding detection and work toward an improved method. This Anti-Islanding Working Group discussed a number of existing methods, shared what had previously been trade secrets and supported the further development of a pair of detection methods, dubbed Sandia Frequency Shift (SFS) and Sandia Voltage Shift (SVS). This meeting was also the genesis of the anti-islanding test described in IEEE Std 929 and used in UL 1741.

- IEA PV Interconnection Workshop in Zurich - An International Energy Agency workshop on islanding was held in 1998 in Zurich, Switzerland, which brought together interconnection experts from utilities, manufacturers, and test and research organizations around the world. Though the meeting was meant to broadly address issues related to the interconnection of PV systems to the utility grid, nearly every presentation and discussion revolved around or ended up dealing with islanding. A generalized conclusion from this workshop was "Islanding is a problem. Islanding is not a problem." The fact that so much of the discussion dealt with islanding underscored the extent of concern. On the other hand, it was also generally agreed that the conditions required for islanding to occur are highly unlikely. Further work needs to be done to address the high level of concern. New results on this very topic were recently presented at a follow up meeting in January 2002 in the Netherlands.

\section{$\underline{\text { Islanding Issues }}$}

The following provides a list of known issues and concerns related to islanding. Distributed Resource testing will attempt to address some or all of these issues.

- Number of devices - Large numbers of small units tripping independently can act as a stabilizing factor in the formation of an island. Islands are usually more stable when the load to generation ratio is equal to or slightly greater than 1.0. When this ratio is less than 1.0, a few DR units tripping off will move the island into a more stable condition.

- The inertia of rotating electrical machines, combined with their tendency to, under loss of load, spin down (rotating loads) or spin up (rotating generators) can confound some active islanding detection schemes, tending to stabilize the island.

- Types of load - Motors, transformers, and other devices can require complex current waveforms that improve the ability some DR to detect an island condition. May depend on device design (motor type, transformer design, magnetization current, etc.) [Stevens or Kern] 
- High penetration of DR with active anti-islanding (i.e., frequency push) may cause power quality problems or force the Area EPS to be unstable or to shift voltage unnecessarily.

- High penetration of DR with active anti-islanding (even some passive) may interact to cause nuisance tripping.

- Some anti-islanding techniques may be incompatible. Interaction of different techniques may cause non-detect or nuisance tripping (one "bad" unit causes all the neighbors to trip or not detect)

- The size of the island (number and magnitude of load and DR) may make detection easier or more difficult. Does the size of the island make an islandable load-to-generation match more or less likely?

- Autonomous voltage support schemes (active VAR compensation) may enhance or impede islanding detection

- Legacy Issue - grandfathered voltage-source DR w/out anti islanding may interfere with islanding detection techniques.

- Future - Automated Meter Reading (AMR)/utility signal may provide a cheap, standard, simple, accurate detection method.

- External controls/ centralized control - A form of transfer trip where a central controller receives the trip signal from the utility and forwards it to various DR under its control.

- Scalability - Will the results from multiple small DR and small load equate to larger DR and larger loads? Are there voltage-related issues?

- Penetration - are there techniques that are more applicable to low penetration? Are there different issues at high penetration than at low penetration?

- DR as a nuisance vs. DR as a resource: Can you make an autonomous DR sufficiently anti islanding? Can you operate DR in a way to create a stable intentional island?

- 1-phase vs. 3 phase, single plus polyphase. Compare single phase DR to threephase, and combinations of both.

- DR type - do slow-response DR island more easily or is it more difficult

- 3-wire vs. 4-wire distribution systems - key issues?

- Are there network-specific islanding issues?

- Transformer configuration and grounding

\section{Possible Islanding Test Procedures}

- In general, islanding testing will require fairly careful matching of generation with real and reactive load, possibly on a real-time basis.

- Indications from manufacturers of relatively small three-phase inverters $(\sim 10 \mathrm{~kW})$ are that defining a load to make the unit island with all anti-islanding schemes turned off is not trivial; finding the non-detect zone is likely to be extremely difficult.

- Get utility people comfortable; they want to see rotating loads and generation. What will be a realistic worst case? Synchronous motor/rotating condenser as part of the load? 
- Should include one or more inverters/devices using impedance detection techniques.

- Individual DR ability to avoid island, aggregate, voltage source. A combination of synchronous generator plus current source inverter will increase the likelihood of islanding or nuisance tripping.

- Go beyond standards to try to find the limits or estimate margins.

\section{$\underline{\text { Classes of Islanding Tests }}$}

1) Motor loads

- Ratio of load to generation to motor load

- Type of motor (synchronous, induction, capacitor start)

- Inertia vs. mechanical load

- Other electrical characteristics (equivalent circuit)

2) Islands with and without transformers (or small transformers)

3) Multiple DR Interaction

4) Detect time versus Q (recloser coordination)

\section{Data measurement needs (Channels, equipment, sampling rates, etc.)}

Voltage, current, power, reactive power on all DR and loads under test. Some testing will require only moderate data rates, e.g., 0.1 to 10 samples per second. Other testing may require high-speed sampling to evaluate sub-cycle response.

\section{$\underline{\text { Related Modeling Needs and Validation }}$}

Validation work could cover models that attempt to predict DR response in island conditions. Such models could also be used to define realistic worst-case test scenarios.

Modeling might prove useful in defining appropriate motor loads.

\section{$\underline{\text { References }}$}

Kern, G., R. H. Bonn, J. Ginn and S. Gonzalez, "Results Of Sandia National Laboratories Grid-tied Inverter Testing", 2nd World Conference and Exhibition on Photovoltaic Solar Energy Conversion, Vienna, Austria, July 1998.

Graf, J. D., and H. Häeberlin, "Photovoltaic Research Program - Quality Assurance of Photovoltaic Systems Final Report", Commissioned by the Swiss Federal Office of Energy, July 2000 (In German). 
Kobayashi, H, K. Cakigawa, E. Hashimoto, A. Kitamura, H. Matsuda, "Method of Preventing Islanding Phenomena on Utility Grid with a Number of Small Scale PV Systems", Proceedings of the $22^{\text {nd }}$ IEEE PV Specialists Conference, Oct 1991.

\subsection{Voltage Regulation}

\section{Overview}

The use of capacitors at the Area and Local EPS is a method of attempting to regulate voltage. One of the significant values that DR offers is the ability to intentionally improve the Local EPS voltage, and by default Area EPS voltage, without the application of capacitors and their associated problems. In addition, the act of current injection by DR - whether simply reducing on-site load or exported to the Area EPS - will also impact voltage unintentionally. That impact may be beneficial or detrimental to the Area EPS depending on the specific circumstances.

DR can have a significant, incidental effect on line voltage within the local EPS. DR output current interacting with Local and Area EPS impedance causes an increase the local voltage levels. The amount that the voltage is pumped up depends principally upon the penetration level of the DR or aggregated DR relative to the EPS KVA rating. In P1547 terms, the stiffness ratio- total short circuit current contribution at the PCC (including the Area EPS and the DR) divided by the DR's short circuit current contribution - may provide an indication of the potential incidental impact of the DR on voltage. Utilities are concerned that DR, especially those that export, may push a line segment that would otherwise be operating within prescribed voltage limits outside of those limits. Some jurisdictions have rules limiting voltage operation to the lower end of the allowable range to limit power consumption and significant penetration of DR could conceivably cause the voltage to rise above accepted levels.

While real-power generation will necessarily cause an increase in local voltage, an example of DR inadvertently reducing Local EPS voltage is by the use of non-corrected induction generators that operate at a power factor related to load. In spite of real power output, these generators typically reduce the voltage because of the VARs that they consume. This has been a historic problem with large wind plants using induction generators. Power factor limits are often specified in part to address this problem.

Many of the new DR technologies have the ability to actively supply or absorb VARs within a limited range and thus may help regulate or at least affect local EPS voltage (VAR compensation). The DR responds to the voltage regulation set point and provides the appropriate level of VARs for a given amount of real power. Under most cases the DR will end up sourcing VARs just as a parallel capacitor bank would. DR has two important advantages over the capacitor bank:

- no switching events or associated switching problems

- ability to finely adjust the VAR levels where capacitors typically provide relatively large step increments. 


\section{Distributed Resource Testing}

- Demonstrate VAR-compensation features and value that the DR provides. This can be accomplished by monitoring the voltage at a selected PCC and regulating this voltage with one or multiple DR systems.

- Evaluate the compatibility of multiple DR systems when they all are attempting to autonomously regulate EPS voltage at their output terminals, in particular looking for instability issues.

- Evaluate the response of utility voltage regulation equipment to exported power (incidental effects) and DR VAR-compensation routines.

\subsection{Reclosing Coordination}

\section{Overview}

Many faults that occur on a utility system are transient in nature. A wind-blown tree limb knocking overhead power lines together may cause a momentary short between the two phases. Even though the tree limb falls away allowing the lines to separate, because of the voltages involved, an arc can be drawn between the lines. This arc, ionized air, becomes a conductive path maintaining the fault. A recloser is a fast-acting device that senses the fault and opens the circuit. With no voltage to sustain the arc, the ionized air quickly dissipates, and the fault is eliminated. Reclosers are set to open for a fixed period (typically between 20 cycles and 3 seconds), then reclose and check to see if the fault is gone. Some reclosers can be programmed or otherwise set up to perform several such "recloser operations" with successively longer open intervals to allow the arc to extinguish. If the fault still does not clear, then the recloser remains open, leaving that line section offline. A utility lineworker will need to be dispatched to clear the fault and restore service.

Because the voltage level necessary to sustain an arc (once it is established) is small, it is critical for the DR to disconnect quickly to allow the recloser to work as intended. Interconnection standards include under/over voltage and under/over frequency trip points and clearing times. A primary consideration for the selection of the undervoltage clearing times is recloser coordination. Table 8 and the associated paragraph delineate the voltage and frequency trip points and clearing times defined in Draft 7 of IEEE P1547.

Thus, for example, the DR must trip within 10 cycles ( 0.16 seconds) if the utility voltage drops below $50 \%$ of nominal. For reclosers set to trip at 20 cycles or more, a 10 cycle clearing time should allow enough time for the recloser to detect the fault (e.g., a ground fault on the primary side of the distribution system), for the voltage to collapse to $50 \%$ or less, and for the DR to detect the fault and trip. 
Table 8. Interconnection System Response to Abnormal Voltages

\begin{tabular}{|cc|}
\hline $\begin{array}{c}\text { Voltage Range }(\% \text { of base voltage) } \\
\mathrm{V}<50\end{array}$ & Clearing Time (s)* \\
$50 \leq \mathrm{V}<88$ & 2 \\
$110<\mathrm{V}<120$ & 1 \\
$\mathrm{~V} \geq 120$ & 0.16 \\
Note. Base voltages are the nominal voltages stated in ANSI C84.1. \\
$*$ DR $\leq 30 \mathrm{~kW}$, Maximum Clearing Times; DR $>30 \mathrm{~kW}$, Default Clearing Times ${ }^{2}$ \\
\hline
\end{tabular}

Frequency Disturbances:

All DR units shall follow the interconnected Area EPS frequency within the range $59.3 \mathrm{~Hz}$ to $60.5 \mathrm{~Hz}$ (on a $60 \mathrm{~Hz}$ base). The frequency measurements shall be either at the point of DR connection or PCC.

A DR unit $<30 \mathrm{~kW}$ shall cease to energize the Area EPS within $0.16 \mathrm{sec}$. if the frequency goes outside this range. A DR unit $>30 \mathrm{~kW}$ shall: (1) cease to energize the Area EPS within $0.16 \mathrm{sec}$. if the frequency exceeds $60.5 \mathrm{~Hz}$, (2) be capable of time delayed disconnection with adjustable underfrequency settings in the range of $59.3 \mathrm{~Hz}$ to $57 \mathrm{~Hz}$, and (3) disconnect within $0.16 \mathrm{sec}$. if the frequency is less than $57.0 \mathrm{~Hz}^{3}$

Two possible situations arise that could be of concern to the utility. The first situation is high-speed reclosing. Some reclosers are capable of responding very quickly, with clearing times of 10-12 cycles. These reclosers could open before the DR. The second situation is a high- impedance fault that does not cause the voltage to collapse. In this case, the DR is allowed 2 seconds to clear if the voltage is in the $50 \%$ to $88 \%$ range, and possibly longer ${ }^{4}$ if the voltage remains in the nominal range and anti-islanding methods must be relied upon. Even "normal-speed" reclosing could be affected. It would be possible for the recloser to operate several times before all of the DR units were able to detect the island condition. Not only could the DR maintain the fault, but if the utility frequency and the island frequency differed by $0.5 \mathrm{~Hz}$ (the DR is allowed to operate between $59.3 \mathrm{~Hz}$ and $60.5 \mathrm{~Hz}$ ), after one second the two systems would be $180^{\circ}$ out of phase, a potentially dangerous scenario.

Several things to note: Reclosing out of phase into inverter based DR would likely only be detrimental to the inverter itself as inverters usually do not have sufficient fault duty to pose a threat. Rotating generators would have sufficient fault duty to potentially cause problems on the distribution system. As the generator is forced to match the phase and frequency of the utility, the inertia of prime mover could also cause mechanical damage

\footnotetext{
${ }^{2}$ The Area EPS Operator can specify different voltage settings or trip times to accommodate Area EPS system requirements.

${ }^{3}$ This frequency in the range $59.3 \mathrm{~Hz}$ to $57 \mathrm{~Hz}$ and time delay can be selected by the Area EPS Operator to provide system security.

${ }^{4}$ IEEE 929 and UL 1741 both require the device to detect the island condition within 2 seconds; IEEE P1547 is considering "up to 10 seconds."
} 
to the DR. The fault would have to be of high enough impedance to not drag the aggregate DR down but low enough to be detected as a fault. Thus it must look like a fault to the recloser and like a load to the DR.

DR testing could be performed to ascertain the probability of this fault scenario and to investigate methods of mitigation. Issues to consider include penetration, fault requirements (what impedances are required and how "stable" it would have to be), and the islanding stability issues. One test might include one or more DRs with a variable simulated fault device (a light bulb is a fixed impedance line to neutral fault device). DR islanding detection might need to be disabled, though this makes the test a very contrived situation.

\section{$\underline{\text { Test Outline }}$}

The primary concern of recloser coordination is the speed at which the islanding detection device is able to perform and the speed at which reclosing occurs. Recloser coordination testing will be an islanding test to determine run on under "rated" conditions.

○ Basic test configuration(s) -numbers/type/size of DR, size, loads, etc.) Match load to generation Primarily a type test issue

- How will the test address one or more of the interests/concerns If anti-islanding operation is timed and presented as a characteristic, that value can be used for relay coordination

- Known/anticipated testing pitfalls/limitations

Test does not represent worst case, though it arguably represents a worse than realistic case.

Data measurement needs

Test 2 - evaluate the impact on DR and loads of a step change in utility wave form - as when an out of synch DR island is suddenly snapped back into synchronization.

\subsection{Sectionalizing Devices}

\section{Overview}

A sectionalizer is a device designed to operate in conjunction with a recloser or circuit breaker. Its principal application is to protect line taps on systems equipped with reclosing equipment. The sectionalizer is connected in series with the line on the load side of its associated recloser.

The operation of the sectionalizer is dependent upon an integrator that counts overcurrent and subsequent openings of an associated recloser. The counting is accomplished by means of a magnetically compensated oil pump. The sectionalizer can be adjusted to cause the trip piston to trip the release mechanism on the first, second, or third recloser 
opening. This causes the sectionalizer contacts to drop open, sectionalizing the faulted line section. Then the recloser or breaker will close, restoring the unfaulted balance of the system. The sectionalizer switch is designed to operate when the circuit is de-energized and therefore it usually has negligible fault current interrupting ability.

If the fault is temporary and is cleared before the sectionalizer locks out, the sectionalizer will start resetting immediately. When the sectionalizer has locked out, a manual operation is necessary to close the sectionalizer.

IEEE/ANSI specifications for line sectionalizers are given in Standard C37.63-1997. Minimum activating current of the line sectionalizer is specified to be 1.6 times the continuous current rating with a tolerance of $\pm 10 \%$.

The opening time between interruption of fault current by the backup recloser and opening of the sectionalizer contacts is typically approximately 10 cycles with a reset time of approximately 3 minutes if the sectionalizer has not opened on a temporary fault. The standard rated making current is the same value as the rated momentary current; therefore the sectionalizer can be closed in on a permanent fault with no danger to the operator since the backup recloser would clear the circuit.

Selectivity between sectionalizers in series, and between sectionalizers and circuit breakers or reclosers, is obtained by counting the number of dead times (times the circuit becomes de-energized) rather than by evaluation of current magnitudes, as with fuses. The application problem is somewhat simplified but a rudimentary knowledge of fault currents is still required to make sure that the current passing through the solenoid is more than the minimum value for counting pulses and not in excess of short-time thermal rating.

Increased interest is being shown in the application of sectionalizers for underground systems. Since most cable faults are permanent faults, it is desirable that the sectionalizer protecting the underground system open on the first count, thus eliminating any automatic reclosing on a faulted cable that could cause further cable damage. A dry type sectionalizer is available that will permit the backup breaker or recloser to interrupt the fault current within 2 to 5 cycles. The sectionalizer then drops out, isolating the fault from the remainder of the system.

Advantages of the sectionalizer are:

1. Approximate methods for fault current calculation may be used, as extreme accuracy is not necessary.

2. Replacement of fuse links is not required after a permanent fault.

3. The sectionalizer relates the fault closing time to the relay setting on the fast-tripping station circuit breaker, thus eliminating arcing, expelling of ionized gases, and the loud report usually associated with the operation of a fuse cutout.

The main disadvantages of the sectionalizer are higher initial cost (about twice that of a sectionalizing fuse installation) and increased maintenance requirements. 


\section{Distribution System Automation Circuit reconfiguration}

Radial Feeders:

Utility Distribution System Automation is often based on a SCADA (Supervisory Control and Data Acquisition) system. SCADA consists of a master station located at the switching center where it communicates with remote devices such as line switches and reclosers. SCADA provides the means for the Switching Center Operator to perform two main functions remotely:

1. Locate and isolate a faulted section of a primary feeder and restore service to unfaulted sections within a few minutes

2. Transfer load from one primary to another without an outage

\section{DR Testing}

A. Determine how to reconfigure or coordinate the SCADA's switch and recloser so that the load will not be equal to generation output (a fault within line section can cause an islanding condition).

B. Does DR have any effect on the RTU's (remote terminal unit) storage energy operator?

C. What are the effects on SCADA feeders that have multiple generation units?

D. At what level is reclose blocking required? $<400 \mathrm{~kW}(50 \%$ of the minimum load) for induction generator?

E. At what level is transfer trip required? $>400 \mathrm{~kW}$ for synchronous generator, windfarm generator, or induction generator?

\section{Voltage maintained by DR leading to Sectionalizer misoperation}

IEEE Standard C37.63-1997 specifies design and production testing for sectionalizers. For DR testing, these tests should be evaluated for the situation where DR may result in the sectionalizer seeing some energization on the circuit during the period when it is operating. In particular, testing could help determine how counting of recloser operations is affected, what level of DR would cause overstress or non-operation of the sectionalizer, and whether the presence of DR will cause damage to the sectionalizer when it operates.

The primary voltage on the distribution feeders must be held within standard allowable maximum and minimum limits. A voltage problem can occur when DR is suddenly disconnected from the distribution feeder. The abrupt voltage drop may exceed the allowable limits for voltage fluctuation (limits is 5 volts on $120 \mathrm{~V}$ base). DR also has impact on substation bus voltage. For example, under peak load conditions, DR may reduce bank loading, which reduces regulator or LTC output voltage below the levels required to maintain voltages within limits on the feeders connected on the same bus.

\section{DR Testing:}

1. How many stages of regulation are allowed for a feeder with DR? (This is to prevent voltage hunting.) 
2. How to bring the voltage within allowable limits? Can the voltage be corrected with capacitor banks, regulators, boosters, etc.?

3. What happens if DR is a single-phase generator? What are the unbalanced voltages?

4. Is DR $<15 \%$ of load on the line section an appropriate or useful rule of thumb for preventing voltage problems?

\section{$\underline{\text { References }}$}

1. IEEE Std C37.63-1997: IEEE Standard Requirements for Overhead, Pad-Mounted, Dry-Vault, and Submersible Automatic Line Sectionalizers for AC Systems. Required definitions for cutout type sectionalizers: ratings, procedures for performing design tests and production tests, constructional requirements, and application considerations for overhead and pad-mounted, dry-vault, and submersible automatic line sectionalizers for AC systems.

2. Electric Distribution Systems Engineering Handbook, Third Edition, McGraw-Hill, 1994.

\subsection{Fuse Coordination}

\section{Overview}

Fuses are very common on distribution circuits. Fuses are typically installed on taps of the main line on both overhead and underground systems. The reasons for installing fuses on taps are to isolate outages so that the number of customers affected by the outage is minimized, to expedite location of a fault, and to protect overhead and underground conductor from $\mathrm{I}^{2} \mathrm{~T}$ damage. Fuses are single-phase devices and may not all melt on a three-phase circuit. It is possible that a fuse can partially melt without blowing, which will effectively change the fuse rating. Current- limiting fuses have a high impedance when interrupting, which will limit the amount of fault current that can flow to a relatively low value.

Because fuses are single-phase devices, there can be situations where one or two phases are open while the other phase(s) remain closed, which could "single-phase" a circuit or part of a circuit. Three-phase generators and load may see unbalanced voltage depending on the transformer configuration.

By design, the time-current curves (TCC) of fuses are steep, meaning that small changes in current translate into large changes in clearing time. Generation on the fault side of a fuse will provide fault current, which could reduce the amount of utility-supplied current through the fuse and desensitize the protection on fused taps.

DR may affect fuse savings schemes on an adjacent feeder if it does not take into account the additional DR fault contribution. 
Localized generation could increase the fault current and cause fuses to melt improperly when upstream fuse-saving schemes are installed.

Fuses could melt due to the fault-side current from a distribution generator for a fault on the utility side of the fuse.

\section{Possible Test Procedures}

1. Set up different distribution system configurations and note when mis-coordination problems occur.

2. Could also look at the repetitive fault current issue - constantly pounding the fuse with fault current just under its trip rating. How many times can you hit it before it changes its trip characteristics?

3. Tests to determine how to design/modify distribution system fusing to deal with DR.

\subsection{Capacitor Switching and Operation}

\section{Overview}

While the interconnect standards remain mostly silent on the issue of capacitor switching, there are potential problems that can occur with DR and with coordinated protection when EPS capacitors are switched. Momentary high in-rush currents, excitation of potential resonant conditions, and voltage transients are the most prevalent situations that can interfere with otherwise coordinated protection systems on the DR and EPS.

The two principal reasons for the use of capacitors at the area and local EPS levels are for power factor correction and for voltage regulation. These two factors are of course related, however it is common to separate them as the cost of voltage regulation is covered through normal usage (real energy) rates while power factor correction are addressed through special charges. Power factor correction is the process of bringing the power factor of the area EPS back toward unity; capacitors are used to supply reactive power because typical local EPS loads are inductive and consume reactive power. When the local EPS power factor approaches unity, the area EPS then operates more efficiently as current corresponding only to real power is provided resulting in lower current magnitude.

Low power factor at the area or local EPS level causes low voltage for two reasons. First, low power factor increases the total current and this increased current interacts with line impedances to reduce area EPS voltage. Second, the consumption of reactive power at the local EPS interacts with area and higher-level EPS reactances to further reduce voltage at the PCC.

Power factor correction has historically been accomplished both at the area EPS level as well as at the local EPS level. Voltage regulation is more typically accomplished at the area level but is occasionally provided at the local level. DR testing that is performed 
relative to capacitor switching issues will consider both levels. One of the principal values that DR can bring to the EPS is that it can effectively deal with power factor correction and voltage regulation issues and potentially can minimize the sizing of EPS capacitors or can eliminate the need for these capacitors altogether.

Possible conditions arise with capacitor switching and its influence on DR that would be of concern to the utility and should therefore be considered by DR testing. First, the switching of the capacitor typically causes a voltage transient on the area EPS; this transient is potentially capable of tripping over voltage protection on the DR, causing the DR to trip off line. Obviously, this is an undesirable situation if DR trips off line every time an area EPS capacitor is switched. Related to this is the voltage withstand capability of the DR device and other associated components. These devices will have to be capable of withstanding multiple short, high voltage transients caused by capacitor switching. Second, the DR can be exposed to high current inrush conditions due to the capacitor switching that is capable of tripping off the DR due to a momentary high current condition. The DR must be able to withstand these conditions without tripping off line or without causing damage to the DR device.

\subsection{Short Circuit Current Contribution}

\section{Overview}

Electrical equipment in distribution systems are separated from ground and from each other by insulating materials, e.g., air, paper, oil, ceramics, and polymers. Unpredictable breakdowns in these materials, due to deterioration or age, or by intrusions of outside agents, can cause a short circuit between conducting elements. These occurrences are known as faults, and the short circuit currents that result are dangerous for two reasons. First, short circuit currents can be high enough to damage electrical equipment before they are cleared, or they may even be high enough to damage the protective equipment (i.e., circuit breakers) designed to interrupt them. In the latter case, the equipment being protected (e.g., a generator) may also be damaged. Second, short circuit currents in distribution systems may, under certain circumstances, be too small for the protective relays to detect. This occurs when the fault path is through a high-impedance element, which limits the short circuit current, and presents a particularly difficult problem for the protection engineer to solve.

In all cases, short circuit currents present hazards to people as well as electrical apparatus, and it is very important to be able to predict their magnitudes under a variety of operating conditions, so that the distribution system can be adequately protected. Utility engineers may also evaluate the short circuit current contribution of a distributed generator as one of the factors to consider when assessing the potential impacts to a particular feeder.

\section{Types of Faults}

Faults are classified generally as either balanced or unbalanced. Balanced faults occur when all three phases of a network are equally affected: the symmetry among the 
voltages and currents in the three phases is maintained. This condition is met by threephase faults (all three phases shorted together but not to ground) and by three-phase-toground faults. A single-phase circuit representation can be used to calculate short circuit currents due to balanced faults. Unbalanced faults generally refer to all other types of faults, such as single-phase-to-ground, phase-to-phase (2-phase), or 2-phase-to-ground. Unbalanced faults create an asymmetry in the network, necessitating a complex analysis based on the mathematical method of symmetrical and Clark components.

Calculating short circuit currents from a particular source is known as the short circuit current contribution from that source, when it is interconnected to the distribution network. It can be calculated given the Thevenin equivalent circuit for the source, i.e., an ideal voltage $V_{\text {th }}$ and internal impedance $Z_{\text {th }}$ of the source, and the impedance $Z_{\mathrm{f}}$ between the source and the fault (see Figure 13 and Equation 6.5.1).

$$
I f=\frac{V_{t h}}{Z_{t h}+Z_{f}}
$$

\section{Figure 13. Thevenin Equivalent Circuit for a Distribution System Fault}

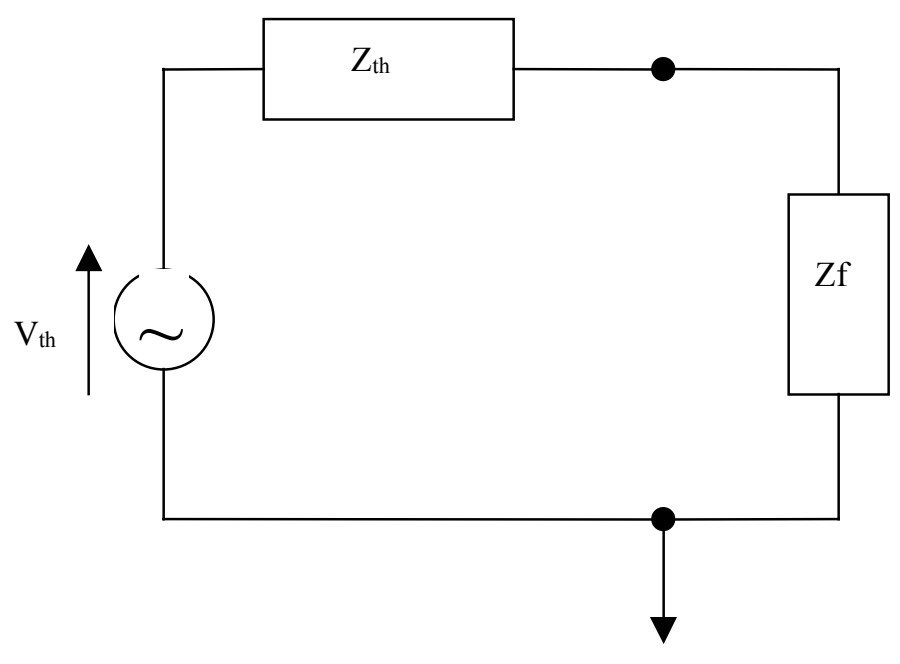

Fault

[Note: While the foregoing applies primarily to synchronous machines, the model for induction machines will be more complicated due to the dynamics of the fault response of induction machines.]

\section{$\underline{\text { Stiffness Ratio versus Short Circuit Current Contribution Ratio }}$}

IEEE P1547 defines the Stiffness Ratio as follows: 
"Stiffness ratio is calculated at the PCC, except when there is a transformer dedicated to one customer, in which case the stiffness ratio is calculated on the high-voltage side of the dedicated transformer."

$$
\text { StiffnessRatio }=\frac{S C_{\text {AreaEPS }}+S C_{D R}}{S C_{D R}}=\frac{S C_{\text {AreaEPS }}}{S C_{D R}}+1
$$

Where:

$S C_{\text {AreaEPS }}=$ the short circuit contribution in kVA of the Area EPS (including all other sources)

$S C_{D R}=$ the short circuit contribution in kVA of the DR in question.

California's Rule 21, adopted in June 2000, defines Short Circuit Contribution Ratio (SCCR) as:

"The ratio of the Generating Facility's short circuit contribution to the Electrical Corporation's short circuit contribution for a three-phase fault at the high voltage side of the distribution transformer connecting the Generating Facility to the Electrical Corporation's system."

Using the P1547 variables, this becomes:

$$
S C C R=\frac{S C_{D R}}{S C_{\text {AreaEPS }}}
$$

So, the two parameters are related by the equation:

$$
\text { StiffnessRatio }=\frac{1}{S C C R}+1
$$

In §4.2.3 Disconnection for Faults, P1547 states the following:

"The DR unit shall cease to energize the Area EPS for faults on the Area EPS circuit to which it is connected.

"With a stiffness ratio of 10 or less, the DR unit shall be equipped with current-based protection and current-based or voltage-based ground fault protection suitable for the detection of Area EPS faults."

In §4.2.4 Loss of Synchronism, P1547 further states:

"Synchronous generator DRs in applications with a stiffness ratio of 20 or less shall be equipped with loss of synchronism (out-of-step) protective functions to isolate the DR from the Area EPS without any intentional time delay." 
California Rule 21 uses SCCR as one of several screens to determine if the application qualifies as a simplified interconnection:

"Short Circuit Current Contribution Screen:

A. At primary side (high side) of the Dedicated Distribution Transformer, for the specified feeder, the sum of the Short Circuit Contribution Ratios (SCCR) of all DR's on the feeder must be less than or equal to 0.1 .

B. At secondary (low side) of a shared distribution transformer, the short circuit contribution of the proposed DR must be less than or equal to 2.5\% of the interrupting rating of the Customer's Service Equipment."

Significance:

No significant DR impact on:

- Distribution System's short circuit duty

- Distribution System fault detection sensitivity

- Distribution System relay coordination

- Distribution System fuse-saving schemes

A stiffness ratio of 10 equals an SCCR of 0.11 ; an SCCR of 0.1 equals a stiffness ratio of 11. Thus the two requirements are roughly equivalent.

\section{Testing}

\section{Rotating Machines}

For purposes of testing distributed generators to determine or verify their short circuit current contributions, the maximum value would occur for a fault at the terminals of the device. For this case, $Z_{\mathrm{f}}=0$ in Figure 13. For rotating machinery, equation (6.5.1) reduces to:

$$
I_{f}=\frac{V_{t h}}{Z_{t h}}
$$

The short circuit current contribution of a distributed generator could be measured in a straightforward manner by imposing fault impedances across the output terminals while the device is operating under no-load, open-circuit conditions, and measuring the resultant phase currents. For three-phase machines, both balanced and unbalanced faults can be staged. External fault impedances can be varied from zero to various lengths, so that short circuit current contributions can be evaluated for a variety of conditions, if desired. IEC and IEEE Standards exist that define the calculation methods and test procedures employed in determination of short circuit current contributions of rotating machines. 
Inverter-Based Distributed Generators

A primary concern here is scalability: can tests on relatively small inverter systems be scaled up to accurately represent larger systems? Another potentially fruitful area might be to investigate a combination of a generator and reactors to limit fault current impacts on nearby customers. The focus is to evaluate mitigation measures to counteract the tendency of a DR's short circuit current contribution to reduce the sensitivity of distribution system protective devices to a fault.

\section{$\underline{\text { References }}$}

1. International Electrotechnical Commission: IEC 909: Short Circuit Calculation for Three-Phase AC Systems, 1988.

2. Electricity Association: Engineering Recommendation G74: Procedure to Meet the Requirements of IEC 909 for the Calculation of Short Circuit Currents in ThreePhase AC Power Systems, 1992.

3. IEEE Standard Test Procedure for Polyphase Induction Motors and Generators, IEEE Standard 112-1996.

4. IEEE Guide: Test Procedures for Synchronous Machines, Part I-Acceptance and Performance Testing, IEEE Standard 115-1995.

5. IEEE Guide: Test Procedures for Synchronous Machines, Part II - Test Procedures and Parameter Determination for Dynamic Analysis, IEEE Standard 115-1995.

6. Jenkins, et. al.: Embedded Generation, Institution of Electrical Engineers (IEE), 2000.

7. Grainger, J. J., and Stevenson, W. D.: Power System Analysis, McGraw-Hill International Editions, 1994.

8. Anderson, P. M.: Analysis of Faulted Power Systems, IEEE Press, 1995.

\subsection{Distribution System Stability}

\section{$\underline{\text { Overview }}$}

[Note that the discussion here deals only with stability issues related to the distribution system, not with utility generation/transmission level stability issues.]

A power system is in equilibrium when the voltage magnitude and angle at each bus are such that power flows from buses with excess generation or to buses with excess demand (load) in a steady-state condition, i.e., voltages, currents, power flows, and frequency are constant. The power flow equation in the simplest case, from bus A to bus B, is given by the equation: 


$$
\mathrm{P}_{\mathrm{AB}}=\left(\frac{1}{X}\right)\left|\mathrm{V}_{\mathrm{A}}\right|\left|\mathrm{V}_{\mathrm{B}}\right| \sin \left(\delta_{\mathrm{A}}-\delta_{\mathrm{B}}\right)
$$

where:

$$
\begin{aligned}
& X=\text { impedance between buses } A \text { and } B \\
& \left|V_{A}\right|=\text { magnitude of voltage at bus } A \\
& \left|V_{B}\right|=\text { magnitude of voltage at bus } B \\
& \delta_{A}=\text { phase angle of voltage at bus } A \\
& \delta_{B}=\text { phase angle of voltage at bus B }
\end{aligned}
$$

Implicit in the concept of equilibrium is that all these values are constant, i.e., non-timevarying. When a disturbance or change occurs, such as a fault, switching operation or load change, the system will transition to a new equilibrium point if there is adequate stability margin. If the new system condition is not a stable one, the system will lose synchronism and breakup or collapse will occur. System planners ordinarily evaluate the stability of a system by means of simulation studies, in which the dynamic response of the system to a range of contingencies is studied to determine if the specified configuration is stable one. That is, an operating condition may be stable, but if a foreseeable disturbance is sufficient to make it unstable, it is considered to have inadequate stability margin. According to equation 6.7.1, system voltages and impedances should be such that the $\delta_{\mathrm{A}}-\delta_{\mathrm{B}}$ term is below 90 degrees. Alternatively, the impedance between the generator and the load bus should be kept low.

For a generating unit, the mechanical power of the prime mover should equal the electrical output of the generator (neglecting losses). A fault on the system will typically cause a decrease in the electrical output of the generator due to depression of the voltages, while the input to the prime mover will take some time to adjust downward. Until it does, the excess mechanical power will accelerate the machine, causing an increase in the frequency of the power generated, which has the effect of increasing the phase angle of the voltage at the generator bus. Since a rotating machine has angular momentum, if the accelerating power is too great, the phase angle will go past $90^{\circ}$ and the machine will slip out of synchronism, and most likely trip off-line. Protective relays should be designed to act fast enough to clear the fault before the generator becomes unstable. The longer the clearing time, the more accelerating power goes into the machine.

The characteristics of the generator's excitation system, which are not taken into account in the above simple example, will have a major effect on stability. Also, losses in the system can provide damping of oscillations.

\section{$\underline{\text { Long Feeders }}$}

The closer a generator is to a stiff system (e.g., a transmission system or primary distribution), the more the generator will be tied, dynamically speaking, to that system. Distribution systems, especially radial systems, are inherently weaker than networked or transmission systems. If a generator is farther out on a feeder, the more it will tend to 
oscillate according to faults on the feeder. In other words, voltage variations will be greater, and these will affect the machine.

Also, generators on the transmission system tend to be larger, with greater mass, and accelerate more slowly relative to the system, compared to the smaller machines typically found on the distribution system. It is relatively straightforward to determine the measures necessary to stabilize a large machine against a very stiff "infinite bus" such as the transmission system. This assumption will not hold in general for distributed generators; the strength (or weakness) of the system to which it is connected must be taken into account.

If the generator is prone to oscillations, then nearby customers on the feeder will see variations in voltage such as surges, sags or flicker. It is possible that responses triggered in customer loads may feed back to the DR and interactions may result.

Induction generator dynamics are somewhat different from synchronous generator dynamics. Its tendency to increase slip angle under faults results in the generator absorbing reactive power, depressing voltages and increasing the likelihood of nonrecovery from the fault.

If other DRs are on the feeder, then the electromechanical oscillations of one generator will cause a response in the others, possibly causing a positive feedback condition that will result in instability. It is also possible that the generator will interact dynamically with rotating loads (pumps, motors, compressors, etc.), or non-linearly with nonsinusoidal devices such as inverters.

\section{$\underline{\text { Testing }}$}

Testing of distributed generators to determine their key parameters for dynamic stability could include:

- Lab testing to determine the generator's "natural" or mechanical modes of oscillation.

- Lab testing to measure DR parameters such as inertia, internal impedance (synchronous, subsynchronous, transient), damping, natural frequency, excitation or governor response, etc., for use in simulation studies.

- Testing to determine the effects of "tweaking" the governor or excitation controls.

- Testing the dynamic response with increasing amounts of impedance between generator and load (to simulate longer feeders).

- Testing between a rotating machine and an inverter to determine the potential for interactions/oscillations.

- Testing between a rotating generator and rotating load (motor, etc.).

\section{$\underline{\text { References }}$}

1. Jenkins, et. al.: Embedded Generation, Institution of Electrical Engineers (IEE), 2000. 
2. Grainger, J. J., and Stevenson, W. D.: Power System Analysis, McGraw-Hill International Editions, 1994.

3. Anderson, P. M.: Analysis of Faulted Power Systems, IEEE Press, 1995.

4. Kundur, P.: Power System Stability and Control, McGraw-Hill, 1994.

5. Krause, P. C. et. al.: Analysis of Electric Machinery, IEEE Press, 1994.

6. Van Cutsem, T., and Vournas, C,: Voltage Stability of Electric Power Systems, Kluwer Academic Press, 1998.

7. Cardell, J., et. al.: Integrating Small Scale Generation into a Deregulated Market: Control Strategies and Price Feedback, Massachusetts Institute of Technology, 1998.

8. IEEE Standard Test Procedure for Polyphase Induction Motors and Generators, IEEE Standard 112-1996.

9. IEEE Guide: Test Procedures for Synchronous Machines, Part I-Acceptance and Performance Testing, IEEE Standard 115-1995.

10. IEEE Guide: Test Procedures for Synchronous Machines, Part II - Test Procedures and Parameter Determination for Dynamic Analysis, IEEE Standard 115-1995.

\subsection{Cold-Load Pickup}

Transient start-up power consumed by electrical equipment can be up to 6 times as much as steady state requirements. The utility must size its distribution equipment to handle a large percentage of its load starting simultaneously after an outage. The magnitude of a customer's peak demand is often established by the startup of certain loads, such as induction motors. Under such startup conditions, voltage sags can occur, high currents can stress equipment, and high demand charges can be incurred. DR can provide benefits to the distribution system but many of those benefits are lost if the customer load is allowed to start up before the DR after an outage. In addition, the entire annual benefit of DR peak shaving could be negated if a long DR restart delay is required in utilities with short demand charge intervals and long restart delays could affect demand charge.

Some DRs, such as induction generators, use power from the utility during startup to "motor" the generator up to a certain speed, after which the prime mover takes control. During this time, the DR is contributing to the utility's load and potentially to the DR owner's demand charge.

The amount of cold load that the utility must pick up after an outage depends on the types of load, the inherent or programmed delay between when the utility returns and when the load restarts, the delay between when the utility returns and when the DR restarts, and to some extent on the length of the outage (i.e., how cold is the load). An energy

management system could be employed to coordinate the restart of loads with the DR. 
DR restart delay is defined in IEEE P1547 Draft 7 §4.1.5.2: Reconnection after Area EPS Outage. This section states basically that the DR shall not restart until the utility has operated continuously within the normal operating range (i.e., between $88 \%$ and $110 \%$ of nominal voltage and between 59.3 and $60.5 \mathrm{~Hz}$ ) for a defined delay period. The current draft of P1547 states that the delay shall be fixed at 5 minutes or adjustable up to 5 minutes.

This delay is necessary to ensure that the Area EPS has adequate time to stabilize after an outage before the DR restarts.

There are additional concerns that DR testing could address, by:

- investigating DR operation during distribution system operations to determine appropriate restart delay;

- evaluating energy management systems (EMS) that control both load and DR.

\subsection{Faults on Adjacent Feeders}

Issues with DR for faults on adjacent feeders include:

- Overstress of station and feeder equipment

- Variation in source impedance for feeder protection studies

- Coordination problems between feeders

- Desensitization of backup protection for feeder breaker failure

- Impact of generator to adjacent feeder coordination

- Voltage sag caused by fault on adjacent feeder leads to loss of DR (a function of under voltage trip settings)

Overstress of substation and distribution feeder equipment

Higher fault duties from distribution generation may cause overstress of station and distribution equipment. Periodically, equipment is installed with minimal margin, and even a small fault duty addition can cause overstress. Even when equipment is adequately rated, higher fault duty causes increased fault stress.

Variation in source impedance for feeder protection studies.

Based on the amount and variation of the cogeneration in service, there could be considerable difference in the source impedance used when checking protection on a feeder. Generation on all adjacent feeders will affect this impedance. Currently, when a feeder is fed from a typical utility system, the source impedance to the feeder is essentially constant. This impedance is primarily the substation distribution bank. The source impedance for feeder protection studies does not vary much for differences in the transmission system.

$\underline{\text { Coordination problems between feeders }}$ 
Coordination is never checked between feeders. Feeder relays are nondirectional. A feeder could trip for a fault on an adjacent feeder if there is a big enough source on the feeder.

Desensitization of backup protection for feeder breaker failure

Distribution feeders breaker fail backup is typically the high side overcurrent relay on the distribution bank. As more generation is added on the distribution, this relay is less likely to detect a feeder fault and trip.

Impact of generator on adjacent feeder coordination

Coordination is not checked on a distribution generator for a fault on an adjacent feeder. A fault on an adjacent feeder could trip generation on an adjacent feeder.

Induced voltage sag leads to DR abnormal condition outage

- Function of under voltage trip settings.

- Those settings defined, in part, as islanding mitigation

- Perform islanding test while varying under voltage trip point and timing

\subsection{Secondary Networks}

In a secondary network distribution system, service is provided through multiple network transformers and multiple secondary feeders as opposed to radial distribution systems where there is only one path for load current to flow from the distribution substation to a particular load. The secondaries of network transformers are connected together via a system of network feeders to provide multiple electrical paths for power to flow resulting in a higher degree of reliability than can be achieved with an single radial feeder. To keep power from inappropriately feeding from one network transformer back through another network transformer (feeding a fault on the primary side, for example), devices called network protectors are used to detect such a backfeed and open very quickly (within a few cycles). This action is required to isolate faulted network transformers and primary feeders and maintain proper load flows to the secondary network.

Many urban downtown areas have secondary networks. The geographic size and electrical capacity of a secondary network is a function of the density of the load and a number of other factors. Facilities in the center of downtown areas are very likely to be on networks, whereas facilities in suburban and rural areas are almost certain to be on a radial distribution system.

- Large critical loads

- Does the presence of DR make a difference to fault detection?

- Nuisance network protector tripping

- Texas $=25 \%$ of load, inverter based, no study needed.

- Can network protectors tolerate a 2 p.u. voltage (DR-fed island on one side of NP falls $180^{\circ}$ out of phase with utility on other side of NP)? 
- Local regenerative loads (elevators) cause nearby network protectors to trip. Will DR do the same?

- Will NP trip/close operations increase due to DR?

What is the typical rating of one network transformer as a percent of total network capacity? Network transformers are 75-150kVA single phase, 300 - 1000kVA 3-phase.

If the aggregate DR output within a networked secondary exceeds the aggregate load, the excess power will backfeed the transformers and activate one or more network protectors. If such a situation were allowed, the reliability of the secondary network would be reduced and the stability of the network jeopardized. In such a circumstance, DR could compromise grid reliability.

\section{Issues to Address in Testing of DR for Network Systems}

Several issues are of interest when looking at the characteristics of the DR facility that may be sited on a network system. These include:

1. Fault Current Contribution from a DR on a Secondary Network

2. DR Capacity relative to site and network loads

3. Anti-Islanding

4. In-rush current (voltage flicker)

\section{$\underline{\text { Fault Current Contribution from a DR on a Secondary Network }}$}

The available fault current from a DR facility is of concern to a utility when considering the rating of the network protective devices. Should a fault occur on the primary side of the network in the vicinity of a DR facility, the fault duty of the network protector could be exceeded if the available additional fault duty of the DR increased the available fault current beyond the limits of the network protector. This typically requires an engineering study to analytically determine whether the additional fault current of the DR could cause damage to the network protector in the event of a fault.

\section{$\underline{\text { Proposed tests }}$}

1. Test currents on equivalent secondary network circuits with DR connected to better understand where fault currents travel in a network and why.

2. Determine under what conditions a network protector will be operated given a specific DR located in the network. Determine how this is different from the variety of other existing circumstances where network protectors operate.

\section{DR Capacity Relative to Site and Network Loads}

Secondary networks are installed where load is sufficiently dense to justify the added reliability and added cost of such a system. As a result, the DR facility (or aggregate DR) could be sizeable before the utility engineer needs to be concerned. For example, a one- 
megawatt DR on a 50-megawatt network may be of little concern. Conversely, a onemegawatt DR on a three-megawatt network would likely be of significant concern.

Texas, for instance, has chosen to assume that all inverter-based DR under $20 \mathrm{~kW}$ is so small that no study is necessary for such small generation. This means that no studies or further review are necessary for small installations like this, because it is assumed that there is little or no effect on a secondary network.

However, there can be large disparities between peak and minimum loads on network systems, and the issues and concerns are typically based on aggregate DR capacity, not individual unit size. The question that DR testing must answer is at what point and for what reasons does a DR facility become of concern to a utility protection engineer. If power is being exported to the secondary network, it may be necessary to determine how much power will be exported and whether any condition exists where a network protector will be operated due to the addition of the DR. If power is never exported, there may be very little if any impact of the operation of the DR on network protector operation.

\section{Power Export Review}

A DR system designed for non-export (i.e., only offsets customer load without feeding into the grid) simplifies the review process. It can be assumed that the DR will not adversely impact the voltage regulation of the secondary network or cause nuisance tripping of network protectors. Additional islanding detection may not be needed if the unit is incapable of maintaining the site load. There are three methods to ensure that power is not exported:

- To ensure no export of power without the use of additional devices, the capacity of the DR compared to the facility load must be no greater than the customer's verifiable minimum annual load.

- To ensure power is never exported, a reverse power protective function must be implemented at the point of common coupling (the meter). Default setting shall be $0.1 \%$ (export) of transformer rating, with a maximum two-second time delay.

- To ensure at least a minimum import of power, an under-power protective function must be implemented at the point of common coupling. Default setting shall be $5 \%$ (import) of DR Gross Nameplate Rating, with maximum two-second time delay.

\section{Proposed tests:}

1. Determine the local impact of an exporting DR on influencing the operation of a lightly loaded network protector.

\section{Conditions When Service Needs To Be Converted To Radial}

As the total DR on a secondary network grows relative to total network load, it becomes more likely that the local network load near a network protector could be reduced to the 
point that the network protector opens and interrupts service on the network. In this case, power flow studies may be needed to determine if it is possible for the network protector to see reverse power (even momentary) from the DR and initiate a trip.

If the power flow study determines that the DR installation could cause unintended operation of the network protector, one way to mitigate this problem is to switch the DR facility service to a radial service. If the proposed DR location is close to a network protector, it might be easier to switch the DR onto a radial feeder, making the change less costly. If the $25 \%$ of network load requirement is not met, the utility should conduct a power flow study and investigate whether it is necessary to convert the DR service from network to radial to mitigate the unintended operation of the network protectors.

\section{Proposed Tests}

1. Determine what the sphere of influence of a DR actually is and what implications this holds for applications that require conversion of service from network to radial.

\section{$\underline{\text { Anti-Islanding }}$}

Given the density of load and lack of line sectionalizing equipment (switches, fuses, etc.), what are the implications for anti-islanding and how do they differ from a radial system?

It is suggested that this issue be studied to determine what types of scenarios could create an islanded condition and how this is affected by DR size and relative network size.

\section{$\underline{\text { In-Rush Current }}$}

Given the generally low impedance found in networked systems, at what level does inrush become an issue on secondary networks? How do networks differ from radial systems in analyzing possible problems?

\subsection{Two Sample Tests}

Two types of tests are discussed below which are representative of the DR test plan and that make use of distinctive features of the modified NTS site. These features are the testing at actual distribution voltages and the ability to place load, DR and capacitance (in the first test) at distance far from the site of a DR user. The modified test site (including the 10MVA substation upgrade) is capable of performing all of the DR testing, however the two tests that follow are selected for discussion because they are considered important topics by utility protection engineers.

\subsubsection{An Islanding Test with Capacitance at the Distribution Level}

A common concern regarding the anti-islanding test in UL1741, IEEE929 and IEEE 1547 is the lack of testing with rotating loads. These anti-islanding test procedures were written 
using a passive, tuned RLC circuit that is intended to support the process of islanding. However, there is concern that rotating induction machine loads can also aid in the process of forming and maintaining an island and that these types of loads are very predominate in practice. The purpose of this test is to perform the islanding tests prescribed in the standards, but with a rotating induction machine and various inertial loads.

Performing this test at the NTS site allows the connection of distribution level power factor correction capacitance at medium voltage outside of the customer's facility. This is very common in practice and the additions of this capacitance can have a significant effect on the $\mathrm{Q}$ factor in the equivalent circuit. This is also significant because the end user is likely to be unaware of whether this capacitance is in circuit. This could lead to a set of conditions where anti-islanding at the end user functions fine without the capacitance in circuit, but fails when the capacitance is added. The NTS feeder yard will allow us to test this hypothesis with capacitance added in, away from the DR and with the capacitance added at the distribution level.

\section{Governing IEEE 1547 Sections (Draft 7), CA Rule 21 (PG\&E Version), Other Documents:}

IEEE 1547: Section 4.2.1 Voltage Disturbances

4.4.1 Unintentional Islanding

5.1.8 Unintentional Islanding

Annex A.5 Interconnection Test to Verify Non-islanding

CA Rule 21: Section D.1.c No Unintentional Islanding

D.3.d.1 Unintended Islanding for generating Facilities that Fail the

Export Screen

J.3.d Anti-Islanding test (UL 1741)

UL 1741: $\quad$ Section 46.3 Anti-islanding Tests

\section{Test Objectives:}

The inertia and generating capability of induction and synchronous motor loads present anti-islanding schemes with potential problems. It has been argued that these types of loads are more likely to cause islanding conditions than the passive RLC type-testing load identified in IEEE 1547. Furthermore, these types of loads are more representative of typical distribution system loads found in practice. For these reasons, and to demonstrate the performance of anti-islanding schemes, a series of anti-islanding tests will be performed that utilize rotating loads. The tests will be performed with a series of different real power levels and with different mechanical inertias connected to the rotating machine. The tests will be performed with both induction and synchronous machine loads, individually and collectively. Capacitance will be added at the distribution level at 1-mile increments away from the DR to determine if and at what distance, the capacitance begins and stops effecting proper operation of the anti-islanding algorithms. 


\section{Key Testing Parameters:}

The key test parameters to be varied in this test include real and reactive power and varying mechanical inertial load.

\section{Expected Results:}

It is expected that measured trip times for DR with active anti-islanding will appreciably increase with the combination RLC/rotating load.

\section{Test Procedure:}

1) Test setup is shown in Figure 14.

2) With select DR units, run standard anti-islanding tests on individual DR utilizing an induction machine load and varying inertia.

3) Connect a single DR with rotating load and set up conditions of real and reactive power as outlined in the applicable standards.

4) Disconnect the utility forming a DR, RLC load, and rotating machine island.

5) Monitor the various voltages, currents, and status signals to determine the time required for the DR to trip.

6) Repeat tests from 2) using a synchronous machine load.

7) Perform anti-islanding tests in aggregate (multiple DR with induction and synchronous rotating machine).

8) Repeat tests with the addition of capacitance at the distribution level in 1-mile increments from the DR location. The capacitance shall be selected to create the highest possible $\mathrm{Q}$ factor at the $\mathrm{DR}$, load point.

\section{Figure 14. Islanding Test Setup}

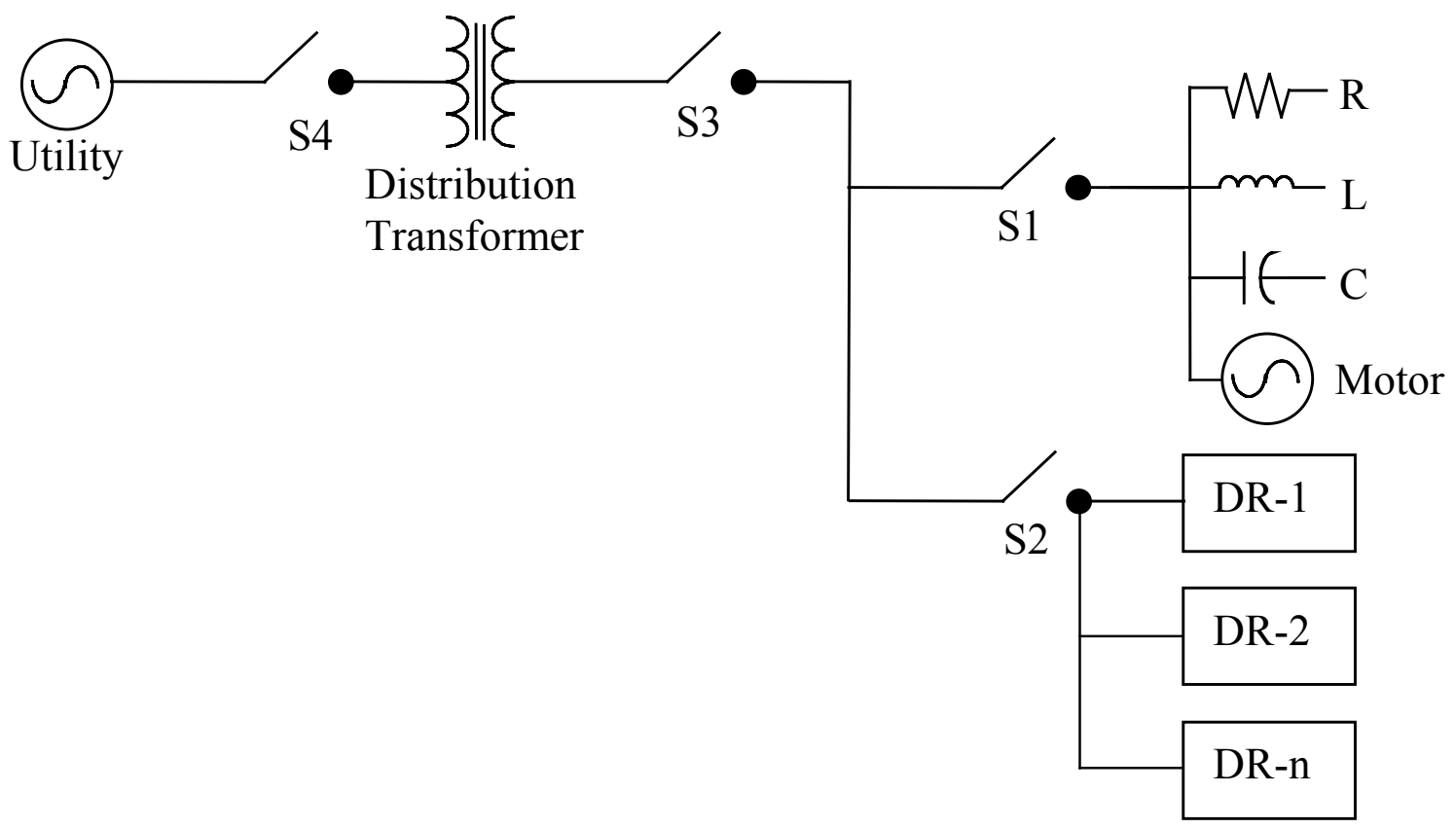


Data Acquisition Requirements:

\begin{tabular}{|l|c|c|c|c|c|}
\hline \multicolumn{1}{|c|}{ Parameter } & Units & Range & Accuracy & $\begin{array}{c}\text { Sampling } \\
\text { Rate }\end{array}$ & $\begin{array}{c}\text { Recording } \\
\text { Rate }\end{array}$ \\
\hline $\begin{array}{l}\text { Island Contactor Status } \\
\text { (i.e. Aux contact closure) }\end{array}$ & $\begin{array}{c}\mathrm{DC} \\
\text { Volts }\end{array}$ & $0-10 \mathrm{Vdc}$ & $5 \%$ & $6 \mathrm{kHz}$ & $6 \mathrm{kHz}$ \\
\hline $\begin{array}{l}\text { Island Contactor Utility- } \\
\text { Side Voltage }\end{array}$ & $\begin{array}{c}\mathrm{AC} \\
\text { Volts }\end{array}$ & $0-480$ & $1 \%$ & $6 \mathrm{kHz}$ & $6 \mathrm{kHz}$ \\
\hline $\begin{array}{l}\text { Island Contactor Island- } \\
\text { Side Voltage }\end{array}$ & $\begin{array}{c}\mathrm{AC} \\
\text { Volts }\end{array}$ & $0-480$ & $1 \%$ & $6 \mathrm{kHz}$ & $6 \mathrm{kHz}$ \\
\hline $\begin{array}{l}\text { DR Output Current (1/DR) } \\
\mathrm{AC} \\
\mathrm{Amps}\end{array}$ & $0-\mathrm{FS}$ & $1 \%$ & $6 \mathrm{kHz}$ & $6 \mathrm{kHz}$ \\
\hline $\begin{array}{l}\text { DR Output Voltage, DR } \\
\text { side of DR contactor, if } \\
\text { accessible }\end{array}$ & $\begin{array}{c}\mathrm{AC} \\
\text { Volts }\end{array}$ & $0-480$ & $1 \%$ & $6 \mathrm{kHz}$ & $6 \mathrm{kHz}$ \\
\hline
\end{tabular}

\section{Control Requirements:}

The test is to rely on the autonomous anti-islanding schemes embedded in DR devices. No special control system requirements for this test.

\section{Facility Requirements:}

This test has no real unique facility requirements other than kVA rating and ampacity need to be consistent with the ratings of the DR. The ability to form an island and provide variable load and VARs is also a requirement for this test.

\section{DR Requirements:}

Where possible, this test should be repeated with a variety of DR using a common islanding detection technique and with DR using differing islanding detection techniques. Tests should be done with combinations of single- and three-phase DRs.

\begin{tabular}{|l|c|l|l|}
\hline \multicolumn{1}{|c|}{ Type } & Qty & \multicolumn{1}{c|}{ Size } & \multicolumn{1}{c|}{ Other } \\
\hline Inverter, any prime mover & $\geq 3$ & $2-50 \mathrm{~kW}$ & $\begin{array}{l}\text { Should have advanced anti- } \\
\text { islanding function }\end{array}$ \\
\hline Synchronous Generator & $\geq 1$ & $100 \mathrm{~kW}$ & Advanced anti-islanding is desirable \\
\hline Induction generator & $\geq 1$ & $100 \mathrm{~kW}$ & Advanced anti-islanding is desirable \\
\hline
\end{tabular}

\section{Other Requirements:}

This testing will require a variety of single- and three-phase motors and variable inertias that can be tied to the motor load. 


\section{Modeling Requirements:}

Dynamic models of the various anti-islanding schemes will be developed. This test would allow for a validation case for these models, but modeling is not required.

\subsubsection{Voltage Regulation Device Interaction with DR Generation on Long Feeders}

This test is well suited for the NTS site because it requires the use of a long feeder and it allows for the testing of real-world voltage regulation equipment at distribution voltages.

The test deals with the characterization of components effecting voltage regulation in a typical radial distribution system. A simple addition of DR at the end of the feeder and its effect on the voltage regulation along the feeder will also be examined in this first test.

\section{Governing IEEE 1547 Sections (Draft 7), CA Rule 21 (PG\&E Version), Other Documents:}

IEEE 1547: Section 4.1.1 Voltage Regulation

4.2.1 Voltage Disturbances

CA Rule 21: Section D.2.a.1, D.2.a.2, D.2.a.3 Normal Voltage Operating Range

UL 1741: $\quad$ Section 42 Maximum-Voltage Measurements

Section 46.2 Utility Voltage and Frequency Variation Test

Section 55 Overvoltage Test.

\section{Test Objectives:}

The objective of this test is to characterize the fundamental voltage regulation elements in a long radial feeder system. The criteria by which the test results will be measured is the ANSI C84.1 standard as identified in IEEE 1547. Voltage will be measured at different points along the feeder to determine compliance with this standard under different load conditions. This voltage will then characterize the performance of the feeder. A second and third test will then be performed which will characterize the voltage regulator and the voltage regulator with DR added at a single point at the end of the feeder.

\section{Key Testing Parameters:}

Key testing parameters in the characterization test are amount of load on the feeder, and voltage measurements at predetermined points along the feeder. 


\section{Expected Results:}

Expected results are that the voltage at all points will drop with increasing load, but still should remain within the range identified by ANSI C84.1. Furthermore, it is expected that the addition of DR at the end of the feeder will cause the voltage regulator to operate over a smaller range than in the case of the long feeder without voltage regulation. The DR may eliminate the need for voltage regulation equipment altogether.

\section{Test Procedure:}

1) Using a long distribution feeder (30 miles), load the feeder up to the full rating of the substation in increments of $25 \%$ at unity power factor. Obtain the voltage at the substation, 10, 20, and 30-mile points along the feeder. There should be no voltage regulation equipment active during this first test. See Figure 15(a).

2) Repeat the test in 1), but with the addition of DR at the end of the feeder. The DR generation should be adjusted so that it is equal to the load. See Figure 15 (b).

3) Insert a voltage regulator at the 20 -mile point. Repeat the test described in 1). Record the data as described in 1) with two measurements made at the voltage regulator as shown in figure1. See Figure 15 (c).

4) With the voltage regulator inserted at the 20-mile point, repeat the test described in 2). Again, the DR should be adjusted so as to equal the load. See Figure 15 (d).

5) Repeat the tests described in steps 1) -4) with a power factor of 0.9 and 0.8 .

\section{Data Acquisition Requirements:}

\begin{tabular}{|l|c|c|c|c|c|}
\hline \multicolumn{1}{|c|}{ Parameter } & Units & Range & Accuracy & $\begin{array}{c}\text { Sampling } \\
\text { Rate }\end{array}$ & $\begin{array}{c}\text { Recording } \\
\text { Rate }\end{array}$ \\
\hline Voltage (12 required) & Volts & $0-21 \mathrm{kV}$ & $+/-0.5 \%$ & $600 \mathrm{~Hz}$ & $600 \mathrm{~Hz}$ \\
\hline Current (9 required) & Amps & $0-300 \mathrm{~A}$ & $+/-0.5 \%$ & $600 \mathrm{~Hz}$ & $600 \mathrm{~Hz}$ \\
\hline $\begin{array}{l}\text { Grid Interconnected } \\
\text { Synchronous Generator }\end{array}$ & & & & & \\
MG set (Watts, VARs, & & & & & \\
Volts, Amps & & & & & \\
\hline
\end{tabular}

\section{Control Requirements:}

This test has no special control requirements. 
Figure 15. Voltage Regulation Test Configuration

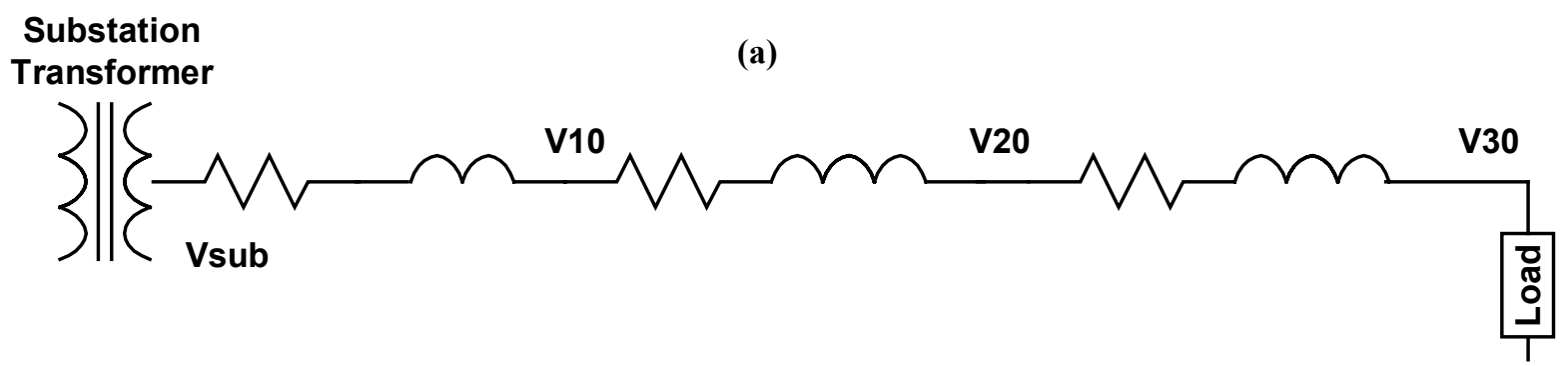

Substation

(b)

Transformer

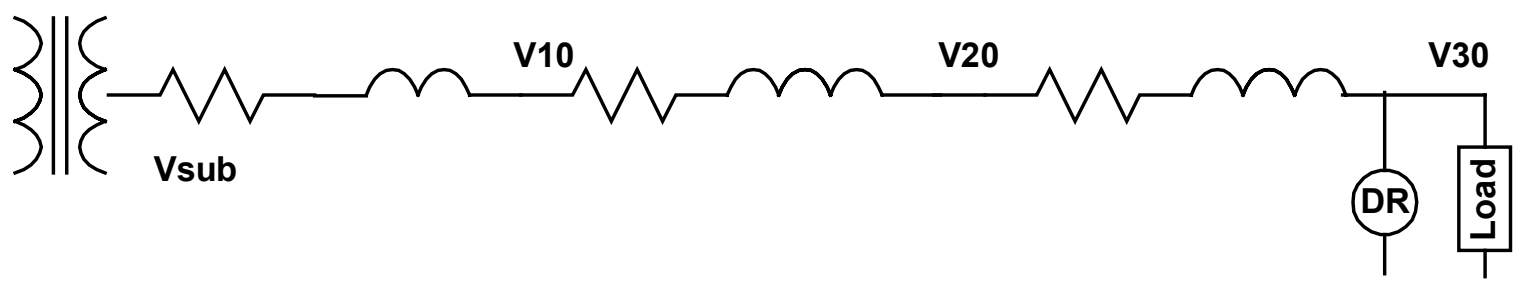

Substation

(c)

Transformer

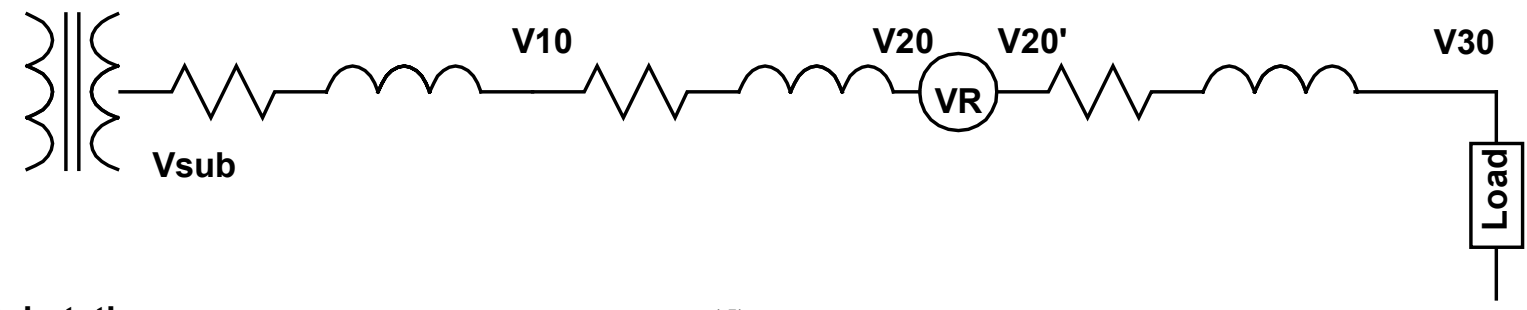

Substation

Transformer

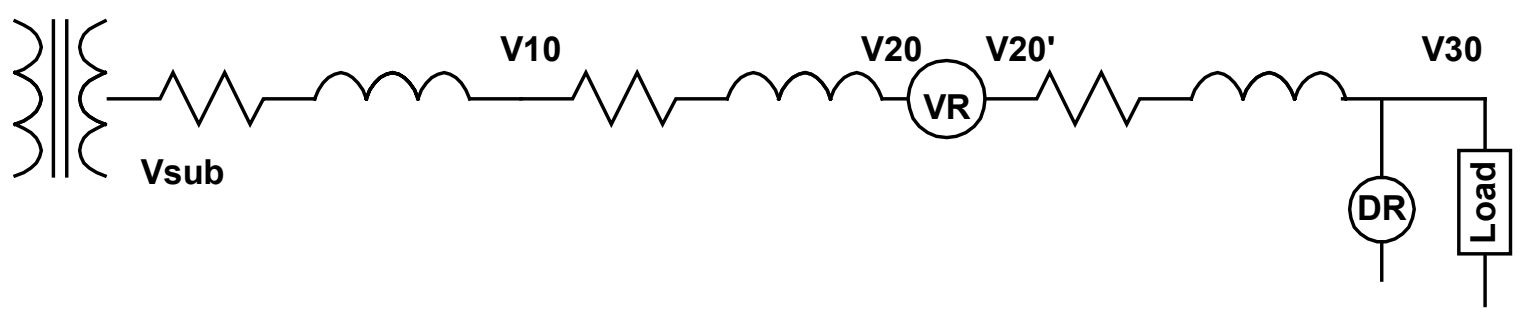

\section{Facility Requirements:}

The facility will require a long feeder system operating at distribution voltage and capable of being loaded to substation MVA rating. The ability to measure voltages at different point along the feeder and to install voltage-regulating equipment at the 20 -mile point are also requirements. 


\section{DR Requirements:}

\begin{tabular}{|l|c|c|c|}
\hline \multicolumn{1}{|c|}{ Type } & Qty & Size & Other \\
\hline $\begin{array}{l}\text { Grid Connected Synchronous } \\
\text { Generator }\end{array}$ & 1 & $1 \mathrm{MW}$ & IEEE 1547 Compliant \\
\hline
\end{tabular}

\section{Other Requirements:}

None

\section{Modeling Requirements:}

This problem lends it self to modeling using standard voltage prediction load flow software. This test could be used to verify voltage regulation modeling programs. The modeling can be done in the frequency or time domain. 


\section{BILLS OF MATERIALS}

\subsection{Interconnection Area}

Bill of Material (BOM) for the construction of an interconnect area as described in this report are provided below.

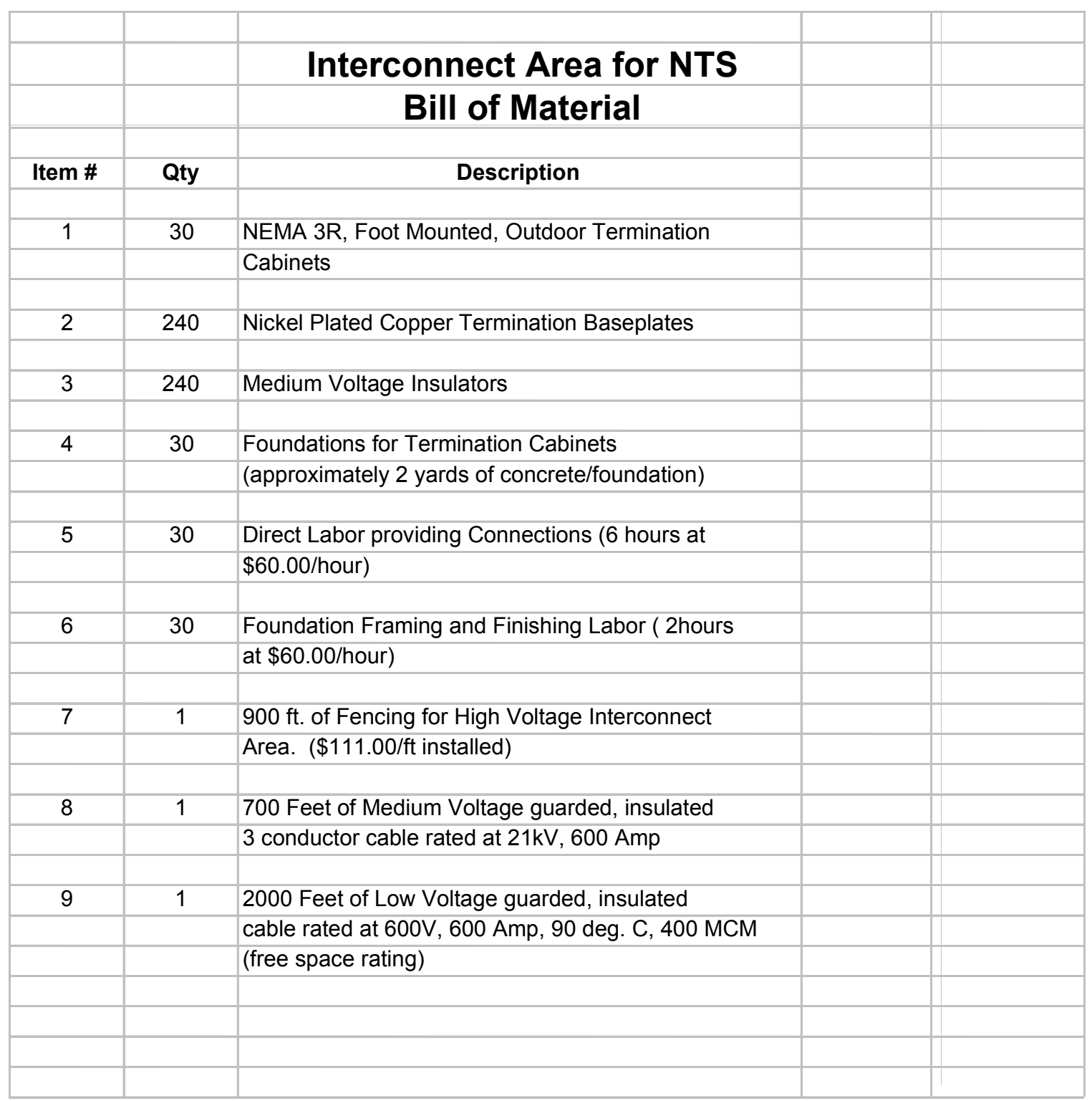




\subsection{Feeder Yard}

The BOM for the 30-mile feeder yard is given below.

\begin{tabular}{|r|r|l|l|}
\hline \multicolumn{3}{|c|}{ Nevada Test Site - Feeder Yard Bill of Materials } \\
\hline & Qty & Unit & Description \\
\hline 280 & ea & Pole \\
\hline 1120 & ea & Crossarm (9' heavy duty Alley Arms with Supports) \\
\hline 96 & mi & Phase conductor \\
\hline 0 & mi & Phase conductor \\
\hline 0 & mi & Phase conductor \\
\hline 16 & mi & ground conductor \\
\hline 2592 & ea & Post insulators with clamptops and pins \\
\hline 560 & ea & Secondary insulators \\
\hline 140 & ea & Ground Assemblies \\
\hline 64 & ea & Dead End guy wires \\
\hline 768 & ea & dead end insulators \\
\hline 64 & ea & double cross arms at ends \\
\hline 64 & ea & cross arms for turn around \\
\hline & & \\
\hline
\end{tabular}




\section{CONCLUSIONS AND RECOMMENDATIONS}

\subsection{Rationale for a Real-World, Full-Scale Facility}

The NTS location was considered as a site for integrated DR testing for numerous reasons. The site was reviewed extensively over the past year and considered in the context of the integrated DR testing plan. It was determined that while the site had some of the assets required for integrated testing of DR, the site in its current state was not really capable of supporting much of the identified DR testing. Three important characteristics of the site were its ability to test over real-world distributed parameter distribution lines, the ability to test at real world distribution voltages, and the true fullscale testing of a complete distribution system comprising DRs, loads, and the interconnecting system between them.

These three points are in contrast to other sites that conduct DR testing, in which lumpedparameter models of the distribution system and low voltages (e.g., 480 volts) are used. The lumped-parameter and low-voltage "approximations" to real world conditions are always subject to question, and might inhibit "buy-in" to test results by reviewing bodies. The reasons that DR testing performed at an alternative type of facility, as envisioned here, might be more credible are discussed below.

It is difficult to take lumped parameter test results and transform them to distributed parameter distribution systems. Without a real world distribution system, computer models would have to be developed for this transformation. Modeling would involve representing the distributed parameter distribution system with computer models and correlating that data with the lumped parameter tests which are actually performed. This approach is dependent upon accurate modeling data being available for the equipment, and representative computer models being available. There would be no direct way in which to actually validate computer results with test results where only a lumped parameter distribution system exists. A large amount of modeling effort can be avoided and unquestioned results can be achieved by using a real world distribution system such as the one that exists and is being proposed at the Area 25 site.

Likewise, low-voltage testing would involve using distribution voltage rated equipment on low voltage systems. For example, the testing of sectionalizing or reclosing devices that normally operate at 2.4 to $35 \mathrm{kV}$ would be tested on 480 - or 575 -volt systems. Our interviews with utility protection engineers revealed a strong preference for testing this equipment at the voltage levels for it was designed and at which it normally operates. Anything less would also call the results into question. One specific example that was cited repeatedly was the arc voltage on switching devices at high voltage, which is a highly non-linear and complex phenomenon, and its effect on other equipment on the 
distribution system. There is strong general consensus that these effects simply cannot be determined accurately at low voltages.

Finally, the NTS site allows for full-scale system representation using actual DRs, loads, transformers, feeders, relays, and other equipment. The site would be constructed and operated exactly as would be the case in real world distribution systems. The testing would be at rated voltage and distributed parameter effects from the distribution system conductors would be included.

The unique and flexible feeder design allows DRs, loads and other equipment to be located anywhere on the feeder, and the feeder can be split up into multiple feeders with a common utility connect point, or even as a loop or networked system. The feeder system will have 32 total miles of conductor, so that long rural feeders ( $>15$ miles) can be simulated accurately. With this full-scale approach, all the non-linearities and difficult-tomodel aspects of a distribution system should be present, just like in the real world. Parameters like line charging, sustained fault arcs, voltage drop, phase imbalances, and so forth are difficult to simulate or test using lumped parameters. Preliminary estimates indicate that building such a system may cost about the same as the low-voltage approach, and may actually cost less if existing inventory of NTS equipment can be utilized.

In summary, the NTS provides an opportunity to develop a facility for Distributed Utility Integration Testing without the constraints to be found in existing testing facilities.

\subsection{Rationale for Integrated DR Testing at NTS}

The preferred type of site for integrated DR testing would be a site with existing DR technologies, testing and monitoring infrastructure, and the collaboration and support of the host utility. Also, the presence of staff experienced in the DR field, flexible loads, and a re-configurable distribution system are viewed as important, positive factors.

The NTS site was initially viewed as a strong candidate site for a number of reasons. First, the site is controlled by DOE and working, trained staff is available for assistance on the DR testing. Secondly, there is an extensive amount of distribution and generation equipment that is inventoried at the site for the purpose of servicing the many miles of distribution system on the NTS property.

When the NTS site was first considered, a number of different substations and areas were reviewed. The result of looking at the different areas was to use the site at Area 25. This site has an existing, under-utilized 2.5 MVA substation, a $13.2 \mathrm{kV}$ distribution system of approximately $1 / 6$ mile in length, building loads, and access to the electrical apparatus inventory mentioned above. Of all these features, however, one of the most compelling advantages of the site is that it is minimally utilized. This is important when conducting controlled DR tests, as many of test protocols have the potential to interfere with adjacent

distribution system customers. With no adjacent customers, testing is relieved of a serious 
scheduling and timing constraint which is prevalent at other sites either inside or outside of NTS. Lastly, the site is secured and controlled and safety concerns and procedures can be readily dealt with.

Despite these benefits, Area 25 in its current state would require extensive modifications before it could be considered fully functional and capable of completing all of the DR test protocols. However, the NTS could be viewed as a site for designing an integrated DR test laboratory virtually from scratch. The advantages of this approach would be to build in the specific testing capabilities required by DR testing, and also avoid the restrictions and lack of flexibility that are drawbacks to many of the existing sites. In addition, it was desired to compare the economics of this approach to the alternative, which is performing modifications to existing test sites. 


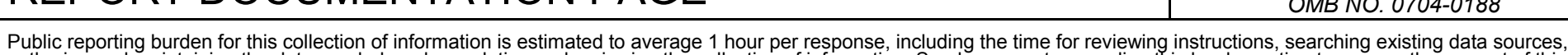

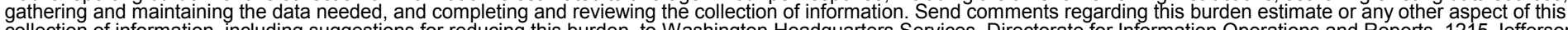

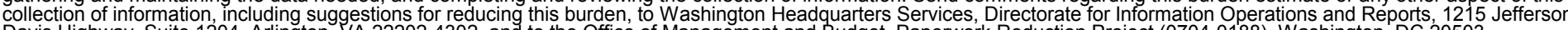
Davis Highway, Suite 1204, Arlington, VA 22202-4302, and to the Office of Management and Budget, Paperwork Reduction Project (0704-0188), Washington, DC 20503.
1. AGENCY USE ONLY (Leave blank)
2. REPORT DATE
May 2002
3. REPORT TYPE AND DATES COVERED
Subcontractor Report March 2002

4. TITLE AND SUBTITLE

Assessment of the Nevada Test Site as a Site for Distributed Resource Testing and Project Plan

5. FUNDING NUMBERS

C: RAD-0-30605-05

TA: DPO2.1001

6. AUTHOR(S)

S. Horgan, J. Iannucci, C. Whitaker, L. Cibulka and W. Erdman

7. PERFORMING ORGANIZATION NAME(S) AND ADDRESS(ES)

Distributed Utility Associates

8. PERFORMING ORGANIZATION REPORT NUMBER

1062 Concannon Blvd.

Livermore, CA 94550

9. SPONSORING/MONITORING AGENCY NAME(S) AND ADDRESS(ES)

National Renewable Energy Laboratory

1617 Cole Blvd.

Golden, CO 80401-3393

10. SPONSORING/MONITORING AGENCY REPORT NUMBER

NREL/SR-560-31931

11. SUPPLEMENTARY NOTES

NREL Technical Monitor: Benjamin Kroposki

12a. DISTRIBUTION/AVAILABILITY STATEMENT

National Technical Information Service

U.S. Department of Commerce

5285 Port Royal Road

Springfield, VA 22161

13. ABSTRACT (Maximum 200 words)

The objective of this project was to evaluate the Nevada Test Site (NTS) as a location for performing dedicated, indepth testing of distributed resources (DR) integrated with the electric distribution system. In this large scale testing, it is desired to operate multiple DRs and loads in an actual operating environment, in a series of controlled tests to concentrate on issues of interest to the DR community.

This report includes an inventory of existing facilities at NTS, an assessment of site attributes in relation to DR testing requirements, and an evaluation of the feasibility and cost of upgrades to the site that would make it a fully qualified DR testing facility.

\begin{tabular}{|c|c|c|c|c|}
\hline \multirow{3}{*}{\multicolumn{4}{|c|}{$\begin{array}{l}\text { 14. SUBJECT TERMS } \\
\text { Distributed Resources; Nevada Test Site; NTS; Distributed Resource Testing }\end{array}$}} & \multirow{3}{*}{$\begin{array}{l}\text { 15. NUMBER OF PAGES } \\
\text { 16. PRICE CODE }\end{array}$} \\
\hline & & & & \\
\hline & & & & \\
\hline 17 & $\begin{array}{l}\text { SECURITY CLASSIFICATION } \\
\text { OF REPORT } \\
\text { Unclassified }\end{array}$ & $\begin{array}{l}\text { 18. SECURITY CLASSIFICATION } \\
\text { OF THIS PAGE } \\
\text { Unclassified }\end{array}$ & $\begin{array}{l}\text { 19. SECURITY CLASSIFICATION } \\
\text { OF ABSTRACT } \\
\text { Unclassified }\end{array}$ & $\begin{array}{l}\text { 20. LIMITATION OF ABSTRACT } \\
\text { UL }\end{array}$ \\
\hline
\end{tabular}

